\title{
TAPBPR Promotes Antigen Loading on MHC-I Molecules Using a Peptide Trap
}

\section{Andrew McShan}

Children's Hospital of Philadelphia

\section{Christine Devlin}

UIUC https://orcid.org/0000-0002-8541-7432

\section{Giora Morozov}

Children's Hospital of Philadelphia

\section{Sarah Overall}

UCSC

\section{Danai Moschidi}

UCSC

\section{Neha Akella}

UIUC

\section{Erik Procko}

University of Illinois at Urbana Champaign https://orcid.org/0000-0002-0028-490X

Nikolaos Sgourakis ( $\sim$ Nikolaos.Sgourakis@pennmedicine.upenn.edu )

University of Pennsylvania, United States https://orcid.org/0000-0003-3655-3902

\section{Article}

Keywords: Chaperoning, Editing, Loop Sequence, Deep Mutagenesis, Biophysical Characterization, Peptide Loading

Posted Date: December 14th, 2020

DOI: https://doi.org/10.21203/rs.3.rs-108935/v1

License: (c) (i) This work is licensed under a Creative Commons Attribution 4.0 International License. Read Full License

Version of Record: A version of this preprint was published at Nature Communications on May 26th, 2021. See the published version at https://doi.org/10.1038/s41467-021-23225-6. 
TAPBPR Promotes Antigen Loading on MHC-I Molecules Using a Peptide Trap

Andrew C. McShan ${ }^{1,2 \dagger}$, Christine A. Devlin ${ }^{3 \dagger}$, Giora I. Morozov ${ }^{1,2}$, Sarah A. Overall ${ }^{1}$, Danai

3 Moschidi $^{1}$, Neha Akella ${ }^{3}$, Erik Procko ${ }^{3 *}$ and Nikolaos G. Sgourakis ${ }^{1,2,4^{*}}$

$4{ }^{1}$ Department of Chemistry and Biochemistry, University of California Santa Cruz, Santa Cruz, 5 CA 95064, USA.

${ }^{2}$ Department of Pathology and Laboratory Medicine, The Children's Hospital of Philadelphia, 3401 Civic Center Blvd, Philadelphia, PA, 19104, USA

${ }^{3}$ Department of Biochemistry and Cancer Center at Illinois, University of Illinois, Urbana, IL 61801, USA.

${ }^{4}$ Department of Biochemistry and Biophysics, Perelman School of Medicine, University of Pennsylvania, 3400 Civic Center Blvd, Philadelphia, PA, 19104, USA

$\dagger$ These authors contributed equally to this work.

* To whom correspondence should be addressed: Erik Procko (procko@illinois.edu) or Nikolaos G. Sgourakis (Nikolaos.Sgourakis@Pennmedicine.upenn.edu).

Lead contact: Nikolaos.Sgourakis@Pennmedicine.upenn.edu

\section{ABSTRACT}

Chaperones Tapasin and TAP-binding protein related (TAPBPR) perform the important functions of stabilizing nascent MHC-I molecules (chaperoning) and selecting high affinity peptides in the MHC-I groove (editing). While X-ray and cryo-EM snapshots of MHC-I in complex with TAPBPR and Tapasin, respectively, have provided important insights into the peptide-deficient MHC-I groove structure, the molecular mechanism through which these chaperones influence the selection of specific amino acid sequences remains incompletely characterized. Based on structural and functional data, a loop sequence of variable lengths has been proposed to stabilize empty MHC-I molecules through direct interactions with the floor of the groove. Using deep mutagenesis on two complementary expression systems, we find that important residues for the Tapasin/TAPBPR chaperoning activity are located on a large scaffolding surface, excluding the loop. Conversely, loop mutations influence TAPBPR interactions with properly conformed MHCI molecules, relevant for peptide editing. Detailed biophysical characterization by solution NMR, ITC and FP-based shows that the loop hovers above the MHC-I groove to promote the capture of incoming peptides, thereby acting as a trap. Our results suggest that the longer loop of TAPBPR lowers the affinity requirements for peptide selection to facilitate peptide loading under conditions and subcellular compartments of reduced ligand concentration, and to prevent disassembly of high affinity peptide-MHC-I complexes that are transiently interrogated by TAPBPR during editing. 
INTRODUCTION

Class I major histocompatibility complex (MHC-I) molecules bind a repertoire of endogenously processed peptide antigens and display them on the cell surface, thereby enabling $\mathrm{CD} 8^{+}$cytotoxic T lymphocytes to surveil the cell proteome (Blum et al., 2013). The disparate surface chemistries of peptide/MHC-I (pMHC-I) antigens encompassing self, pathogen or tumor derived peptides allows $\mathrm{T}$ lymphocytes to detect aberrant protein expression and mount a response toward infected or tumor cells (Rossjohn et al., 2015). Assembly of pMHC-I molecules occurs in the endoplasmic reticulum (ER), where the association between a peptide, the polymorphic heavy chain (human leukocyte antigen, HLA), and the invariant light chain ( $\beta_{2}$-microglobulin, $\beta_{2} \mathrm{~m}$ ) is facilitated by dedicated molecular chaperones, the ER-restricted tapasin of the peptide-loading complex (PLC) and the PLC-independent TAPBPR (TAP-binding protein related)(van Hateren et al., 2017; Hermann et al., 2015a). In addition to chaperoning MHC-I, tapasin and TAPBPR function as catalytic enhancers of peptide association and dissociation within the MHC-I groove (peptide exchange) and participate in peptide editing and quality control of assembled pMHC-I molecules (Fleischmann et al., 2015; Hermann et al., 2015b; McShan et al., 2019; Morozov et al., 2016). Additional quality control is achieved by the association of TAPBPR with UDPglucose:glycoprotein glucosyltransferase (UGGT1), which promotes reglycosylation of empty or suboptimally loaded MHC-I towards their recycling to the PLC (Neerincx et al., 2017; Zhang et al., 2011). Collectively, these processes ensure the correct folding, trafficking and prolonged cell surface display of pMHC-I antigens (Neerincx and Boyle, 2017). Deregulation of chaperone function has been observed during disease progression in the context of autoimmunity, cancer and pathogen infection (Cabrera et al., 2005; Montserrat et al., 2006; Park et al., 2004; Shionoya et al., 2017).

Two crystal structures of TAPBPR-bound MHC-I molecules have illuminated aspects of the chaperoning and peptide editing functions (Jiang et al., 2017; Thomas and Tampé, 2017). TAPBPR has fused $\beta$-sandwich and immunoglobulin-like type 5 (IgV) folds forming a bilobed N-terminal domain with a large concave surface that cradles the underside of the MHC-I $\alpha_{1} / \alpha_{2}$ "platform", beneath the $\alpha_{2}$ domain. The peptide-binding groove of the MHC-I is held in an open conformation at the $\mathrm{F}$ pocket, where the antigenic peptide $\mathrm{C}$-terminus would normally reside, with smaller distortions extending to the $\mathrm{A}$ and $\mathrm{B}$ pockets. These groove perturbations promote the release of low affinity peptides. The C-terminal IgC domain of TAPBPR makes additional contacts to the MHC-I $\alpha_{3} / \beta 2 \mathrm{~m}$ domain junction, giving the appearance of a long scaffold supporting the different structural elements of the MHC-I. In one of the TAPBPR crystal structures (Thomas and Tampé, 2017), a protruding loop (residues G24-R36) of TAPBPR (Fig. 1A) was modeled in an $\alpha$-helical conformation extending from the luminal tip of the $\mathrm{N} / \mathrm{IgV}$ domain into the peptide-binding groove to occupy the F pocket (Fig. 1B, C-middle). The loop was hypothesized to "scoop" bound peptide out of the groove through steric competition. A simultaneous publication from the same group of the tapasin-dependent PLC at low resolution seemed to support this mechanism, with the equivalent loop of tapasin partially modeled projecting into the F pocket (Blees et al., 2017) (Fig. 1B, C-left), while X-ray structures of MHC-I/dipeptide complexes together with a short hydrophobic peptide occupying the groove, derived from the tapasin loop, appear to show a stable, bound conformation (Hafstrand et al., 2019). Recent studies have provided supporting evidence that the TAPBPR G24-R36 loop influences peptide exchange on the MHC-I, either by functioning as a peptide placeholder in the empty MHC-I/TAPBPR complexes (Sagert et al., 2020) or by acting 
as a lever to promote dissociation of suboptimal peptides (Ilca et al., 2018). In contrast, mutational insults to the "scoop" loop have only minor effects on tapasin-mediated intracellular processing of nascent MHC-I (Hafstrand et al., 2019). In an independent crystal structure of the TAPBPR/MHCI complex, density for the G24-R36 loop is lacking (Fig. 1C-right), presumably either due to inherent disorder of the loop or due to the presence of a disulfide-linked truncated peptide with large degrees of rotational freedom that could influence the loop's conformation (Jiang et al., 2017). Thus, while the TAPBPR G24-R36 loop seems to influence peptide exchange and antigen selection, there remain outstanding questions of whether it adopts a conformation that enters the empty MHC-I groove and how it affects peptide loading relative to the shorter tapasin loop.

Here, using a combination of in situ functional assays, yeast display/MHC-I tetramer staining, and a range of complementary biophysical techniques including solution NMR, we address the G24R36 loop discrepancy between the two MHC-I/TAPBPR X-ray structures (Jiang et al., 2017; Thomas and Tampé, 2017) and the MHC-I/Tapasin cryoEM structural model (Blees et al., 2017), and determine its role in the chaperoning and editing functions. Our findings suggest that the G24R36 loop is not necessary for chaperoning activity, but directly participates in peptide editing on the MHC-I groove. The TAPBPR G24-R36 loop does not interact directly with the floor of the MHC-I groove to compete with incoming peptides, but instead hovers above the MHC-I groove to promote loading by acting as a trap for early peptide intermediates within the MHC-I/TAPBPR intermediate complex. Our study also suggests the possibility that there may be significant differences in how TAPBPR utilizes the G24-R36 loop to perform its peptide editing function across different MHC-I alleles due to unique steric or electrostatic chemical properties of the pMHC-I surface. Together, our results underscore a role for TAPBPR as an auxiliary editor that operates in compartments of reduced peptide concentration.

\section{RESULTS}

\section{Unexpected conformational plasticity of the TAPBPR G24-R36 loop}

109 modeled as projecting in to the $\mathrm{F}$ pocket falls outside the electron density and has $\mathrm{B}$ factors fixed at $30.00 \AA^{2}$, indicating it was excluded from refinement. Nearby density suggests that the loop instead rests above the peptide-binding groove (Fig. 1C). The TAPBPR G24-R36 loop was built in only one of the TAPBPR co-crystal structures where it was bound to the $\mathrm{H}-2 \mathrm{D}^{\mathrm{b}}$ murine MHC-I (Thomas and Tampé, 2017), and its assigned B factors were exceedingly high (Fig. 1C; PDB ID 5OPI), with additional large $\mathrm{B}$ factor transitions between bonded amino acids across the entire model. In the second crystal structure of TAPBPR-bound H-2D (Jiang et al., 2017), no clear density was observed for the 24-36 loop in the four different complexes of the asymmetric unit (Fig. 1C; PDB ID 5WER). The loop's conformation and placement relative to the empty MHC-I groove are therefore uncertain in the original structural data.

To investigate the structural plasticity of the TAPBPR G24-R36 loop in the MHC-I/TAPBPR complex, we used complementary computational approaches. We chose a common human MHCI molecule frequently represented in Caucasian and other global populations, HLA-A*02:01, as our model system (Gonzalez-Galarza et al., 2011). In the first approach, the HLA-A*02:01 sequence was threaded onto the H2-D $/$ TAPBPR X-ray structure missing electron density for the G24-R36 loop (PDB ID 5WER) (Jiang et al., 2017). In our model, we replaced the cysteine mutation present in the initial H2-D $/$ TAPBPR structure with the wild-type HLA-A*02:01 residue 
and did not include the truncated peptide in the groove. The resulting peptide-deficient HLAA*02:01/TAPBPR complex was used as a template to explore whether an $\alpha$-helical conformation of the G24-R36 loop could be sampled during loop modeling. We employed a variety of sampling algorithms, including cyclic coordinate descent (CCD), kinematic closure (KIC), and comparative modeling (CM), within the Rosetta modeling suite (Leaver-Fay et al., 2011). The resulting lowest energy HLA-A*02:01/TAPBPR models revealed a wide range of TAPBPR G24-R36 loop conformations, each differing significantly from the $\alpha$-helical conformation of the $\mathrm{H} 2$ $\mathrm{D}^{\mathrm{b}}$ /TAPBPR X-ray structure (Fig. S1 A-C, Fig. 1A-C). In the second approach, the HLA-A*02:01 sequence was threaded onto the H2-D /TAPBPR X-ray structure containing the G24-R36 "scoop loop" modeled with poorly resolved electron density (PDB ID 5OPI). The modeled peptidedeficient HLA-A*02:01/TAPBPR complex was used as a starting point to determine whether the "scoop loop" conformation was stable in all-atom molecular dynamics (MD) simulations, performed in explicit solvent. The entire HLA-A*02:01/h $\beta 2 \mathrm{~m} / \mathrm{TAPBPR}$ complex was allowed to move while applying standard MD constraints over the entire system. Our MD trajectory revealed a loss of helical propensity of the short $\alpha$-helix formed by TAPBPR residues G24-L30, as well as movement of the TAPBPR G24-R36 loop away from the HLA-A*02:01 groove as early as within the first $50 \mathrm{nsec}$. This was highlighted by a marked increase in $\mathrm{C} \alpha-\mathrm{C} \alpha$ distances measured between HLA-A*02:01 groove (D77, T80, K146) and TAPBPR G24-R36 loop (A29, L30) residues over the course of the simulation (Fig. 1D, E). During the MD simulations, the TAPBPR G24-R36 loop sampled both an open state (pointing away from MHC-I groove) and a closed state that hovers above the MHC-I groove in an extended conformation (Fig. 1D, E). Notably, other loops of TAPBPR showed less conformational variation, suggesting conformational diversity is a unique property of the G24-R36 loop (Fig. S1D). MD simulations and Rosetta modeling use different energy functions, and yet the two approaches independently sampled similar, non-helical TAPBPR G24-R36 loop conformations (Fig. S1A-C, Fig. 1D, E) that do not interact with the floor of the MHC-I groove.

\section{The G24-R36 loop of TAPBPR and its equivalent in tapasin are not essential for chaperoning MHC-I}

Tapasin was knocked out in human Expi293F cells, causing diminished chaperone-dependent processing and trafficking of endogenous HLA-A*02:01 to the cell surface, as measured by flow cytometry (Fig. S2). Surface expression of HLA-A*02:01 was rescued by transfection with a plasmid encoding tapasin, forming the basis for a fluorescence-based assay and selection measuring the effects of tapasin mutations (Fig. 2A, S2B). Based on structural alignments (Fig. 1B), residues 11-19 of the tapasin loop were replaced with 22-35 of TAPBPR, and the protein remained functional, albeit with decreased activity which may reflect a minor structural perturbation (Fig. 2A). G15 of tapasin resides at the very tip of the loop, and shortening the loop by two residues either side (tapasin $\Delta 2$ step) had no effect on tapasin activity (Fig. 1A and $2 \mathbf{A}$ ). Shortening the loop further to remove L18 (tapasin $\Delta 3$ step) caused a sudden drop in activity, although the protein still remained highly active. The cryo-EM density for the PLC (Blees et al., 2017) is consistent with tapasin L18 contacting the rim of the peptide-binding groove above Y84 of HLA-A*02:01. Targeted substitutions of tapasin L18 caused similar decreases in activity, whereas substitutions of G15 at the very tip of the loop had minimal effect.

Defective surface expression of endogenous HLA-A*02:01 in tapasin-knockout (tapasin-KO) cells was rescued by transfection of a tapasin library encompassing 2,160 single substitutions at 
108 sites. Cells with the highest surface HLA-A*02:01 were collected by FACS and deep sequenced to determine the enrichment or depletion of all tapasin variants in the library; this method is known as deep mutational scanning. As controls, mutations to 12 buried residues in the tapasin core were found to be generally depleted except for hydrophobic substitutions, whereas 8 surface residues distal from the MHC-I interface were mutationally permissive, with the exception of F218 which contacts Erp57 and is conserved (Blees et al., 2017). The most highly conserved tapasin residues in the selection experiment were on the concave face of the $\mathrm{N} / \mathrm{IgV}$ domain that rests below the MHC-I $\alpha_{2}$ domain, and at the hinge where the $\mathrm{N} / \mathrm{IgV}$ and $\mathrm{C} / \mathrm{IgC}$ domains meet. There is weaker sequence conservation dispersed across the $\mathrm{C} / \mathrm{IgC}$ domain that interacts with the $\beta_{2} \mathrm{~m}$ and $\alpha_{3}$ domains. Tapasin loop residues V10-K20 were highly tolerant of mutations except for V10 and L18, which strongly prefer hydrophobic amino acids and are appropriately positioned to interact with HLA-A*02:01 M138 and Y84 on the upper rims of the $\alpha_{2-1}$ and $\alpha_{1}$ helices, respectively. Overall, targeted and deep mutagenesis show that, for folding and processing of HLA-A*02:01, a long loop on the chaperone is not necessary, but binding contacts to the top of the MHC-I $\alpha$-helices are important.

We refer to the functional replacement of tapasin with TAPBPR in tapasin-KO cells as a tapasin surrogate assay. Overexpression of TAPBPR partially rescued surface HLA-A*02:01, although a subset of cells retained HLA-A*02:01 intracellularly at greater levels (Fig. 2A and S2B). Substitution of the TAPBPR transmembrane and cytosolic segments with those of tapasin (called TAPBPR-CT) increased TAPBPR-mediated rescue of surface HLA-A*02:01, despite substantially reduced protein expression (Fig. 2B). We hypothesize that TAPBPR-CT may be recruited in to the PLC (Fig. S2A), though this remains undemonstrated. TAPBPR-CT was used as the background in which mutations to the luminal domains of TAPBPR were tested. Deletion of the TAPBPR loop tip (TAPBPR $\triangle$ ALAS, removing the last turn of the helix modeled for the loop in PDB 5OPI) caused a small decrease in HLA-A*02:01 processing, and deletion of the entire TAPBPR 24-36 loop ( $\triangle \mathrm{G} 24-\mathrm{R} 36)$ caused a further decrease in activity.

Using the tapasin surrogate assay as the basis for fluorescence-based selection, the TAPBPR 2435 loop was deep mutationally scanned to assess the relative activities of all 240 single amino acid substitutions. Apart from heavy depletion of nonsense mutations, the mutational landscape across the 24-35 loop is relatively featureless (Fig. 2C). Overall, these results demonstrate that the loop is not essential for chaperoning function, although some effects can be observed for different length and sequence variants.

To compare with other regions of TAPBPR that may be important, a larger library was constructed encompassing all single amino acid substitutions across 75 TAPBPR residues at the crystallographic interface with MHC-I (Jiang et al., 2017), in addition to 10 surface residues on the opposite side and to 7 buried residues as controls. Following selection of the TAPBPR library for high levels of surface HLA-A*02:01 expression, polar mutations to buried residues in the TAPBPR core were depleted, whereas surface residues distal from the MHC-I interface were mutationally tolerant. Similar to our observations for deep mutagenesis of tapasin, two regions of TAPBPR within the MHC-I interface were tightly conserved for activity: the concave face of the $\mathrm{N} / \mathrm{IgV}$ domain that rests below the MHC-I $\alpha_{2}$ domain, and the edge of the $\mathrm{C} / \operatorname{IgC}$ domain that bridges the $\beta_{2} \mathrm{~m}$ and $\alpha_{3}$ domains (Fig. 2D). There was a preference for hydrophobic amino acids across the interface, with polar residues increasingly tolerated towards the interface periphery. 
Targeted alanine substitutions were tested to confirm that TAPBPR residues contacting the $\alpha_{2}$ underside (G212A and I261 A) and $\alpha_{3} / \beta 2 \mathrm{~m}$ junction (S333A) were critical for mediating rescue of surface HLA-A*02:01 in tapasin-KO cells, whereas residues contacting the upper rim of the peptide groove (E102A and M122A) were not (Fig. 2G). Overall, TAPBPR chaperone activity is primarily encoded in sites that scaffold the correct folded architecture of the heavy chain with $\beta 2 \mathrm{~m}$, consistent with our prior conclusions that TAPBPR chaperones nascent, improperly folded MHCI substrates within the cell (McShan et al., 2019). Notably, the G24-R36 loop is not critical for this activity.

\section{The loop affects TAPBPR recognition of folded PMHC-I in an allele-dependent manner}

Trafficking of HLA-A*02:01 to the plasma membrane will depend on chaperoning activity of TAPBPR, but not necessarily its editing function. To directly assess how mutations impact TAPBPR binding to folded pMHC-I molecules, as would occur during editing of the bound peptide, the extracellular domain of TAPBPR was displayed on the surface of yeast and binding to fluorescent pMHC-I tetramers was detected by flow cytometry (Fig. S3A-L). Bound MHC-I was competed off by the addition of peptides in a dose-dependent manner that correlated with peptide affinities (Fig. S3K, L). The TAPBPR 24-35 loop was mutated, and the yeast-displayed library was screened for tight binding to two MHC-I alleles: mouse $\mathrm{H} 2-\mathrm{D}^{\mathrm{d}}$ and human HLAA*02:01 (Fig. S3I, J). No binding was observed for tetramers of a third allele, human HLA$\mathrm{A}^{*} 01: 01$, consistent with TAPBPR having restricted recognition of folded pMHC-I allotypes (McShan et al., 2019). At nearly all positions of the 24-35 loop there was enrichment of large, hydrophobic and aromatic residues for increased binding to both H2- $\mathrm{D}^{\mathrm{d}}$ and HLA-A*02:01 (Fig. 3A). Design of protein-protein interfaces has shown that large hydrophobic residues can promote binding through non-specific apolar interactions (Karanicolas et al., 2011; Procko et al., 2013). Instead, our attention was drawn to allele-specific differences that are unlikely to be due to generic mutational effects. For binding to H2- $\mathrm{D}^{\mathrm{d}}$, positions 28 and 30 near the center of the TAPBPR 2435 loop have strong preferences for aliphatic or aromatic side chains, whereas all non-basic substitutions of R27 are enriched (excluding cysteine, which is deleterious at all positions). The data are therefore suggestive that the tip of the loop is near an apolar patch on $\mathrm{H} 2-\mathrm{D}^{\mathrm{d}}$ with a nearby electropositive charge; surfaces meeting these criteria can be found near the middle of the $\alpha_{1}$ helix (MHC-I residues V76 and R79) or at the end of the $\alpha_{2-1}$ helix (K146, A149, and A150). However, permissiveness in the landscape also suggests contacts between the 24-35 loop and H2- $\mathrm{D}^{\mathrm{d}}$ are sufficiently loose to tolerate mutations. Amino acid preferences within the 24-35 loop were weaker in the selections for binding HLA-A*02:01, although position 30 again prefers hydrophobic side chains. L30 has also been found to be important for binding to HLA-A*68:02 (Ilca et al., 2018). TAPBPR D35 is tightly conserved as an acidic residue for high $\mathrm{H} 2-\mathrm{D}^{\mathrm{d}}$ binding due to electrostatic complementarity with basic residues (H2-D ${ }^{d}$ R79 and R83) on the upper rim of the peptide-binding groove. HLA-A*02:01 has a glycine at position 79 , and nearly all non-acidic substitutions of TAPBPR E34 and D35 enhance HLA-A*02:01 binding, consistent with Rosetta models of the 2435 loop contacting the upper surfaces of the MHC-I $\alpha$-helices (Fig. 3B).

Selected mutations that increase or decrease MHC-I binding, predicted from the deep mutational scans, were validated by targeted mutagenesis (Fig. S3I, J). Furthermore, the binding of yeastdisplayed TAPBPR $\triangle$ ALAS to tetramers of $\mathrm{H} 2-\mathrm{D}^{\mathrm{d}}$ or HLA-A*02:01 was only slightly reduced compared to wild type (WT). TAPBPR $\triangle$ ALAS and targeted point mutants exhibited competitive interactions with peptide (Fig. S3K, L), indicating that differences in how tightly variants of the 
G24-R36 loop recognize MHC-I has no major bearing on peptide-mediated chaperone displacement. Rather, other sites of contact between TAPBPR and MHC-I must act as the sensors for high affinity peptide binding within the groove. We further note that peptides of different sequence were slightly better or worse at displacing some TAPBPR mutants, indicating mutations in the G24-R36 loop have subtle, peptide sequence-specific effects.

\section{The TAPBPR G24-R36 loop does not interfere with the empty MHC-I groove}

TAPBPR mutants $\triangle$ ALAS and $\Delta \mathrm{G} 24-\mathrm{R} 36$ were recombinantly expressed in S2 Drosophila cells, purified and characterized in vitro. Circular dichroism (CD) spectroscopy showed that TAPBPR G24-R36 loop mutants retain the expected immunoglobulin (Ig)-like fold, as highlighted by the 2-sheet characteristic of a negative band between 215 and $219 \mathrm{~nm}$ (Fig. 4A, top). By differential scanning fluorimetry (DSF), TAPBPR G24-R36 loop mutants exhibited thermal stability comparable to WT with melting temperature $\left(\mathrm{T}_{\mathrm{m}}\right)$ in the $48-49^{\circ} \mathrm{C}$ range (Fig. 4A, bottom). Finally, both $\mathrm{TAPBPR}^{\mathrm{WT}}$ and $\mathrm{TAPBPR}^{\triangle \mathrm{G} 24-\mathrm{R} 36}$ proteins readily formed high-affinity complexes with empty H2-D ${ }^{d}$ or HLA-A*02:01 molecules, prepared upon refolding with the photosensitive peptides photoP18-I10 and photoFluM1, respectively, upon UV-mediated peptide release (Fig. S4A-B).

To investigate specific loop interactions with MHC-I molecules, we used solution NMR and characterized HLA-A*02:01/TAPBPR complexes prepared using either wild-type or mutant TAPBPR (McShan et al., 2018, 2019). We isolated 1:1 stoichiometric peptide-deficient HLAA*02:01/TAPBPR complexes where the HLA-A*02:01 heavy chain was selectively ILV ${ }^{\text {proS }}$ ${ }^{13} \mathrm{C} /{ }^{1} \mathrm{H}$ methyl labeled on a ${ }^{12} \mathrm{C} /{ }^{2} \mathrm{H}$ background, whereas $\mathrm{h} \beta_{2} \mathrm{~m}$ and TAPBPR were at natural isotopic abundance. These experiments allowed us to examine how the presence of the TAPBPR G24-R36 loop influences the chemical environment of the 37 ILV ${ }^{\text {pros }}$ methyl probes on HLAA*02:01, several of which are in the groove and within 10 from the TAPBPR G24-R36 loop in the proposed "scoop loop" conformation (Fig. 4B). Analysis could not be performed on a subset of the probes (L78 $\delta 2, L 81 \delta 2$ and L156 2 ) due to NMR line broadening resulting from conformational exchange in the intermediate ( $\mu \mathrm{sec}-\mathrm{msec})$ timescale (Fig. 4B, gray spheres). Chemical shift analysis of the remaining probes did not identify any noticeable changes in $2 \mathrm{D}{ }^{1} \mathrm{H}$ ${ }^{13} \mathrm{C}$ methyl HMQC spectra of peptide-deficient HLA-A*02:01/TAPBPR complexes prepared with TAPBPR $^{\mathrm{WT}}, \mathrm{TAPBPR}^{\triangle \mathrm{ALAS}}$, or TAPBPR ${ }^{\triangle \mathrm{G} 24-\mathrm{R} 36}$ (Fig. 4C). These results were corroborated by similar observations using independently prepared peptide-deficient MHC-I/TAPBPR complexes employing a more general methyl labeling scheme (AILV) on HLA-A*02:01, where the number of total methyl probes increased to 94, 20 of which were within $10 \AA$ from the TAPBPR G24-R36 loop (Fig. S5A). We also examined chemical shift changes in HLA-A*02:01/TAPBPR complexes transiently bound to unlabeled TAX9 peptide in the presence of excess TAPBPR, to minimize TAPBPR dissociation from the pMHC-I. This allowed us to perform a full analysis of methyl groups along the MHC-I groove, since resonances previously broadened in the spectra of peptidedeficient complexes can now be directly observed (Fig. S5B). Chemical shift analysis of the AILV methyl probes in wild-type and mutant TAX9/HLA-A*02:01/TAPBPR complexes did not reveal any measurable changes in $2 \mathrm{D}^{1} \mathrm{H}_{-}{ }^{13} \mathrm{C}$ HMQC spectra (Fig. S5C). Together, these findings support the lack of a direct, stable interaction between the TAPBPR G24-R36 loop and the floor of the HLA-A*02:01 groove either in the empty or the peptide-bound intermediate complex states.

\section{The TAPBPR loop promotes peptide loading on empty chaperoned MHC-I}


312 Our group has previously characterized the full thermodynamic cycle of TAPBPR-mediated 313 MHC-I peptide exchange (McShan et al., 2018). The cycle is defined by dissociation constants $314\left(\mathrm{~K}_{\mathrm{D}}\right)$ for four reversible steps: association of TAPBPR with MHC-I in the absence of peptide $\left(\mathrm{K}_{\mathrm{D} 1}\right)$, association of peptide with MHC-I in the absence of TAPBPR $\left(\mathrm{K}_{\mathrm{D} 2}\right)$, association of pMHC-I with TAPBPR $\left(\mathrm{K}_{\mathrm{D} 3}\right)$, and association of peptide with the MHC-I/TAPBPR complex $\left(\mathrm{K}_{\mathrm{D} 4}\right)$ (Fig. 5A). We measured apparent $K_{D}$ values for each of the specific steps using suitable isothermal titration calorimetry (ITC) experiments. ITC was performed on a range of known HLA-A*02:01 peptides (TAX8 - LFGYPVYV, TAX9 - LLFGYPVYV and KLL15 - KLLEIPDPDKNWATL) to uncover any differences in the TAPBPR G24-R36 loop effect in relation to peptide length (Hassan et al., 2015; Khan et al., 2000). Optimization of ITC experimental conditions (Methods) allowed us to focus on different steps of the thermodynamic cycle (Fig. 5B and Fig. S6A-C). First, direct measurement of the binding of peptide to the empty MHC-I groove $\left(\mathrm{K}_{\mathrm{D} 2}\right)$ is hindered by the inherent instability of unchaperoned peptide-deficient MHC-I molecules. Thus, we utilized TAPBPR as a stabilizer of peptide-deficient HLA-A*02:01. Purified 1:1 HLA-A*02:01/TAPBPR complex in the calorimeter cell was titrated by injecting peptide. The apparent $\mathrm{K}_{\mathrm{D} 2}$ can be obtained from the experiment when peptide binds to the MHC-I and promotes the release of TAPBPR under conditions where no excess TAPBPR is included (Fig. 5B-left and Fig. S6A). The $\mathrm{K}_{\mathrm{D} 2}$ values, which range from 40 to $400 \mathrm{nM}$ across our peptide set, did not differ significantly between HLA$\mathrm{A}^{*}$ 02:01/TAPBPR complexes prepared using TAPBPR ${ }^{\mathrm{WT}}$ or TAPBPR ${ }^{\mathrm{G} 24-\mathrm{R} 36}$, suggesting that our measurements were dominated by peptide binding to empty, unchaperoned MHC-I (Fig. 5C and Table 1). Our determined $\mathrm{K}_{\mathrm{D} 2}$ values are consistent with previous reports of low to medium $\mathrm{nM}$ affinity binding for peptide to MHC-I, confirming that our assay provides a close approximation for $\mathrm{K}_{\mathrm{D} 2}$ (Assarsson et al., 2007; Harndahl et al., 2012).

By titration of TAPBPR with pMHC-I in the presence of excess peptide in both the cell and syringe, the $\mathrm{K}_{\mathrm{D} 3}$ for the formation of ternary pMHC-I/TAPBPR complex was obtained (Fig. 5Bmiddle and Fig. S6A). Measured $\mathrm{K}_{\mathrm{D} 3}$ values, which were in the range of $2 \mu \mathrm{M}$ for the different peptides in our set, were similar between $\mathrm{pMHC}-\mathrm{I} / \mathrm{TAPBPR}$ complexes formed using TAPBPR ${ }^{\mathrm{WT}}$ or TAPBPR ${ }^{\triangle \mathrm{G} 24-\mathrm{R} 36}$ (Fig. 5C and Fig. S6A-C and Table 1), suggesting that the loop does not affect recognition of peptide-loaded MHC-I. Finally, titration of empty HLA-A*02:01/TAPBPR complex by injecting the peptide in the presence of excess TAPBPR in both the cell and syringe (to minimize dissociation of TAPBPR from the pMHC-I/TAPBPR complex) allowed measurement of an apparent value for $\mathrm{K}_{\mathrm{D} 4}$, binding of peptide to an empty MHC-I/TAPBPR complex (Fig. 5B-right and Fig. S6B). Here, we observed binding to two sequential sites (Fig. 5B-right), due to a combination of processes that are described by the steps indicated with $\mathrm{K}_{\mathrm{D} 2}$ and $\mathrm{K}_{\mathrm{D} 4}$ (Fig. 5A). However, given that the $\mathrm{K}_{\mathrm{D} 2}$ process does not involve TAPBPR, results obtained in these conditions can be used to probe effects of TAPBPR loop variations on $\mathrm{K}_{\mathrm{D} 4}$.

Notably, apparent $\mathrm{K}_{\mathrm{D} 4}$ values were increased by a factor of two to three-fold between pMHCI/TAPBPR complexes prepared using TAPBPR ${ }^{\triangle \mathrm{G} 24-\mathrm{R} 36}$ versus TAPBPR ${ }^{\mathrm{WT}}$ (Fig. 5A-C and Fig. S6A-C and Table 1); i.e. the G24-R36 loop increases the affinity of empty, chaperoned MHC-I for incoming peptides. While instability of peptide-deficient HLA-A*02:01 molecules in the absence of TAPBPR did not permit direct measurement of $\mathrm{K}_{\mathrm{D} 1}$ (i.e. binding of TAPBPR to empty MHC-I), this value was inferred from thermodynamic balance along the exchange cycle (Fig. 5A and Table 1). $K_{D 1}$ was decreased by a factor of two to three-fold for TAPBPR ${ }^{\triangle \mathrm{G} 24-\mathrm{R} 36}$ versus $\mathrm{TAPBPR}^{\mathrm{WT}}$ (Table 1), suggesting that the presence of the loop reduces the affinity of TAPBPR 
for empty MHC-I, likely due to steric clashes between the TAPBPR loop and the MHC-I groove (Fig. S1 A-C, Fig. 1D, E). This result is inconsistent with models of the TAPBPR 24-36 loop acting as a stabilizer of empty MHC-I molecules and a steric competitor of incoming peptides (Ilca et al., 2018; Sagert et al., 2020). In agreement with our NMR results (Fig. 4C, Fig. S5A, C), the ITC data suggest that the TAPBPR G24-R36 loop does not form a strong, stabilizing interaction with the empty MHC-I groove but instead functions to promote peptide loading to the empty MHCI/TAPBPR complex.

\section{The TAPBPR loop length is important for peptide loading function in vitro}

To determine whether the full length of the TAPBPR G24-R36 loop is required for normal function, we applied a similar design approach from our ITC studies to fluorescence polarization (FP) experiments. We have previously shown that the association of peptides with the MHC-I groove can be monitored with FP competition assays where purified peptide-deficient MHCI/TAPBPR complexes are incubated with fluorescently labeled TAMRA-peptide and a range of concentrations of unlabeled competitor peptide (McShan et al., 2018). Analogous to our ITC experiments, optimization of FP assay conditions (Methods) allowed us to independently probe each step of the thermodynamic cycle (Fig. S7A-C). First, dilution of peptide-deficient HLAA*02:01/TAPBPR complexes under substoichiometric conditions (in the absence of excess TAPBPR) promotes dissociation of HLA-A*02:01 from TAPBPR in the presence of peptide, which allows for measurement of peptide $\mathrm{IC}_{50} 2$ values. FP was performed with TAX8, TAX9, and KLL15 serving as the competitor peptides. In agreement with ITC, $\mathrm{IC}_{502}$ values determined by FP did not differ between HLA-A*02:01/TAPBPR complexes prepared using TAPBPR ${ }^{\mathrm{WT}}$, $\mathrm{TAPBPR}^{\triangle A L A S}$, or TAPBPR ${ }^{\triangle \mathrm{G} 24-\mathrm{R} 36}$ (Fig. 5D, left and Fig. S7B). Second, titration of TAPBPR into a sample containing fluorescently labeled TAMRA-TAX9 in complex with HLA-A*02:01 allows measurement of $\mathrm{K}_{\mathrm{D} 3}$ in the peptide exchange cycle (Fig. 5A). In agreement with our ITC experiments, we find that measured $\mathrm{K}_{\mathrm{D} 3}$ values from $\mathrm{FP}$, which are in a similar range to ITC of 2 $\mu \mathrm{M}$, did not differ between pMHC-I/TAPBPR complexes formed using TAPBPR ${ }^{\mathrm{WT}}$, TAPBPR $^{\triangle A L A S}$, or TAPBPR ${ }^{\triangle \mathrm{G} 24-\mathrm{R} 36}$ (Fig. S7A). Finally, dilution of peptide-deficient HLAA*02:01/TAPBPR complexes under stoichiometric conditions (in the presence of excess TAPBPR to minimize dissociation of TAPBPR from the pMHC-I/TAPBPR complex) allows for measurement of $\mathrm{IC}_{50} 4$. In agreement with our ITC data, we find that measured $\mathrm{IC}_{50} 4$ values are increased by a factor of two to three-fold between pMHC-I/TAPBPR complexes formed using $\triangle$ G24-R36 versus wild-type TAPBPR (Fig. 5D, right and Fig. S7C). In summary, the combined ITC and FP results suggest that the TAPBPR G24-R36 loop influences the formation of the pMHC-I/TAPBPR intermediate complex. These results further suggest that, because the short $T_{\text {TAPBPR }}{ }^{\triangle A L A S}$ deletion variant already has the same behavior as TAPBPR ${ }^{\triangle \mathrm{G} 24-\mathrm{R} 36}$, a long TAPBPR G24-R36 loop is an important factor for peptide exchange.

\section{The TAPBPR loop does not explicitly control the length of bound peptides}

We applied our FP experiments to determine whether the length of the MHC-I cargo influences TAPBPR G24-R36 loop mediated peptide selection. Since it is established that peptides of length longer than ten bulge out of the MHC-I groove (Hassan et al., 2015; Tynan et al., 2005), we hypothesized that steric clashes between protruding peptide residues with the G24-R36 loop, which hovers above the groove, could influence TAPBPR-mediated peptide exchange. To test our hypothesis, we prepared a set of peptides derived from the HTLV-1 TAX epitope ranging from 8 to 12 amino acids in length, each containing the same residue types in the two anchor positions. 
Comparison of X-ray structures available for TAX8 and TAX9 with RosettaCM models of TAX10 (LLFGGYPVYV), TAX11 (LLFGGGYPVYV), and TAX12 (LLFGGGGYPVYV) revealed the expected trend with longer peptides bulging from the HLA-A*02:01 groove (Fig. 5E). Using DSF experiments we observed that optimal peptide length (9-10 residues (Trolle et al., 2016)) correlates with highest thermal stability of the pMHC-I complex, as shown by the low stability of TAX8 and TAX12 $\left(\mathrm{T}_{\mathrm{m}}=43.2\right.$ and $\left.53.2^{\circ} \mathrm{C}\right)$ and higher stability for TAX9 and $\mathrm{TAX} 10\left(\mathrm{~T}_{\mathrm{m}}=62.9\right.$ and $\left.58.9^{\circ} \mathrm{C}\right)$ (Fig. S8A). Next, we performed FP competition experiments under substoichiometric conditions for each of the TAX length variants, to quantify peptide binding to empty MHC-I molecules upon release from TAPBPR. We observed a similar trend for FP determined $\mathrm{IC}_{50} 2$ values, where TAX9 and TAX10 peptides exhibited stronger association with HLA-A*02:01 (Fig. S8B). In addition, as observed in our ITC and previous FP experiments, measured $\mathrm{IC}_{50}$ values were similar between HLA-A*02:01/TAPBPR complexes prepared using TAPBPR ${ }^{\mathrm{WT}}$, TAPBPR ${ }^{\triangle A L A S}$, or TAPBPR ${ }^{\triangle \mathrm{G} 24-}$ ${ }^{R 36}$ (Fig. S8B). We observed an excellent correlation between FP determined $\mathrm{IC}_{50} 4$ values and $\mathrm{T}_{\mathrm{m}}$ values of pMHC-I complexes (Fig. 5F). In addition, we measured $\mathrm{IC}_{50} 4$ values for the TAX peptide length variants and found an increase by a factor of 2-3 between pMHC-I/TAPBPR complexes prepared using TAPBPR ${ }^{\triangle A L A S}$ or TAPBPR $^{\triangle \mathrm{G} 24-\mathrm{R} 36}$ versus $\mathrm{TAPBPR}^{\mathrm{WT}}$, consistently across all peptides (Fig. 5G and Fig. S8C). It is worth noting that the 15mer KLL15 peptide exhibits a similar magnitude in the G24-R36 loop effect compared to our TAX length variant dataset (Fig. 5D, G). Together, these data suggest that the TAPBPR G24-R36 loop promotes loading of moderate and high affinity peptides, irrespective of their length.

\section{The TAPBPR loop promotes formation of a transiently bound peptide state}

To gain a high-resolution view of how the TAPBPR G24-R36 loop might affect the binding of peptides on the MHC-I groove in an aqueous environment, we turned to NMR experiments using ${ }^{13} \mathrm{C}$-LV (Leu/Val) methyl-labeled peptides. We first examined a high affinity TAX9 peptide, containing two N-terminal Leu and two C-terminal Val methyl groups which act as sensitive probes of the dynamics and local magnetic environment using samples where the MHC and TAPBPR components are at natural isotopic abundance (Fig. 6A). In the $2 \mathrm{D}^{1} \mathrm{H}^{-13} \mathrm{C}$ methyl HMQC spectra of pMHC-I refolded with labeled peptide and followed by addition of 8 -fold molar excess TAPBPR, we observed NMR resonances corresponding to the free peptide, unloaded from the MHC-I groove by TAPBPR (denoted "f"), in slow exchange (ms timescale) with the MHC-I bound form (denoted "b") (Fig. 6B). Resonances corresponding to bound peptide in the MHC-I/TAPBPR complex are broadened beyond detection, likely due to conformational exchange at the intermediate $(\mu \mathrm{s}-\mathrm{ms})$ timescale. To examine the effects on the TAPBPR G24-R36 loop on exchange, we developed an in vitro NMR peptide un-loading assay. The NMR signal intensities of methyl resonances corresponding to free TAX9 provided us a robust quantification of the amount of peptide in solution when pMHC-I is incubated with saturating concentration (8-fold molar excess) of TAPBPR, expressed with and without the G24-R36 loop (Fig. 6C, D). We found that incubation of pMHC-I with TAPBPR containing G24-R36 loop deletions resulted in $\sim 3$ to 4fold increase of free TAX9 peptide relative to samples containing the equivalent concentrations of wild-type TAPBPR (Fig. 6E), suggesting that a longer loop results in reduced peptide unloading activity, consistent with our previous FP and ITC results (Fig. 5).

We hypothesized that the longer TAPBPR G24-R36 loop might act by promoting the capture of a transiently formed encounter complex between the peptide and the empty, chaperoned MHC-I groove (Fig. 6C). To test this hypothesis and to identify a plausible peptide loading pathway, we 
introduced a disulfide bond linking the N-terminus of isotopically ${ }^{13} \mathrm{C}$ LV-labeled CysTAX9 peptide (L1C mutation) to the MHC-I groove (W167C mutation), which serves to mimic a transiently bound peptide state (Fig. 6F). This allowed us to observe a new set of methyl resonances, corresponding to an intermediate state with an N-terminally tethered peptide which lies outside of the groove (denoted "i"), in slow exchange with the resonances corresponding to the fully bound peptide (Fig. 6G). Contrary to our results using free, isotopically labeled peptides (Fig. 6E), comparison of the intensities of methyl resonances reveals that tethering the peptide to the MHC-I groove alleviates the effect of the TAPBPR G24-R36 loop deletion in our NMR-based assay, resulting in a similar amount of peptide outside of the groove relative to WT TAPBPR (Fig. 6H, I). Since incoming peptides may anneal to the empty MHC groove via either their N-terminal or C-terminal anchors, TAPBPR may promote loading by stabilizing different ensembles of intermediate states with partially bound peptide conformations (Fig. 6J). However, if the dominant pathway for loading proceeded from the peptide $\mathrm{N}$ - to $\mathrm{C}$ - terminus then mutations of the TAPBPR G24-R36 loop would lead to a significant signal increase for methyl resonances corresponding to the intermediate state "i", contrary to our results (Fig. 6H). Therefore, TAPBPR likely acts by stabilizing an ensemble of peptide conformations forming transient interactions with the F-pocked of the MHC-I groove, adjacent to the TAPBPR loop. Similar results were obtained using an isotopically labeled $15 \mathrm{mer}$ peptide (Fig. S9A-F and Fig. S10A-H), demonstrating that the TAPBPR G24-R36 loop employs a similar mechanism to promote peptide capture irrespective of peptide length.

\section{DISCUSSION}

Recent structural studies have revealed that chaperone-mediated peptide exchange/editing is achieved through (i) stabilization of the peptide-deficient MHC-I in a peptide-receptive conformation, (ii) ejection of suboptimal peptides by inducing an $\sim 3 \AA$ widening of the MHC-I groove, and (iii) regulation of a dynamic switch located in the MHC-I groove (Jiang et al., 2017; McShan et al., 2018, 2019; Thomas and Tampé, 2017). Despite these important findings, the mechanistic details of how chaperones influence the repertoire of MHC-I presented antigens remains incompletely characterized, while a significant difference between published X-ray structures challenge the proposed role of the TAPBPR G24-R36 loop as a direct peptide competitor.

Here, we resolve the key discrepancy between recent MHC-I/TAPBPR structures by examining the conformational landscape of the TAPBPR G24-R36 loop and directly probing for an interaction to the MHC-I groove using solution NMR. Our data show that the TAPBPR G24-R36 loop is intrinsically disordered and does not form stable contacts with the floor of the empty MHCI groove (Fig. 1D, E, Fig. 4C). These observations are consistent with the H2-D d/TAPBPR structure in which the TAPBPR G24-R36 loop is missing due to poorly defined electron density. Our data and interpretations are also consistent with electron density for the equivalent loop of tapasin in the PLC cryo-EM structure, yet for reasons that are not clear, the authors chose to model the loop outside of the density as entering the empty MHC-I groove. One limitation of our study is that in vitro binding experiments were carried out using recombinant proteins prepared in $E$. coli. We note that while this is also the case for the X-ray crystallography and other biophysical studies in our field (Jiang et al., 2017; McShan et al., 2018; Morozov et al., 2016; Thomas and Tampé, 2017), there may be differences in MHC-I / chaperone interactions for proteins expressed 
in mammalian cells, primarily due to glycosylation (Neerincx and Boyle, 2019). For example, MD simulations of the peptide loading complex suggest that the MHC-I-linked glycan promotes movement of the tapasin loop toward the peptide binding groove of the MHC-I (Fisette et al., 2020). Secondly, due to the lack of an experimental HLA-A*02:01/TAPBPR structure, our study is restricted to interpreting models built from available X-ray structures as templates (Fig. 1 and Fig. S1), although modeling is highly accurate when homology to the template is high, as is the case between MHC-I alleles. Solution NMR experiments provide clear evidence for a lack of a direct interaction between the TAPBPR G24-R36 loop and the HLA-A*02:01 groove (Fig. 4C), however in vitro binding data were acquired using the human HLA-A*02:01 heavy chain and it remains unclear how differences in amino acid polymorphisms within other MHC-I, such as the mouse H2 groove, influence behavior of the TAPBPR G24-R36 loop (McShan et al., 2019; Morozov et al., 2016). While we did not find differences in the formation of empty H2D /TAPBPR or HLA-A*02:01/TAPBPR complexes in vitro by SEC (Fig. S4), our yeast display experiments do suggest there may be differences in behavior of the TAPBPR G24-R36 loop as the result of allele specific chemistry of the pMHC-I surface (Fig. 3), in agreement with recent binding results using a range of human HLA alleles (Ilca et al., 2019). Bound peptide alters the chemical features of the pMHC-I surface in an allele-dependent manner and thus both sterics and electrostatics may influence transient interactions with the intrinsically disordered loop. Future NMR experiments should probe for direct interaction between the TAPBPR G24-R36 loop and empty or peptide bound MHC-I comprised of different heavy chain alleles.

We sought to determine the role of the G24-R36 loop on TAPBPR's recently identified dual functions of chaperoning and peptide editing. Deep mutagenesis based on the ability of tapasin or TAPBPR variants to functionally replace tapasin for HLA-A*02:01 processing within the cell suggests that the loop tip does not substantially participate in the chaperone function, while tapasin L18 at the base of the loop makes important contacts, possibly above Y84 on the upper rim of the MHC-I groove based on the PLC cryo-EM density. However, deep mutagenesis of yeast-displayed TAPBPR indicates the G24-R36 loop does have a specific role in determining affinity with folded pMHC-I, as occurs in peptide editing. It is well established that, in conjunction with its role as a stabilizing chaperone, TAPBPR functions as an enzyme catalyst for peptide exchange for the MHC-I (Hermann et al., 2015b), which requires a cycle of chaperone, peptide and pMHC-I/MHCI binding and unbinding events. We carefully designed novel ITC and FP assays that allowed us to uniquely probe each step of the thermodynamic cycle describing the peptide exchange process (Fig. 5A, S6 and S7). According to the "scoop loop" model, removal of the TAPBPR G24-R36 loop would result in a lower $\mathrm{K}_{\mathrm{D} 4}$ (tighter binding of peptides to the $\mathrm{MHC}$-I groove). Instead, we find that removal of the TAPBPR G24-R36 loop results in a higher $\mathrm{K}_{\mathrm{D} 4}$ (Fig. 5C, G). Together, these observations, in conjunction with our loop modeling and solution NMR studies, lead us to conclude that the TAPBPR G24-R36 loop functions as a peptide trap (or lid), rather than a "scoop loop". Our NMR experiments suggest that instead of participating in a direct, stable interaction with the peptide or floor of the MHC-I groove, the TAPBPR G24-R36 loop promotes the early capture of a peptide intermediate within the MHC-I groove across the timescale of peptide annealing within pMHC-I complexes that are transiently interrogated by TAPBPR during editing (Fig. 6 and Fig. S10). This will provide sufficient time for the peptide to 'activate' the MHC-I $\alpha_{1-}$ 2 conformational switch located near the TAPBPR binding site, which triggers TAPBPR release (McShan et al., 2018).

541 
Two recent studies investigated the putative function of the TAPBPR G24-R36 loop (Ilca et al., 2018; Sagert et al., 2020). Ilca et al examined TAPBPR constructs with a mutated but full-length G24-R36 loop, while Sagert et al examined TAPBPR constructs with 12 or 5 residue deletions, which are similar to the TAPBPR ${ }^{\triangle \mathrm{G} 24-\mathrm{R} 36}$ and TAPBPR ${ }^{\triangle \mathrm{ALAS}}$ mutants tested here. Notably, both ours and the Sagert et al mutant TAPBPR constructs lack L30, which Ilca et al proposed to participate in a lever-like mechanism. In corroboration with the data presented here (Fig. 4 and Fig. 5), these studies report that TAPBPR with a modified or absent G24-R36 loop can still associate with the MHC-I and that TAPBPR loop mutants can still promote peptide exchange but in a less efficient manner. While both Ilca et al and Sagert et al hypothesize that interactions between the TAPBPR G24-R36 loop and the floor of the MHC-I groove are important for its function, neither study provided molecular-level data in support of this hypothesis. Here, direct observation of recombinant MHC-I proteins, albeit lacking glycosylation at Asn 86, by solution NMR provides clear evidence that the TAPBPR loop does not enter the MHC-I groove (Fig. 4 and Fig. S5) for HLA-A*02:01, an MHC-I heavy chain allele also examined by Ilca et al and Sagert et al and relevant to the biology of human tapasin and TAPBPR.

In our ITC and FP assays, we explicitly control experimental conditions, such as peptide, MHC-I and TAPBPR concentrations, to perform separate experiments under stoichiometric and substoichiometric conditions towards resolving specific steps of the peptide exchange thermodynamic cycle (Fig. 5A). Here, a major experimental parameter for distinguishing between $\mathrm{K}_{\mathrm{D} 3}$ (association of pMHC-I with TAPBPR) and $\mathrm{K}_{\mathrm{D} 4}$ (association of peptide with the MHCI/TAPBPR complex) is the concentration of TAPBPR relative to the peptide and MHC-I (Fig. S6, Fig. S7). This distinction allows us to deconvolute the contributions of the TAPBPR G24-R36 loop at each specific step of the cycle. Our approach provides direct evidence for a clear role of the TAPBPR G24-R36 loop in acting as a peptide trap (i.e. the loop decreases $\mathrm{K}_{\mathrm{D} 4}$ ). In contrast, both Ilca et al and Sagert et al used fluorescence spectroscopy to measure peptide exchange and suggest that the TAPBPR G24-R36 loop promotes peptide dissociation from the MHC-I groove in a "scoop"-like manner. The authors sought to evaluate peptide dissociation from the MHC$\mathrm{I} / \mathrm{TAPBPR}$ groove (corresponding to $\mathrm{K}_{\mathrm{D} 4}$ ). In their experiments, binding of $300 \mu \mathrm{M}$ competitor peptide was assayed in mixtures of $1 \mu \mathrm{M}$ TAPBPR and $300 \mathrm{nM}$ MHC-I loaded with fluorescent peptide. However, when put in the context on our determined $\mathrm{K}_{\mathrm{D}}$ values, the concentrations used by Sagert et al (3.3-fold excess compared to 20 -fold excess TAPBPR used here) correspond to non-saturating TAPBPR conditions and thus do not accurately capture $K_{D 4}$ values. Since our $K_{D}$ measurements of peptide binding to the MHC-I/TAPBPR groove are in the low to medium $\mu \mathrm{M}$ range, the concentration used by Sagert et al was insufficient to achieve saturation of binding of the unlabeled competitor peptide to the MHC-I/TAPBPR groove. Finally, Ilca et al performed experiments on the surface of cells where it is unclear what concentrations of MHC-I and TAPBPR are present. Thus, because the authors were unable to separate $\mathrm{K}_{\mathrm{D} 3}$ and $\mathrm{K}_{\mathrm{D} 4}$, but instead measured the average effect of the loop across the two steps, there is the potential for misinterpretation. Our results and conclusions are consistent across binding experiments by NMR, yeast surface display, ITC and FP.

We further examined whether the TAPBPR G24-R36 loop may have a function in selecting peptides with a specific length by FP and NMR. Our data show that the presence of the TAPBPR G24-R36 loop exerts a broad effect across the repertoire, independent of peptide length, by promoting binding of peptides according to their global affinity for the empty MHC-I groove (Fig. 
S6, Fig. S7, Fig. 6, Fig. S10), although some subtle effects were observed between TAPBPR loop mutants and specific peptide sequences by yeast display (Fig. S3K, L). In other words, while TAPBPR lowers the peptide affinity requirements across the sampled peptidome, it appears that the specificity of peptide binding is determined by interactions with the MHC-I groove, not the TAPBPR loop.

Based on our results, we propose a model for how a longer loop in the TAPBPR sequence may contribute to shaping the displayed peptide repertoire on MHC-I molecules. The G24-R36 loop serves as a trap, allowing moderate to high affinity peptides of lengths 8 to 15 from the cellular pool to associate with the MHC-I/TAPBPR complex with a binding affinity in the low micromolar range (relative to high $\mu \mathrm{M}$, as observed for loop deletion mutants) (Fig. 6A). By lowering the affinity requirements for binding across the peptide pool, TAPBPR may function as an auxiliary peptide loader for peptides of low and moderate affinity (Fig. 6B); studies suggest that even low to moderate stability pMHC-I can provide robust T cell responses (Motyka and Teh, 1998; Zheng et al., 2008). Local peptide concentrations will be highest in the vicinity of the TAP transporter, which acts as a hub around which PLC components associate. Tapasin lacks a long loop, but is tethered to the TAP transporter through transmembrane domain interactions (Blees et al., 2015) and therefore can load cognate peptide ligands efficiently due to their increased local concentration (Fig. 6C). In contrast, TAPBPR is not tethered to TAP, but instead utilizes a long loop acting as a trap to load peptides on empty or suboptimally loaded MHC-I molecules that have escaped the PLC. (Fig. 6C). Therefore, the longer loop of TAPBPR is matched to its editing function in the Golgi where peptide concentrations will be low and only pMHC-I complexes with suboptimal peptides are to be disassembled, while tapasin has a short loop to favor competition between peptide substrates where they are in abundance surrounding the PLC (Fig. 6C). In summary, our work offers a paradigm of how two closely related molecular chaperones have developed subtle variations of both static and dynamic conformational elements around a common structural theme, to achieve unique functions that are highly adapted to their specific cellular compartments. 


\section{Human Cell Expression Constructs}

For expression in human cells, cDNAs were cloned into the NheI-XhoI sites of pCEP4 (Invitrogen) (isoform 1 a.a. 21-448; GenBank Acc. No. NP_003181) was synthesized (IDT) with a canonical signal peptide and N-terminal FLAG epitope tag. The cloning of TAPBPR is previously described(McShan et al., 2019). TAPBPR-CT was constructed by PCR-based fragment assembly: the final sequence comprises a canonical signal peptide, a FLAG tag, TAPBPR residues 22-405 and tapasin residues 406-448. Both targeted mutations and generation of the libraries using oligos with degenerate NNK codons were by overlap extension PCR(Procko et al., 2013).

\section{Yeast Expression Constructs}

For yeast surface display, the extracellular domain of TAPBPR (a.a. 22-405) was cloned into the NheI-XhoI sites of pETCON(Fleishman et al., 2011), fusing Aga2p and a c-myc tag to the TAPBPR N- and C-termini for surface display and detection, respectively. To generate the SSM library on the 24-35 loop, the TAPBPR insert was amplified using oligos with degenerate NNK codons by overlap extension PCR. The pooled PCR product was mixed with linearized pETCON (cut NdeI/Xhol) and electroporated in to yeast, thereby using natural homologous recombination pathways to fuse the TAPBPR insert in to the pETCON backbone.

\section{Human Cell Culture}

Expi293F cells were cultured in suspension at $37^{\circ} \mathrm{C}, 8 \% \mathrm{CO}_{2}, 125 \mathrm{rpm}$ using Expi293 Expression Media (ThermoFisher). To generate the tapasin knockout line, cells were co-transfected with plasmids(Mali et al., 2013) encoding human codon-optimized Streptococcus pyogenes Cas9 and two guide RNAs targeting the tapasin gene immediately following the signal peptide (target sequences 5'-GACCCGCGGTGATCGAGTGTTGG-3' and 5'AACCAACACTCGATCACCGCGGG-3'). After a week, cells with reduced surface MHC-I following staining with anti-HLA-A2-PE (1/200 dilution, clone BB7.2, Biolegend) were enriched by sorting on a BD FACSAria II. Genomic DNA was purified (DNeasy Blood and Tissue Kit, Qiagen), and the targeted region of the tapasin gene was PCR amplified and sequenced on an Illumina MiSeq. Based on analysis with CRISPR-GA(Güell et al., 2014), >99 \% of tapasin gene copies in the polyclonal knockout line had indel mutations (GEO sample ID GSM3593598), whereas copies of the tapasin gene were mostly wild type in the parental line (GEO sample ID GSM3593597). To test targeted mutants of TAPBPR or tapasin, Expi293F cells (wild type or tapasin-KO) were transfected using ExpiFectamine (Life Technologies) with $500 \mathrm{ng}$ plasmid DNA per $\mathrm{ml}$ of cells at a density of $2 \times 10^{6} / \mathrm{ml}$. Cells were analyzed $24-26 \mathrm{~h}$ post-transfection. For sorting libraries, tapasin-KO Expi293F cells $\left(2 \times 10^{6} / \mathrm{ml}\right)$ were transfected with $1 \mathrm{ng}$ SSM library plasmid diluted with $1500 \mathrm{ng}$ carrier plasmid (pCEP4- $\Delta \mathrm{CMV}$ (Park et al., 2019)) using ExpiFectamine, and the medium was replaced after 2 hours. Cells were sorted 24-25 h posttransfection.

\section{Flow Cytometry of Expi293F Cells}

To assess surface HLA-A2 expression, cells were stained on ice for 30 minutes with anti-HLA-A2 PE (clone BB7.2, BioLegend) diluted 1:200 in PBS supplemented with $0.2 \%$ bovine serum 
662 albumin (PBS-BSA) and then washed twice with PBS-BSA. Fluorescence was measured using a BD LSRII and results were analyzed using FCS Express 6. Tapasin-KO Expi293F cells expressing the tapasin or TAPBPR-CT libraries were stained with 1:200 anti-HLA-A2 PE in PBS-BSA for 30 minutes at $4{ }^{\circ} \mathrm{C}$ and washed twice with PBS-BSA. After gating for the main population by forward-side scatter and excluding dead cells based on DAPI uptake, the top $0.5 \%$ of cells for PE fluorescence were collected using a BD FACSAria II. RNA was extracted from sorted cells (GeneJet RNA purification kit, ThermoFisher), first strand cDNA was synthesized using Accuscript (Agilent) primed with the EBV reverse sequencing primer, which anneals to the 3' UTR of pCEP4-encoded transcripts. DNA fragments covering mutated regions were PCR amplified in two rounds to append sequences complementary to Illumina sequencing primers and add experiment-specific barcodes and Illumina adaptamers. Products were sequenced on a NovaSeq 6000 and analyzed with Enrich(Fowler et al., 2011). Scripts for analysis are included with the GEO submission.

\section{Immunoblots}

Cells were pelleted, lysed in reducing SDS load dye and sonicated. Proteins were separated by electrophoresis on $10 \%$ SDS polyacrylamide gels and transferred to PVDF. For the detection of FLAG-tagged TAPBPR or tapasin, membranes were blocked with 3\% BSA in Tris-buffered saline supplemented with $0.1 \%$ tween 20 (TBS-T) for 30 mins, followed by staining with 1:2000 antiFLAG (clone M2)-AP (Sigma-Aldrich) for 30 mins, washed 5 times with TBS-T, and developed using 1-Step NBT-BCIP (ThermoFisher). For the detection of cyclophilin B as a loading control, membranes were blocked with 5\% nonfat milk (Biorad) in TBS-T for 30mins, followed by incubation with 1:2000 rabbit anti-cyclophilin B (Invitrogen PA1-027A) for 30 mins, washed 5 times with TBS-T, followed by secondary incubation with 1:10,000 goat anti-rabbit HRP (Rockland Immunochemicals) for 30 mins, washed 5 times with TBS-T, and developed using Clarity Western ECL Substrate (BioRad).

\section{Yeast Display}

Saccharomyces cerevisiae strain EBY100 were grown in YPAD medium. To test targeted mutants, lithium acetate/polyethylene glycol 3350-treated competent yeast were heat shocked to promote plasmid uptake. For generating the TAPBPR 24-35 loop library, yeast were electroporated. Transformed yeast were selected in SDCAA medium $(2 \% \mathrm{w} / \mathrm{v}$ glucose, $0.67 \% \mathrm{w} / \mathrm{v}$ yeast nitrogen base, $0.5 \% \mathrm{w} / \mathrm{v}$ casamino acids, $0.1 \mathrm{M}$ sodium phosphate $\mathrm{pH} 6.6)$ at $30{ }^{\circ} \mathrm{C}$ for $1-2$ days, before induction in SGCAA (in which glucose is replaced with galactose) at $\mathrm{OD}(600 \mathrm{~nm})=$ 0.5 for 2 days at $24{ }^{\circ} \mathrm{C}$. Induced EBY100 were washed with PBS-BSA and incubated with APCconjugated MHC-I tetramers (concentrations are indicated in figure legends) and FITC-conjugated chicken anti-c-myc (1/100 dilution, Immunology Consultants Laboratory) for 40 minutes at $24^{\circ} \mathrm{C}$, $215 \mathrm{rpm}$. Cells were washed twice with cold PBS-BSA before being resuspended for analysis on a BD Accuri C6 or sorted on a BD FACSAria II.

\section{Deep Mutational Scan of TAPBPR 24-35 Loop using Yeast Display}

Generation of the TAPBPR library and yeast preparation are described above. Naive and sorted yeast cultures were lysed with $125 \mathrm{U} / \mathrm{ml}$ Zymolase $\left(37^{\circ} \mathrm{C}, 5 \mathrm{hr}\right)$ and plasmid DNA was purified using a Zymoprep kit (Zymo Research). The mutated region of TAPBPR was PCR amplified in 
two stages. A first round of PCR used primers that added sequences complementary for Illumina sequencing primers. A second round of PCR added end sequences for annealing to the Illumina flow cell and included $6 \mathrm{bp}$ barcodes for unique sample identification. Amplicons were sequenced on a Illumina HiSeq 4000 and data were analyzed with Enrich(Fowler et al., 2011). Scripts for analysis are included in the GEO submission.

Protein Expression and Purification. DNA plasmid constructs encoding the luminal domain of human HLA-A*02:01 (heavy chain) and $\mathrm{h} \beta_{2}$ m (light chain) were generously provided by the NIH tetramer facility and transformed into BL21(DE3) Escherichia coli (New England Biolabs). DNA Plasmid construct encoding the luminal domain of mouse $\mathrm{H} 2-\mathrm{D}^{\mathrm{d}}$ molecule was generously provided by Kannan Natarajan, NIH. MHC-I heavy and light chain molecules were individually expressed in Luria-Broth, extracted from inclusion bodies, and refolded in vitro together with peptide at $4^{\circ} \mathrm{C}$ as previously described(Garboczi et al., 1992). Peptides used in this study were prepared by chemical synthesis (Biopeptik Inc, Malvern, USA or GenScript, Piscataway, USA). Peptides sequences include: P18-I10 (RGPGRAFVTI), TAX8 (LFGYPVYV), TAX9 (LLFGYPVYV), TAX10 (LLFGGYPVYV), TAX11 (LLFGGGYPVYV), TAX12 (LLFGGGGYPVYV) and KLL15 (KLLEIPDPDKNWATL). The UV-labile conditional ligands photoP18-I10 (RGPGRAF JTI) and photoFluM1 (KILGFVF $J$ ), where $J=3$-amino-3-(2nitrophenyl)-propionic acid were refolded with $\mathrm{H} 2-\mathrm{D}^{\mathrm{d}} / \mathrm{h} \beta_{2} \mathrm{~m}$ and HLA-A*02:01/h $\beta_{2} \mathrm{~m}$, respectively, under dark conditions (Rodenko et al., 2006). For disulfide linked peptide studies, CysTAX9 (LLFGYPVYV) and CLW15 (CLWDIETGQQKTVFV) were refolded with HLAA*02:01 W167C, while ACW15 (ACWDIETGQQKTVFV) was refolded with HLA-A*02:01 K66C. Purification of pMHC-I complexes was performed by size-exclusion chromatography (SEC) with a HiLoad 16/600 Superdex $75 \mathrm{pg}$ column at $1 \mathrm{~mL} / \mathrm{min}$ with running buffer $(150 \mathrm{mM}$ $\mathrm{NaCl}, 25 \mathrm{mM}$ Tris, $\mathrm{pH}$ 8). The luminal domains of various TAPBPR forms used in this study were expressed using a Drosophila S2 cell expression system and purified as previously described (Morozov et al., 2016). The TAPBPR ${ }^{\triangle A L A S}$ construct was prepared by PCR using through deletion of A29-S32 using forward primer: 5' - AAG GAC GGT GCG CAC CGT GGA AGT GAG GAC AGG GCA AGG GCC - 3' and reverse primer: 5' - GGC CCT TGC CCT GTC CTC ACT TCC ACG GTG CGC ACC GTC CTT - 3', and confirmed by DNA sequencing. The TAPBPR ${ }^{\mathrm{WT}}$ and $\mathrm{TAPBPR}^{\triangle \mathrm{G} 24-\mathrm{R} 36}$ constructs were generously provided by Kannan Natarajan, NIH. DNA transfection of the TAPBPR constructs into Drosophila S2 cells was performed using standard protocols with X-tremeGENE 9 (Sigma-Aldrich). Following expression and purification all proteins were exhaustively buffer exchanged into $50 \mathrm{mM} \mathrm{NaCl}, 20 \mathrm{mM}$ sodium phosphate $\mathrm{pH}$ 7.2.

Sequence alignment. Sequence alignment was performed between Homo sapiens (Hs, human) TAPBPR (UniProtID: Q9BX59) and tapasin (UniProtID: O15533), Mus musculus (Mm, mouse) TAPBPR (UniProtID: Q8VD31) and tapasin (UniProtID: Q9R233), and Rattus norvegicus (Rn, rat) TAPBPR (UniProtID: D4A6L1) and tapasin (UniProtID: Q99JC6) using ClustalOmega.

Disulfide Design Constructs. Disulfide linked constructs for CysTAX9, ACW15 (ACWDIETGQQKTVFV) and CLW15 (CLWDIETGQQKTVFV) were designed using Disulfide by Design v2 (http://cptweb.cpt.wayne.edu/DbD2/) (Craig and Dombkowski, 2013) using PDB ID 1DUZ or a RosettaCM model based on PDB ID 4U6Y. 
Rosetta Modeling. Rosetta modeling of MHC-I/TAPBPR complexes and the TAPBPR G24-R36 loop was performed using either RosettaCCD (Wang et al., 2007), RosettaKIC (Mandell et al., 2009), or RosettaCM (Song et al., 2013) using template X-ray structure PDB ID 5WER or PDB ID 5OPI. In each case the sequence for $\mathrm{H} 2-\mathrm{D}^{\mathrm{d}}$ or $\mathrm{H} 2-\mathrm{D}^{\mathrm{b}}$ was replaced with HLA-A*02:01 using Rosetta's partial thread application. Fragment files for loop modeling were generated using the Robetta server (http://robetta.bakerlab.org/). The lowest energy structures were selected from a total of 1,000 models calculated for each protocol. Rosetta modeling of TAX10, TAX11 or TAX12 peptides in complex with HLA-A*02:01 was performed using RosettaCM against PDB ID 1HHH, 5D9S, and 4JQX, respectively.

Molecular dynamics simulations. All-atom molecular dynamics (MD) simulations in explicit solvent were carried out as previously described in GROMACS version 2019.2 using an AMBER99SB-ILDN protein force field and TPI3P water model (McShan et al., 2018). The input structure was the lowest energy RosettaCM model of peptide-deficient HLAA*02:01/h $\beta_{2}$ m/TAPBPR built from template PDB ID 5OPI. LINCS and SETTLE constraint algorithms were used to constrain protein and water molecules, respectively. An integration time step of 4 fsec was used with coordinates output every $10 \mathrm{psec}$. Short range interactions were treated with a Verlet cut-off scheme with $10 \AA$ electrostatic and van der Walls cutoffs and long-range electrostatics were treated with the PME method with a grid spacing of $1.2 \AA$ and cubic interpolation. Periodic dodecahedron boundaries were used. The thermodynamic ensemble was nPT where temperature was kept constant at $300 \mathrm{~K}$ by a V-rescale modified thermostat with 0.1 psec time constant and pressure was kept constant at 1 bar pressure using an isotropic Berendsen barostat. The system was solvated to overall neutral charge and contained $\mathrm{Na}^{+}$and $\mathrm{Cl}^{-}$ions to yield physiological concentration of $0.15 \mathrm{M}$. Following 500 steps of steepest-descent energy minimization, initial velocities were generated at $65 \mathrm{~K}$ with linear heating up to $300 \mathrm{~K}$ over 2 nsec. Trajectories were acquired for $200 \mathrm{nsec}$. Structures were extracted after the final $200 \mathrm{nsec}$ simulations using GROMACS.

Differential Scanning Fluorimetry. DSF experiments were performed on an Applied Biosystems ViiA 7 qPCR machine with excitation and emission wavelengths set to $470 \mathrm{~nm}$ and $569 \mathrm{~nm}$ with proteins in buffer of $50 \mathrm{mM} \mathrm{NaCl}, 20 \mathrm{mM}$ sodium phosphate $\mathrm{pH}$ 7.2. Experiments were conducted in triplicate in MicroAmp Fast 96-well plates with $50 \mu \mathrm{L}$ total volume containing final concentrations of $7 \mu \mathrm{M}$ protein and $10 \times$ SYPRO orange dye (ThermoFisher). Temperature was incrementally increased at a scan rate of $1^{\circ} \mathrm{C} / \mathrm{min}$ between $25^{\circ} \mathrm{C}$ and $95^{\circ} \mathrm{C}$. Data analysis and fitting were performed in GraphPad Prism v7.

Circular Dichroism. Far-UV CD spectra were acquired using a JASCO J-815 Spectropolarimeter. CD spectra of wild-type TAPBPR, TAPBPR ${ }^{\triangle A L A S}$ and TAPBPR ${ }^{\triangle \mathrm{G} 24-\mathrm{R} 36}$ were acquired using 0.05 $\mathrm{mg} / \mathrm{mL}$ protein in $2 \mathrm{~mL}$ of $50 \mathrm{mM} \mathrm{NaCl}, 20 \mathrm{mM}$ sodium phosphate $\mathrm{pH} 7.2$ in a quartz cuvette. A buffer blank was acquired and subtracted from each CD spectra. CD spectra were acquired from 190 to $260 \mathrm{~nm}$ in triplicate at $25^{\circ} \mathrm{C}$ with a scan rate of $50 \mathrm{~nm} /$ minute. The experimental CD values of ellipticity (mdeg) were converted to molar ellipticity $\left(\theta=\operatorname{deg~} \mathrm{cm}^{2} / \mathrm{dmol}\right)$.

798

NMR Spectroscopy. For NMR performed on labeled heavy chain, samples were prepared using either ILV ${ }^{\text {proS }}$ (Ile ${ }^{13} \mathrm{C} \delta 1$, Leu ${ }^{13} \mathrm{C} \delta 2$, Val ${ }^{13} \mathrm{C} \gamma 2$ ) or AILV methyl (Ala ${ }^{13} \mathrm{C} \beta$, Ile ${ }^{13} \mathrm{C} \delta 1$, Leu ${ }^{13} \mathrm{C} \delta 1 /{ }^{13} \mathrm{C} \delta 2$, Val ${ }^{13} \mathrm{C} \gamma 1 /{ }^{13} \mathrm{C} \gamma 2$ ) isotopic labeling at the HLA-A*02:01 heavy chain against a 
${ }^{12} \mathrm{C} /{ }^{2} \mathrm{H} /{ }^{15} \mathrm{~N}$ background. Bound peptide, $\mathrm{h} \beta_{2} \mathrm{~m}$ or TAPBPR were fully protonated. NMR methyl resonance assignments of free and TAPBPR bound states of HLA-A*02:01 were reported previously by our group (McShan et al., 2019). Peptide-deficient HLA-A*02:01/h $\beta_{2} \mathrm{~m} / \mathrm{TAPBPR}$ complexes were prepared as described above in the section "Preparation of empty MHCI/TAPBPR complexes" where HLA-A*02:01 was ILV ${ }^{\text {pros }}$ or AILV methyl labeled. The resulting purified HLA-A*02:01/h $\beta_{2} \mathrm{~m} / \mathrm{TAPBPR}^{\mathrm{WT}}$, HLA-A*02:01/h $\beta_{2} \mathrm{~m} / \mathrm{TAPBPR}{ }^{\triangle A L A S}$, or HLA$\mathrm{A}^{*} 02: 01 / \mathrm{h} \beta_{2} \mathrm{~m} / \mathrm{TAPBPR}^{\Delta \mathrm{G} 24-\mathrm{R} 36}$ complexes were exhaustively dialyzed into NMR buffer (50 mM $\mathrm{NaCl}, 20 \mathrm{mM}$ sodium phosphate $\left.\mathrm{pH} 7.2,5 \% \mathrm{D}_{2} \mathrm{O}\right)$ and concentrated to $\sim 80 \mu \mathrm{M}$. For NMR performed on labeled TAX9, CysTAX9 or CLW15 peptides, samples were ${ }^{15} \mathrm{~N} /{ }^{13} \mathrm{C}$ LV or ILV isotopically labeled against a protonated HLA-A*02:01 and $\mathrm{h} \beta_{2} \mathrm{~m}$ background. ${ }^{15} \mathrm{~N} /{ }^{13} \mathrm{C}$ ILV or LV isotopically labeled peptides were obtained from GenScript (Piscataway, USA). Free peptide, peptide in complex with HLA-A*02:01/h $\beta_{2} \mathrm{~m}$ or peptide/HLA-A*02:01/h $\beta_{2} \mathrm{~m}$ in the presence of 8 -fold molar excess TAPBPR were exhaustively dialyzed into NMR buffer (50 mM NaCl, $20 \mathrm{mM}$ sodium phosphate $\mathrm{pH} 7.2,5 \% \mathrm{D}_{2} \mathrm{O}$ ). Spectra were obtained at $\sim 100 \mu \mathrm{M}$ free peptide or pMHC-I concentrations. Two-dimensional ${ }^{1} \mathrm{H}^{13} \mathrm{C}$ methyl SOFAST HMQC experiments (Rossi et al., 2016) were recorded at $25^{\circ} \mathrm{C}$ at a ${ }^{1} \mathrm{H}$ field strength of $800 \mathrm{MHz}$ or $600 \mathrm{MHz}$. A total number of 320 scans were used with a $0.2 \mathrm{sec}$ recycle delay (d1) and acquisition times of $12 \mathrm{msec}$ and $30 \mathrm{msec}$ in the ${ }^{13} \mathrm{C}$ dimension for labeled heavy chain and labeled peptide, respectively. Data were processed with $4 \mathrm{~Hz}$ and $10 \mathrm{~Hz}$ Lorentzian line broadening in the direct and indirect dimensions. Chemical shift deviations (CSD, p.p.m.) were determined between TAX9/HLA-A*02:01/h $\beta_{2} \mathrm{~m}$ and TAPBPR bound HLA-A*02:01/h $\beta_{2} \mathrm{~m}$ using the equation $\Delta \delta^{\mathrm{CH} 3}=\left[1 / 2\left(\Delta \delta_{\mathrm{H}}{ }^{2}+\Delta \delta_{\mathrm{C}}{ }^{2} / 4\right)\right]^{1 / 2}$ for each methyl resonance. All NMR data were processed with NMRPipe (Delaglio et al., 1995) and analyzed using NMRFAM-SPARKY (Lee et al., 2015).

Isothermal Titration Calorimetry. ITC was performed using a MicroCal VP-ITC system (Malvern Panalytical). All proteins were exhaustively dialyzed into the buffer $(50 \mathrm{mM} \mathrm{NaCl}, 20$ $\mathrm{mM}$ sodium phosphate $\mathrm{pH}$ 7.2) filtered through a $0.22 \mu \mathrm{m}$ PES membrane. ITC experiments to probe the $\mathrm{K}_{\mathrm{D} 2}$ step of the peptide exchange cycle were performed under substoichiometric conditions in the absence of excess TAPBPR to allow for dissociation of HLA-A*02:01 from TAPBPR in the presence of incoming peptide. Syringe containing $\sim 50$ to $100 \mu \mathrm{M}$ peptide was titrated into a calorimetry cell containing $\sim 15 \mu \mathrm{M}$ purified peptide-deficient HLA$\mathrm{A} * 02: 01 / \mathrm{h} \beta_{2} \mathrm{~m} / \mathrm{TAPBPR}$ complex. ITC experiments to probe the $\mathrm{K}_{\mathrm{D} 3}$ step of the peptide exchange cycle were performed by titration of $\sim 150$ to $200 \mu \mathrm{M}$ purified pMHC-I into a calorimetry cell containing $\sim 15 \mu \mathrm{M}$ TAPBPR and $1 \mathrm{mM}$ excess peptide. ITC experiments to probe the $\mathrm{K}_{\mathrm{D} 4}$ step of the peptide exchange cycle were performed under stoichiometric conditions in the presence of excess TAPBPR to minimize dissociation of TAPBPR from the pMHC-I/TAPBPR complex. Syringe containing $\sim 150$ to $200 \mu \mathrm{M}$ peptide was titrated into a calorimetry cell containing $\sim 15$ $\mu \mathrm{M}$ peptide-deficient HLA-A*02:01/h $\beta_{2} \mathrm{~m} / \mathrm{TAPBPR}$ complex and $50 \mu \mathrm{M}$ excess TAPBPR. In all ITC experiments injection volumes were $10 \mu \mathrm{L}$ performed for a duration of $10 \mathrm{sec}$ and spaced 220 sec apart to allow for a complete return to baseline. Data was subtracted from a control experiments. Data were processed and analyzed with Origin software. Isotherms were fit using a one-site ITC binding model. The first data point was excluded from analysis. Each ITC experiment was performed with one technical replicate. Error bars were determined from fitting to a one-site binding model. 
Fluorescence Polarization. FP was performed using a modified TAX9 peptide labeled with fluorescent TAMRA dye (K ${ }^{\text {TAMRA }}$ LFGYPVYV, herein called TAMRA-TAX9) (Biopeptik Inc, Malvern, USA). Peptide-deficient HLA-A*02:01/h $\beta_{2} \mathrm{~m} / \mathrm{TAPBPR}$ complexes for FP were prepared by UV-irradiation at $365 \mathrm{~nm}$ for 1 hour of photoFluM1/HLA-A*02:01/h $\beta_{2} \mathrm{~m} / \mathrm{TAPBPR}$ complexes followed by purification, as described in the section "Preparation of empty MHC-I/TAPBPR complexes". FP experiments to probe the $\mathrm{K}_{\mathrm{D} 2}$ step of the peptide exchange cycle (defined as $\mathrm{IC}_{50}$ 2 in the FP competition experiments) were performed under substoichiometric conditions in the absence of excess TAPBPR to allow for dissociation of HLA-A*02:01/h $\beta_{2} \mathrm{~m}$ from TAPBPR in the presence of incoming peptide. Graded concentrations $(0 \mathrm{nM}, 2.5 \mathrm{nM}, 5 \mathrm{nM}, 10 \mathrm{nM}, 25 \mathrm{nM}, 50$ nM, $100 \mathrm{nM}, 500 \mathrm{nM}, 1000 \mathrm{nM}, 2000 \mathrm{nM}, 3000 \mathrm{nM}, 4000 \mathrm{nM}$ and $5000 \mathrm{nM}$ ) of TAX8, TAX9, TAX10, TAX11, TAX12, or KLL15 were added to a mixture of $1 \mathrm{nM}$ TAMRA-TAX9 and either $50 \mathrm{nM}$ of peptide-deficient HLA-A*02:01/h $\beta_{2} \mathrm{~m} / \mathrm{TAPBPR}^{\mathrm{WT}}$, peptide-deficient HLA$\mathrm{A}^{*} 02: 01 / \mathrm{h} \beta_{2} \mathrm{~m} / \mathrm{TAPBPR}^{\triangle \mathrm{ALAS}}$, or peptide-deficient HLA-A*02:01/h $\beta_{2} \mathrm{~m} / \mathrm{TAPBPR}^{\Delta \mathrm{G} 24-\mathrm{R} 36}$. FP experiments to probe the $\mathrm{K}_{\mathrm{D} 3}$ step of the peptide exchange cycle were performed by titration of graded concentrations $(0 \mu \mathrm{M}, 0.1 \mu \mathrm{M}, 2 \mu \mathrm{M}, 4 \mu \mathrm{M}, 10 \mu \mathrm{M}, 30 \mu \mathrm{M}, 50 \mu \mathrm{M}$ and $80 \mu \mathrm{M})$ of TAPBPR $^{\mathrm{WT}}$, TAPBPR ${ }^{\triangle \mathrm{ALAS}}$ or $\mathrm{TAPBPR}^{\triangle \mathrm{G} 24-\mathrm{R} 36}$ into $1 \mathrm{nM}$ TAMRA-TAX9 and $50 \mathrm{nM}$ TAX8/HLA-A*02:01/h $\beta_{2} \mathrm{~m}$. FP experiments to probe the $\mathrm{K}_{\mathrm{D} 4}$ step of the peptide exchange cycle (defined as $\mathrm{IC}_{50} 4$ in the FP competition experiments) were performed under stoichiometric conditions in the presence of excess TAPBPR ${ }^{\mathrm{WT}}$, TAPBPR ${ }^{\triangle \mathrm{ALAS}}$ or TAPBPR ${ }^{\triangle \mathrm{G} 24-\mathrm{R} 36}$ to minimize dissociation of TAPBPR from the pMHC-I/TAPBPR complex. Graded concentrations $(0 \mathrm{nM}, 10$ $\mathrm{nM}, 50 \mathrm{nM}, 250 \mathrm{nM}, 500 \mathrm{nM}, 1000 \mathrm{nM}, 2000 \mathrm{nM}, 3000 \mathrm{nM}, 4000 \mathrm{nM}, 6000 \mathrm{nM}, 8000 \mathrm{nM}, 10,000$ $\mathrm{nM}, 50,000 \mathrm{nM}, 100,000 \mathrm{nM}$ ) of TAX8, TAX9, TAX10, TAX11, TAX12, or KLL15 were added to a mixture of $1 \mathrm{nM}$ TAMRA-TAX9 and either $50 \mathrm{nM}$ of peptide-deficient HLAA*02:01/h $\beta_{2}$ m/TAPBPR ${ }^{\mathrm{WT}}$, peptide-deficient HLA-A*02:01/h $\beta_{2} \mathrm{~m} / \mathrm{TAPBPR}{ }^{\triangle A L A S}$, or peptidedeficient HLA-A*02:01/h $\beta_{2}$ m/TAPBPR ${ }^{\Delta \mathrm{G} 24-\mathrm{R} 36}$ together with $1 \mu \mathrm{M}$ of their respective free $\mathrm{TAPBPR}^{\mathrm{WT}}$, TAPBPR ${ }^{\triangle \mathrm{ALAS}}$ or TAPBPR ${ }^{\triangle \mathrm{G} 24-\mathrm{R} 36}$. Each experiment was performed in a volume of $140 \mu \mathrm{L}$ and loaded onto a black 96-well polystyrene assay plate (Costar 3915). FA data was recorded via a Perkin-Elmer Envision 2103 plate reader with excitation filter $\lambda_{\mathrm{ex}}=531 \mathrm{~nm}$ and emission filter $\lambda_{\mathrm{em}}=595 \mathrm{~nm}$ with measurement height 4.3 , excitation light 100 , G-factor 1.36 and a total of 100 flashes. In each of the above experiments, the average of FP of after incubation for 95-105 minutes $25^{\circ} \mathrm{C}$ was plotted as a function of the $\log _{10}$ of excess peptide. Each experiment was performed in triplicate and is representative of at least two independent experiments. Experimental values were subtracted from background FA values obtained from incubation of TAMRA-TAX9 alone. All samples were prepared in matched buffer $(50 \mathrm{mM} \mathrm{NaCl}, 20 \mathrm{mM}$ sodium phosphate $\mathrm{pH} 7.2,0.05 \%$ (v/v) tween-20). Data were fit using GraphPad Prism v7.

881 Plasmids are deposited with Addgene (ID numbers 141308-9 and 153471-8). All Illumina sequencing data is deposited with GEO under series accession numbers GSE147137, GSE126206, GSE159247 and GSE118568. NMR assignments have been deposited into the Biological Magnetic Resonance Data Bank (http://www.bmrb.wisc.edu) under accession numbers 28107 and 28108.

\section{CONFLICT OF INTEREST STATEMENT}

890

E.P. is a cofounder of Orthogonal Biologics, Inc; the company had no role in this study. N.G.S. is a cofounder of MultiplexThera, Inc., and a named inventor on licensed patents concerning the preparation of peptide-receptive MHC-I molecules; the company had no role in this study. 
AUTHOR CONTRIBUTIONS

A.C.M., C.A.D., E.P., and N.G.S. designed research. A.C.M., C.A.D., N.A., and E.P. performed research. G.I.M., S.A.O., D.M. and N.A. contributed new reagents/analytic tools. A.C.M., C.A.D., E.P., and N.G.S. wrote the manuscript.

\section{ACKNOWLEDGEMENTS}

We are grateful to Kannan Natarajan and David Margulies (NIH) for helpful comments and for providing the insect cell lines and DNA constructs for TAPBPR ${ }^{\mathrm{WT}}$ and TAPBPR ${ }^{\triangle \mathrm{G} 24-\mathrm{R} 36}$ protein expression. We thank Arne Schön (Johns Hopkins) for helpful comments on ITC experiments. E.P. was supported through NIAID (5R01AI129719). N.G.S. was supported through NIAID (5R01AI143997) NIGMS (5R35GM125034) and High-End Instrumentation (HIE) Grant S10OD018455, which funded the $800 \mathrm{MHz}$ NMR spectrometer at UCSC. We acknowledge the use of the Fox Chase Cancer Center NMR facility. Flow cytometry and Illumina sequencing were supported by the UIUC Roy J. Carver Biotechnology Center.

\section{REFERENCES}

Assarsson, E., Sidney, J., Oseroff, C., Pasquetto, V., Bui, H.-H., Frahm, N., Brander, C., Peters, B., Grey, H., and Sette, A. (2007). A quantitative analysis of the variables affecting the repertoire of T cell specificities recognized after vaccinia virus infection. J. Immunol. Baltim. Md 1950

$911 \quad 178,7890-7901$.

912

913

914

915

916

917

918

919

920

921

922

923

924

925

926

927

928

929

Blees, A., Reichel, K., Trowitzsch, S., Fisette, O., Bock, C., Abele, R., Hummer, G., Schäfer, L.V., and Tampé, R. (2015). Assembly of the MHC I peptide-loading complex determined by a conserved ionic lock-switch. Sci. Rep. 5, 17341.

Blees, A., Januliene, D., Hofmann, T., Koller, N., Schmidt, C., Trowitzsch, S., Moeller, A., and Tampé, R. (2017). Structure of the human MHC-I peptide-loading complex. Nature 551, 525.

Blum, J.S., Wearsch, P.A., and Cresswell, P. (2013). Pathways of antigen processing. Annu. Rev. Immunol. 31, 443-473.

Cabrera, C.M., López-Nevot, M.-A., Jiménez, P., and Garrido, F. (2005). Involvement of the chaperone tapasin in HLA-B44 allelic losses in colorectal tumors. Int. J. Cancer 113, 611-618.

Craig, D.B., and Dombkowski, A.A. (2013). Disulfide by Design 2.0: a web-based tool for disulfide engineering in proteins. BMC Bioinformatics 14, 346.

Delaglio, F., Grzesiek, S., Vuister, G.W., Zhu, G., Pfeifer, J., and Bax, A. (1995). NMRPipe: a multidimensional spectral processing system based on UNIX pipes. J. Biomol. NMR 6, 277-293.

Fisette, O., Schröder, G.F., and Schäfer, L.V. (2020). Atomistic structure and dynamics of the human MHC-I peptide-loading complex. Proc. Natl. Acad. Sci. U. S. A. 117, 20597-20606.

Fleischmann, G., Fisette, O., Thomas, C., Wieneke, R., Tumulka, F., Schneeweiss, C., Springer, S., Schäfer, L.V., and Tampé, R. (2015). Mechanistic Basis for Epitope Proofreading in the Peptide-Loading Complex. J. Immunol. Baltim. Md 1950 195, 4503-4513. 
930 Fleishman, S.J., Whitehead, T.A., Ekiert, D.C., Dreyfus, C., Corn, J.E., Strauch, E.-M., Wilson, 931 I.A., and Baker, D. (2011). Computational design of proteins targeting the conserved stem region 932 of influenza hemagglutinin. Science 332, 816-821.

933 Fowler, D.M., Araya, C.L., Gerard, W., and Fields, S. (2011). Enrich: software for analysis of 934 protein function by enrichment and depletion of variants. Bioinforma. Oxf. Engl. 27, 3430-3431.

935 Garboczi, D.N., Hung, D.T., and Wiley, D.C. (1992). HLA-A2-peptide complexes: refolding and 936 crystallization of molecules expressed in Escherichia coli and complexed with single antigenic peptides. Proc. Natl. Acad. Sci. 89, 3429-3433.

938

939

940

941

942

943

944

945

946

947

948

949

950

951

952

953

954

955

956

957

958

959

960

961

962

963

964

965

Gonzalez-Galarza, F.F., Christmas, S., Middleton, D., and Jones, A.R. (2011). Allele frequency net: a database and online repository for immune gene frequencies in worldwide populations. Nucleic Acids Res. 39, D913-919.

Güell, M., Yang, L., and Church, G.M. (2014). Genome editing assessment using CRISPR Genome Analyzer (CRISPR-GA). Bioinforma. Oxf. Engl. 30, 2968-2970.

Hafstrand, I., Sayitoglu, E.C., Apavaloaei, A., Josey, B.J., Sun, R., Han, X., Pellegrino, S., Ozkazanc, D., Potens, R., Janssen, L., et al. (2019). Successive crystal structure snapshots suggest the basis for MHC class I peptide loading and editing by tapasin. Proc. Natl. Acad. Sci. U. S. A. 116, 5055-5060.

Harndahl, M., Rasmussen, M., Roder, G., Dalgaard Pedersen, I., Sørensen, M., Nielsen, M., and Buus, S. (2012). Peptide-MHC class I stability is a better predictor than peptide affinity of CTL immunogenicity. Eur. J. Immunol. 42, 1405-1416.

Hassan, C., Chabrol, E., Jahn, L., Kester, M.G.D., de Ru, A.H., Drijfhout, J.W., Rossjohn, J., Falkenburg, J.H.F., Heemskerk, M.H.M., Gras, S., et al. (2015). Naturally processed noncanonical HLA-A*02:01 presented peptides. J. Biol. Chem. 290, 2593-2603.

van Hateren, A., Bailey, A., and Elliott, T. (2017). Recent advances in Major Histocompatibility Complex (MHC) class I antigen presentation: Plastic MHC molecules and TAPBPR-mediated quality control. F1000Research $6,158$.

Hermann, C., Trowsdale, J., and Boyle, L.H. (2015a). TAPBPR: a new player in the MHC class I presentation pathway. Tissue Antigens 85, 155-166.

Hermann, C., van Hateren, A., Trautwein, N., Neerincx, A., Duriez, P.J., Stevanović, S., Trowsdale, J., Deane, J.E., Elliott, T., and Boyle, L.H. (2015b). TAPBPR alters MHC class I peptide presentation by functioning as a peptide exchange catalyst. ELife 4.

Ilca, F.T., Neerincx, A., Hermann, C., Marcu, A., Stevanović, S., Deane, J.E., and Boyle, L.H. (2018). TAPBPR mediates peptide dissociation from MHC class I using a leucine lever. ELife 7.

Ilca, F.T., Drexhage, L.Z., Brewin, G., Peacock, S., and Boyle, L.H. (2019). Distinct Polymorphisms in HLA Class I Molecules Govern Their Susceptibility to Peptide Editing by TAPBPR. Cell Rep. 29, 1621-1632.e3. 
966

967

968

969

970

971

972

973

974

975

976

977

978

979

980

981

982

983

984

985

986

987

988

989

990

991

992

993

994

995

996

997

998

999

1000

1001

Jiang, J., Natarajan, K., Boyd, L.F., Morozov, G.I., Mage, M.G., and Margulies, D.H. (2017). Crystal structure of a TAPBPR-MHC I complex reveals the mechanism of peptide editing in antigen presentation. Science 358, 1064-1068.

Karanicolas, J., Corn, J.E., Chen, I., Joachimiak, L.A., Dym, O., Peck, S.H., Albeck, S., Unger, T., Hu, W., Liu, G., et al. (2011). A de novo protein binding pair by computational design and directed evolution. Mol. Cell 42, 250-260.

Khan, A.R., Baker, B.M., Ghosh, P., Biddison, W.E., and Wiley, D.C. (2000). The structure and stability of an HLA-A*0201/octameric tax peptide complex with an empty conserved peptide-Nterminal binding site. J. Immunol. Baltim. Md 1950 164, 6398-6405.

Leaver-Fay, A., Tyka, M., Lewis, S.M., Lange, O.F., Thompson, J., Jacak, R., Kaufman, K.W., Renfrew, P.D., Smith, C.A., Sheffler, W., et al. (2011). ROSETTA3: an object-oriented software suite for the simulation and design of macromolecules. Methods Enzymol. 487, 545-574.

Lee, W., Tonelli, M., and Markley, J.L. (2015). NMRFAM-SPARKY: enhanced software for biomolecular NMR spectroscopy. Bioinforma. Oxf. Engl. 31, 1325-1327.

Mali, P., Yang, L., Esvelt, K.M., Aach, J., Guell, M., DiCarlo, J.E., Norville, J.E., and Church, G.M. (2013). RNA-guided human genome engineering via Cas9. Science 339, 823-826.

Mandell, D.J., Coutsias, E.A., and Kortemme, T. (2009). Sub-angstrom accuracy in protein loop reconstruction by robotics-inspired conformational sampling. Nat. Methods 6, 551-552.

McShan, A.C., Natarajan, K., Kumirov, V.K., Flores-Solis, D., Jiang, J., Badstübner, M., Toor, J.S., Bagshaw, C.R., Kovrigin, E.L., Margulies, D.H., et al. (2018). Peptide exchange on MHC-I by TAPBPR is driven by a negative allostery release cycle. Nat. Chem. Biol. 14, 811-820.

McShan, A.C., Devlin, C.A., Overall, S.A., Park, J., Toor, J.S., Moschidi, D., Flores-Solis, D., Choi, H., Tripathi, S., Procko, E., et al. (2019). Molecular determinants of chaperone interactions on MHC-I for folding and antigen repertoire selection. Proc. Natl. Acad. Sci. U. S. A. 116, 25602-25613.

Montserrat, V., Galocha, B., Marcilla, M., Vázquez, M., and López de Castro, J.A. (2006). HLAB*2704, an allotype associated with ankylosing spondylitis, is critically dependent on transporter associated with antigen processing and relatively independent of tapasin and immunoproteasome for maturation, surface expression, and T cell recognition: relationship to B*2705 and B*2706. J. Immunol. Baltim. Md 1950 177, 7015-7023.

Morozov, G.I., Zhao, H., Mage, M.G., Boyd, L.F., Jiang, J., Dolan, M.A., Venna, R., Norcross, M.A., McMurtrey, C.P., Hildebrand, W., et al. (2016). Interaction of TAPBPR, a tapasin homolog, with MHC-I molecules promotes peptide editing. Proc. Natl. Acad. Sci. U. S. A. 113, E1006-1015.

Motyka, B., and Teh, H.S. (1998). Naturally occurring low affinity peptide/MHC class I ligands can mediate negative selection and T cell activation. J. Immunol. Baltim. Md 1950 160, 77-86. 
1002 Neerincx, A., and Boyle, L.H. (2017). Properties of the tapasin homologue TAPBPR. Curr.

1003 Opin. Immunol. 46, 97-102.

1004 Neerincx, A., and Boyle, L.H. (2019). Preferential interaction of MHC class I with TAPBPR in 1005 the absence of glycosylation. Mol. Immunol. 113, 58-66.

1006 Neerincx, A., Hermann, C., Antrobus, R., van Hateren, A., Cao, H., Trautwein, N., Stevanović, 1007 S., Elliott, T., Deane, J.E., and Boyle, L.H. (2017). TAPBPR bridges UDP-glucose:glycoprotein 1008 glucosyltransferase 1 onto MHC class I to provide quality control in the antigen presentation 1009 pathway. ELife 6.

1010 Park, B., Kim, Y., Shin, J., Lee, S., Cho, K., Früh, K., Lee, S., and Ahn, K. (2004). Human 1011 cytomegalovirus inhibits tapasin-dependent peptide loading and optimization of the MHC class I 1012 peptide cargo for immune evasion. Immunity 20, 71-85.

1013 Park, J., Selvam, B., Sanematsu, K., Shigemura, N., Shukla, D., and Procko, E. (2019). Structural 1014 architecture of a dimeric class C GPCR based on co-trafficking of sweet taste receptor subunits.

1015 J. Biol. Chem. 294, 4759-4774.

1016 Procko, E., Hedman, R., Hamilton, K., Seetharaman, J., Fleishman, S.J., Su, M., Aramini, J., 1017 Kornhaber, G., Hunt, J.F., Tong, L., et al. (2013). Computational design of a protein-based 1018 enzyme inhibitor. J. Mol. Biol. 425, 3563-3575.

1019 Rodenko, B., Toebes, M., Hadrup, S.R., van Esch, W.J.E., Molenaar, A.M., Schumacher, 1020 T.N.M., and Ovaa, H. (2006). Generation of peptide-MHC class I complexes through UV1021 mediated ligand exchange. Nat. Protoc. 1, 1120-1132.

1022 Rossi, P., Xia, Y., Khanra, N., Veglia, G., and Kalodimos, C.G. (2016). 15N and 13C- SOFAST1023 1024 HMQC editing enhances 3D-NOESY sensitivity in highly deuterated, selectively [1H,13C]labeled proteins. J. Biomol. NMR 66, 259-271.

1025 Rossjohn, J., Gras, S., Miles, J.J., Turner, S.J., Godfrey, D.I., and McCluskey, J. (2015). T cell 1026 1027 antigen receptor recognition of antigen-presenting molecules. Annu. Rev. Immunol. 33, 169200.

1028 Sagert, L., Hennig, F., Thomas, C., and Tampé, R. (2020). A loop structure allows TAPBPR to 1029

1030 Shionoya, Y., Kanaseki, T., Miyamoto, S., Tokita, S., Hongo, A., Kikuchi, Y., Kochin, V., 1031 Watanabe, K., Horibe, R., Saijo, H., et al. (2017). Loss of tapasin in human lung and colon 1032 cancer cells and escape from tumor-associated antigen-specific CTL recognition. 1033 Oncoimmunology 6, e1274476.

1034 Song, Y., DiMaio, F., Wang, R.Y.-R., Kim, D., Miles, C., Brunette, T., Thompson, J., and Baker, 1035 D. (2013). High-Resolution Comparative Modeling with RosettaCM. Structure 21, 1735-1742.

1036 Thomas, C., and Tampé, R. (2017). Structure of the TAPBPR-MHC I complex defines the 1037 mechanism of peptide loading and editing. Science 358, 1060-1064. 
1038 Trolle, T., McMurtrey, C.P., Sidney, J., Bardet, W., Osborn, S.C., Kaever, T., Sette, A., 1039 Hildebrand, W.H., Nielsen, M., and Peters, B. (2016). The length distribution of class I restricted 1040 T cell epitopes is determined by both peptide supply and MHC allele specific binding preference. 1041 J. Immunol. Baltim. Md 1950 196, 1480-1487.

1042 Tynan, F.E., Borg, N.A., Miles, J.J., Beddoe, T., El-Hassen, D., Silins, S.L., van Zuylen, W.J.M., 1043 Purcell, A.W., Kjer-Nielsen, L., McCluskey, J., et al. (2005). High resolution structures of highly 1044 bulged viral epitopes bound to major histocompatibility complex class I. Implications for T-cell 1045 receptor engagement and T-cell immunodominance. J. Biol. Chem. 280, 23900-23909.

1046 Wang, C., Bradley, P., and Baker, D. (2007). Protein-protein docking with backbone flexibility. 1047 J. Mol. Biol. 373, 503-519.

1048 Zhang, W., Wearsch, P.A., Zhu, Y., Leonhardt, R.M., and Cresswell, P. (2011). A role for UDP1049 glucose glycoprotein glucosyltransferase in expression and quality control of MHC class I 1050 molecules. Proc. Natl. Acad. Sci. U. S. A. 108, 4956-4961.

1051 Zheng, H., Jin, B., Henrickson, S.E., Perelson, A.S., von Andrian, U.H., and Chakraborty, A.K. 1052 (2008). How Antigen Quantity and Quality Determine T-Cell Decisions in Lymphoid Tissue. 1053 Mol. Cell. Biol. 28, 4040-4051. 


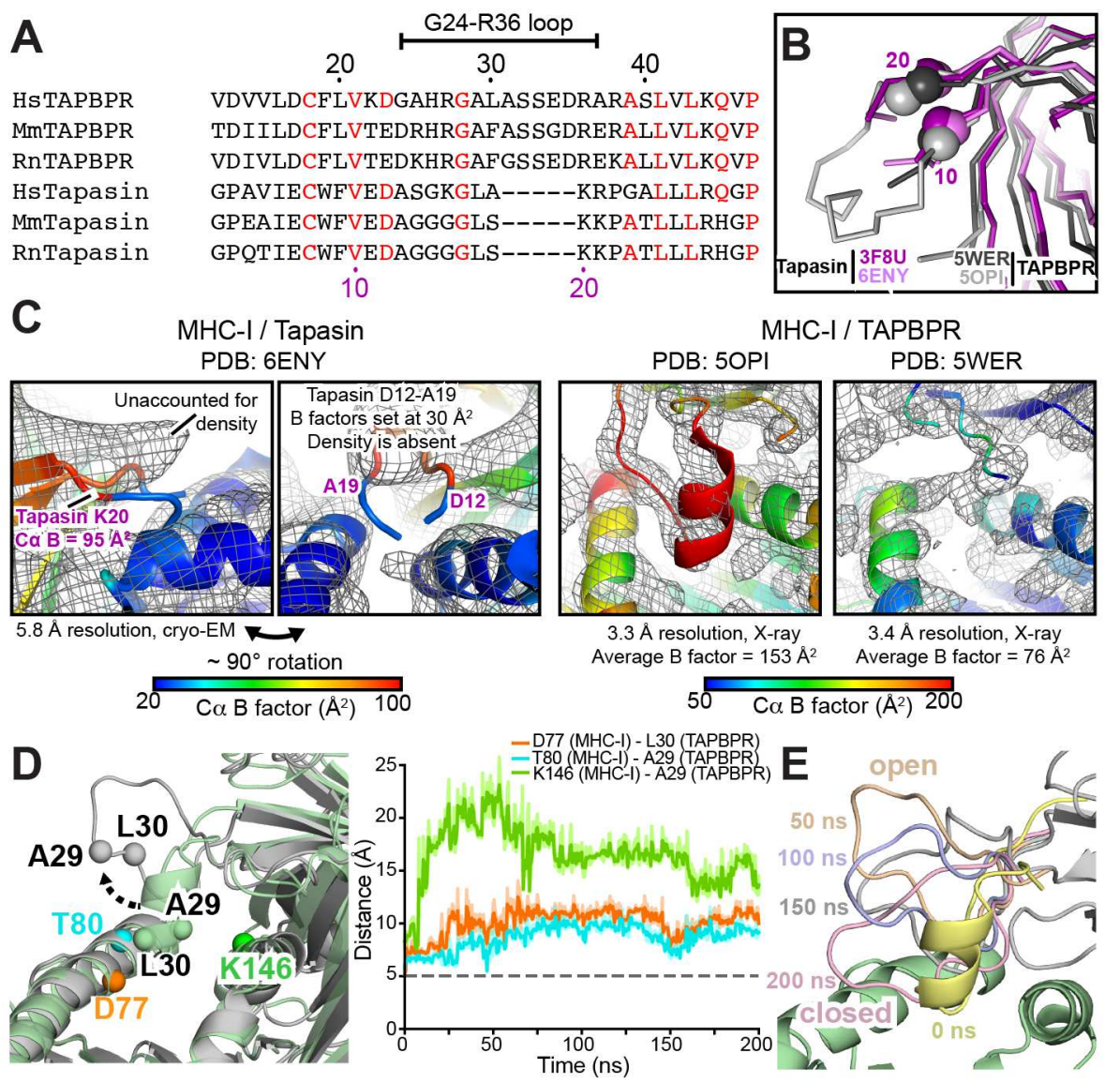

Figure 1. Conformational plasticity of the TAPBPR G24-R36 loop. (A) Sequence alignment between TAPBPR and tapasin from Homo sapiens (Hs, human), Mus musculus (Mm, mouse) and Rattus norvegicus (Rn, rat) highlighting differences in the TAPBPR G24-R36 loop region. Black and purple numbering reference TAPBPR and tapasin, respectively. Red residues are conserved. (B) Overlay of X-ray structures of tapasin (PDB IDs 3F8U and 6ENY) and TAPBPR (PDB IDs 5WER and 5OPI). (C) (Left) Cryo-EM density map (gray mesh, $5.0 \sigma$ ) plotted on the cartoon of MHC-I in complex with tapasin (PDB ID 6ENY). (Right) $2 \mathrm{~F}_{\mathrm{o}}-\mathrm{F}_{\mathrm{c}}$ electron density maps (gray mesh, $1.0 \sigma$ ) plotted on the cartoon of MHC-I in complex with TAPBPR (PDB ID 5OPI and 5 WER). The cartoons are colored by $\mathrm{C} \alpha \mathrm{B}$ factors. (D) (Left) Before (green) and during (gray) snapshots of peptide-deficient HLA-A*02:01/ $\mathrm{h} \beta_{2} \mathrm{~m} / \mathrm{TAPBPR}$ complex from all-atom MD simulations. The $\mathrm{C} \alpha$ atoms used for distance measurements are shown as spheres. (Right) Intermolecular $\mathrm{C} \alpha-\mathrm{C} \alpha$ distances measured between HLA-A*02:01 groove (D77, T80, K146) and TAPBPR G24-R36 loop (A29, L30) residues over the course of the simulation. The dotted line represents $\mathrm{C} \alpha-\mathrm{C} \alpha$ distances at the start of the simulation. (E) The range of conformations of the TAPBPR G24-R36 loop captured at different times during the MD simulation. The open (wheat, $50 \mathrm{~ns}$ ) and closed (pink, $200 \mathrm{~ns}$ ) states of the TAPBPR G24-R36 loop are oriented away from and covering the HLA-A*02:01 groove, respectively. The MHC-I groove (green) and TAPBPR N domain (gray) are shown as a static snapshot from the $0 \mathrm{~ns}$ MD time point for clarity. 
A

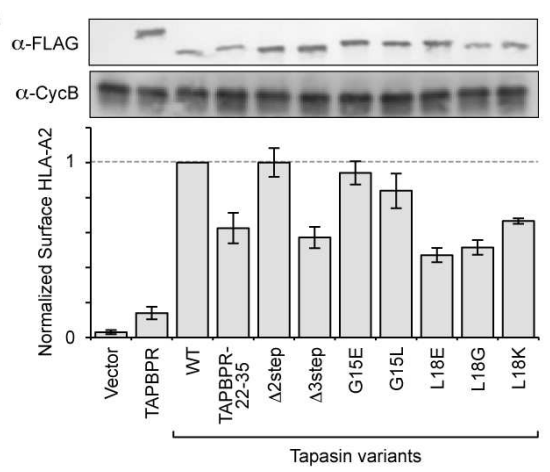

B

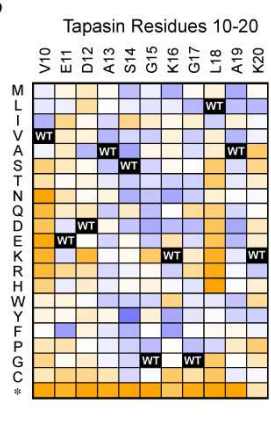

D

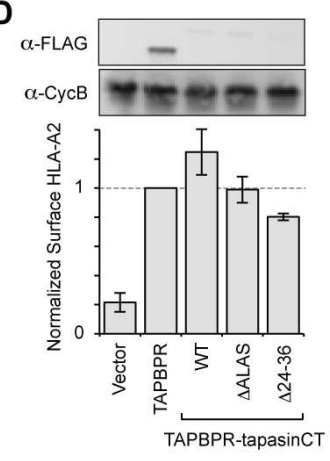

E

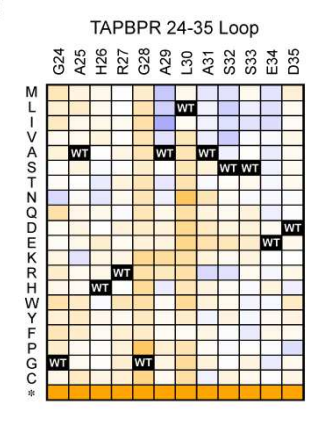

C

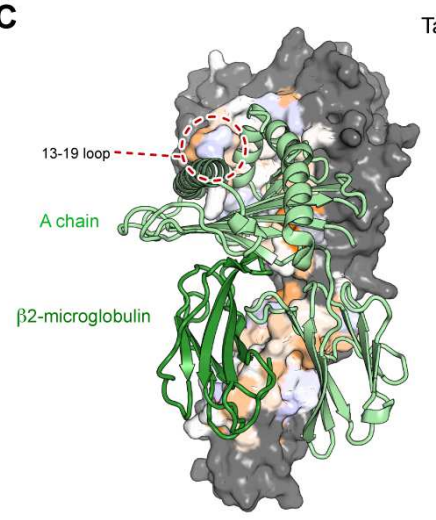

G

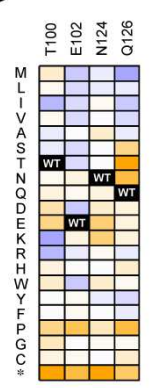

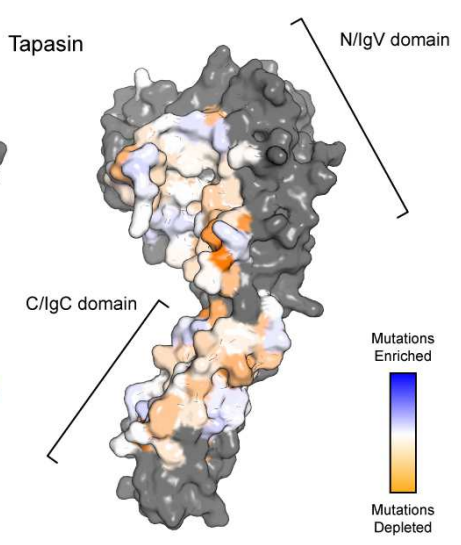

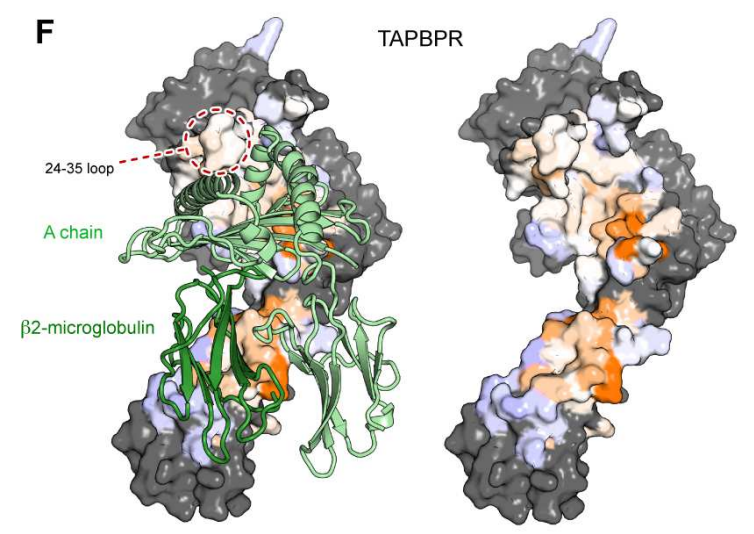

1077 -3 (depleted)

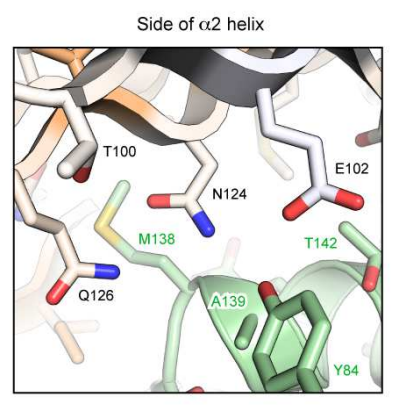

$\log _{2}$ Enrichment Ratio
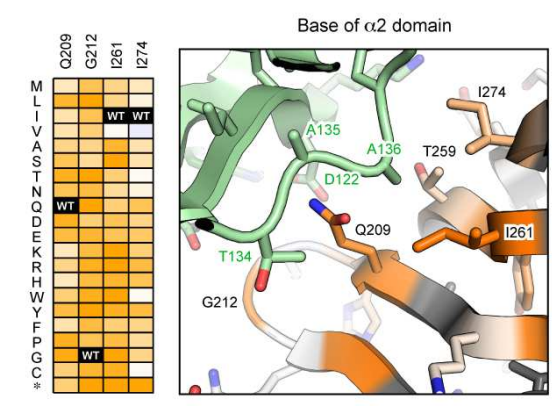

H

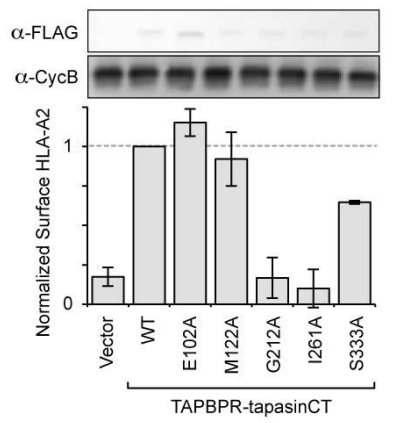

1079

1080

1081

1082

1083

1084

1085

1086

1087

1088

1089

1090

1091
Figure 2. Important chaperone features for functional replacement of tapasin localize to scaffolding sites for MHC-I. (A) TAPBPR and variants of tapasin were transfected in tapasinKO Expi293F cells, and relative surface HLA-A*02:01 expression as measured by flow cytometry is plotted. Data are mean $\pm \mathrm{SD}, \mathrm{n}=4$. Proteins were FLAG-tagged at their luminal N-termini and immunoblots of whole lysate are shown, with cyclophilin B (CycB) used as a loading control. (B) Tapasin was deep mutationally scanned based on selection of tapasin-KO cells with rescued surface HLA-A*02:01. $\log _{2}$ enrichment ratios for mutations across residues 10-20 are plotted from $\leq-3$ (depleted/deleterious, orange) to $\geq+3$ (enriched, dark blue). Residue position is on the horizontal axis, and amino acid substitutions are on the vertical axis (*, stop codon). (C) Conservation scores from the entire deep mutational scan of the tapasin/MHC-I interface are mapped to a homology model of HLA-A*02:01-bound tapasin. Highly conserved residues for mediating the folding and surface trafficking of HLA-A*02:01 are colored orange, while neutral regions are pale white/blue. Residues excluded from the library and analysis are grey. MHC-I H 
1092 chain and $\mathrm{h} \beta_{2} \mathrm{~m}$ are pale and dark green ribbons, respectively. (D) A chimera of the TAPBPR 1093 luminal domain with the tapasin TM and cytosolic domains, called TAPBPR-CT, has increased 1094 activity for chaperoning endogenous HLA-A*02:01, despite reduced protein expression by 1095 immunoblot (upper inset). Variants of TAPBPR were tested for rescue of surface HLA-A*02:01 1096 in the TAPBPR-CT background. Data are mean $\pm \mathrm{SD}, \mathrm{n}=4$. (E) As in $\mathrm{B}$, now plotting $\log _{2}$ 1097 enrichment ratios for mutations in TAPBPR residues 24-35 from a deep mutational scan for rescue 1098 of surface HLA-A*02:01 in TAPBPR library-transfected tapasin-KO cells. (F) As in C, now 1099 showing sequence conservation from a deep mutational scan of TAPBPR mapped to a model of 1100 TAPBPR/HLA-A*02:01. (G) Close up views of two structural regions, colored as in F. 1101 Accompanying heatmaps plot $\log _{2}$ enrichment ratios for each mutation from depleted/deleterious 1102 (orange) to neutral (white and pale colors) to enriched (dark blue). (H) Individual mutations of 1103 TAPBPR-CT were validated by targeted mutagenesis in the tapasin surrogate assay. Data are mean $1104 \pm \mathrm{SD}, \mathrm{n}=4$. 

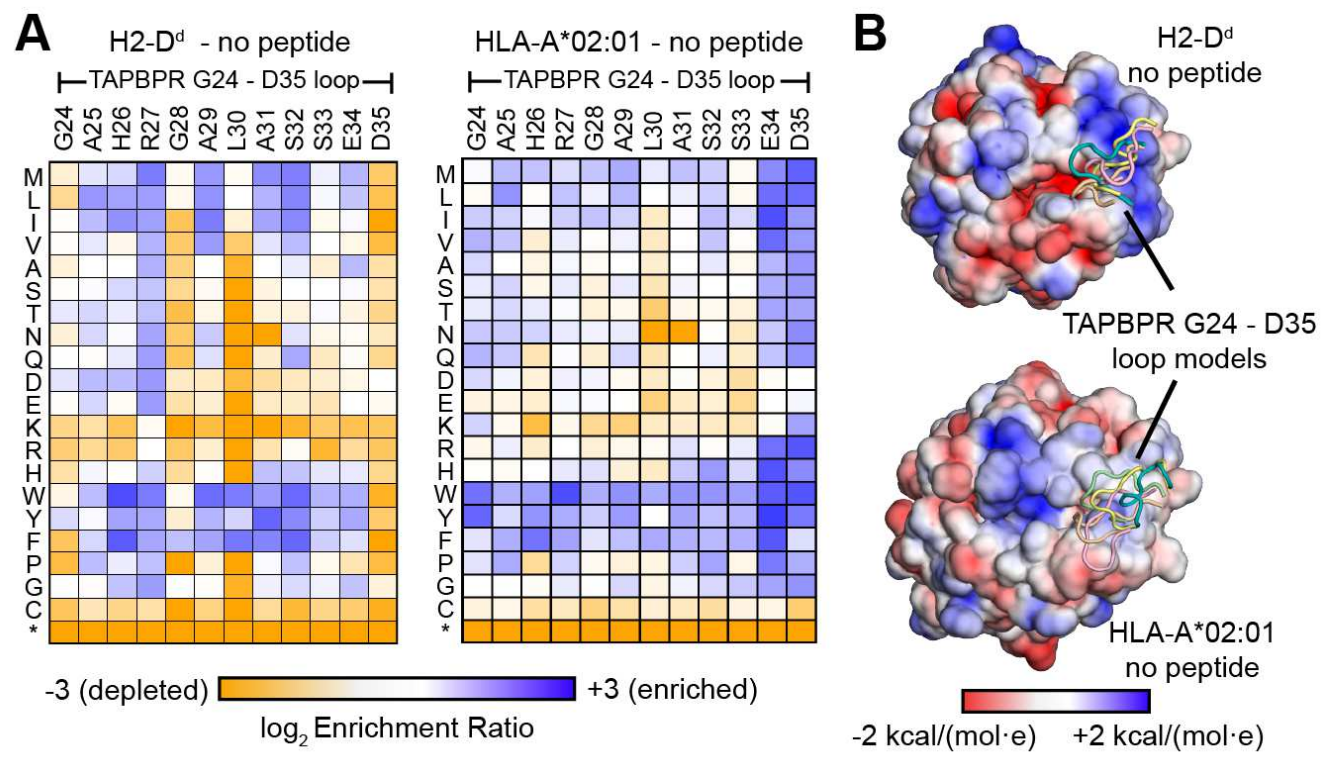

Figure 3. TAPBPR 24-35 loop sequence interaction landscape is pMHC-I allele-dependent. (A) A TAPBPR library of substitution mutants in the 24-35 loop was displayed on the yeast surface and sorted for high binding signal to fluorescent pMHC-I tetramers made using refolded P18I10/H2- $\mathrm{D}^{\mathrm{d}}$ and TAX9/HLA-A*02:01. In these experiments there was no excess of competing peptide; see Figure S3 for data from equivalent selections with competing free peptide. In the mutational landscapes, $\log _{2}$ enrichment ratios for each mutation are plotted from $\leq-3$ (depleted/deleterious, orange) to $\geq+3$ (enriched, dark blue). TAPBPR 24-35 loop residue position is on the horizontal axis, and amino acid substitutions are on the vertical axis (*, stop codon). (B) Solvent-accessible surfaces of MHC-I molecules colored by electrostatic potential (negative in red, to positive in blue) as calculated in CHARMM-GUI PBEQ-Solver for H2- $\mathrm{D}^{\mathrm{d}}$ (PDB 3ECB) and HLA-A*02:01 (PDB 1DUZ). The five lowest energy RosettaCM models of the TAPBPR 2435 loop are shown as references. 

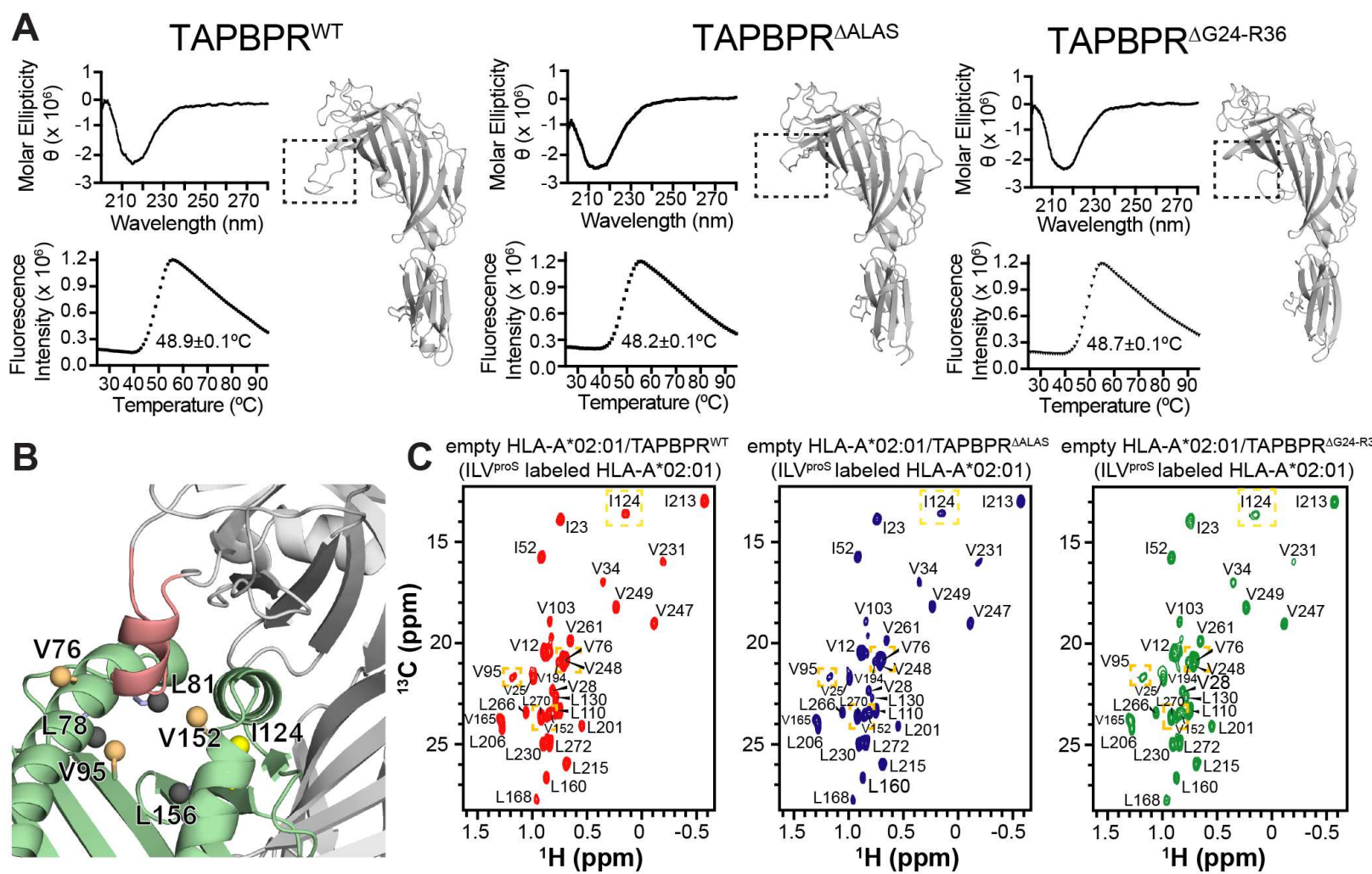

1121

1122

1123

1124

1125

1126

1127

1128

1129

1130

1131

1132

1133

1134

1135

1136

1137

Figure 4. The TAPBPR G24-R36 loop does not enter the HLA-A*02:01 groove.

(A) Comparison between wild-type (WT) and mutant TAPBPR constructs used in this study. $\triangle \mathrm{ALAS}=$ deletion of residues A29-S32 and $\Delta \mathrm{G} 24-\mathrm{R} 36=$ deletion of residues G24-R36. (Top) Far-UV CD and (Bottom) DSF spectra of each TAPBPR construct. The average from three technical replicates is shown. An inset in the DSF spectra notes measured thermal melt $\left(T_{m}\right)$ values. The corresponding RosettaCM model of each TAPBPR construct is shown. The dotted box highlights differences in the G24-R36 loop region. (B) View of the peptide-deficient HLA$\mathrm{A}^{*}$ 02:01/TAPBPR model (template PDB ID 5OPI) showing ILV ${ }^{\text {proS }}$ methyl probes on HLA$A^{*}$ 02:01 (as spheres) within $10 \AA$ of the TAPBPR G24-R36 loop (salmon). Methyl resonances of residues L78, L81 and L156 (shown in black) are missing in $2 \mathrm{D}{ }^{1} \mathrm{H}-{ }^{13} \mathrm{C}$ methyl HMQC spectra of peptide-deficient HLA-A*02:01/TAPBPR complex due to conformational exchange induced line broadening. (C) $2 \mathrm{D}{ }^{1} \mathrm{H}_{-}{ }^{13} \mathrm{C}$ methyl HMQC spectra of $80 \mu \mathrm{M}$ peptide-deficient HLA-A*02:01 (ILV ${ }^{\text {proS }}$ labeled) $/ \mathrm{h} \beta_{2} \mathrm{~m}$ in complex with TAPBPR ${ }^{\mathrm{WT}}$ (red), TAPBPR ${ }^{\triangle A L A S}$ (blue) or TAPBPR ${ }^{\triangle \mathrm{G} 24-}$ ${ }^{\mathrm{R} 36}$ (green) recorded at $25^{\circ} \mathrm{C}$ at a ${ }^{1} \mathrm{H}$ field of $800 \mathrm{MHz}$. Dotted boxes highlight methyl probes (shown in panel B) that are modeled to be near the TAPBPR G24-R36 loop. 
A

Thermodynamic balance: $\mathrm{K}_{\mathrm{D} 1} \mathrm{~K}_{\mathrm{D} 4}=\mathrm{K}_{\mathrm{D} 2} \mathrm{~K}_{\mathrm{D} 3}$ TAPBPR

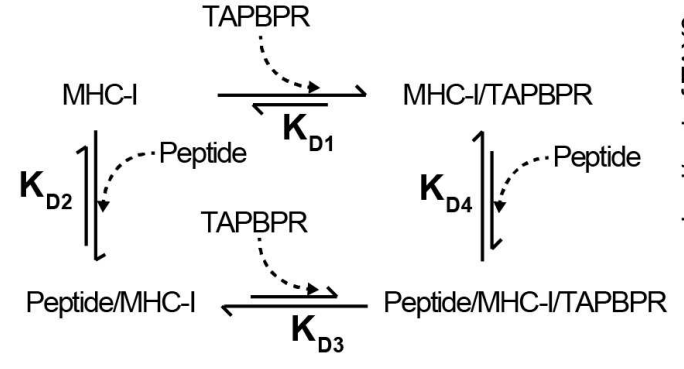

C

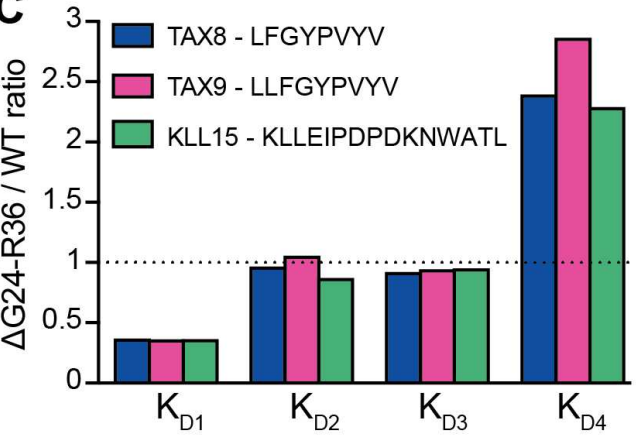

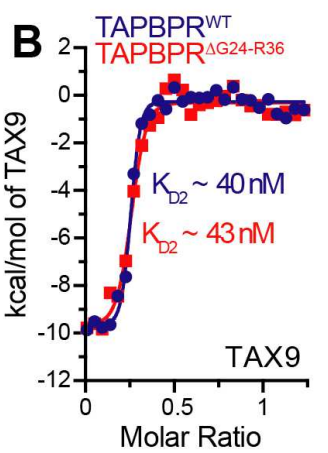
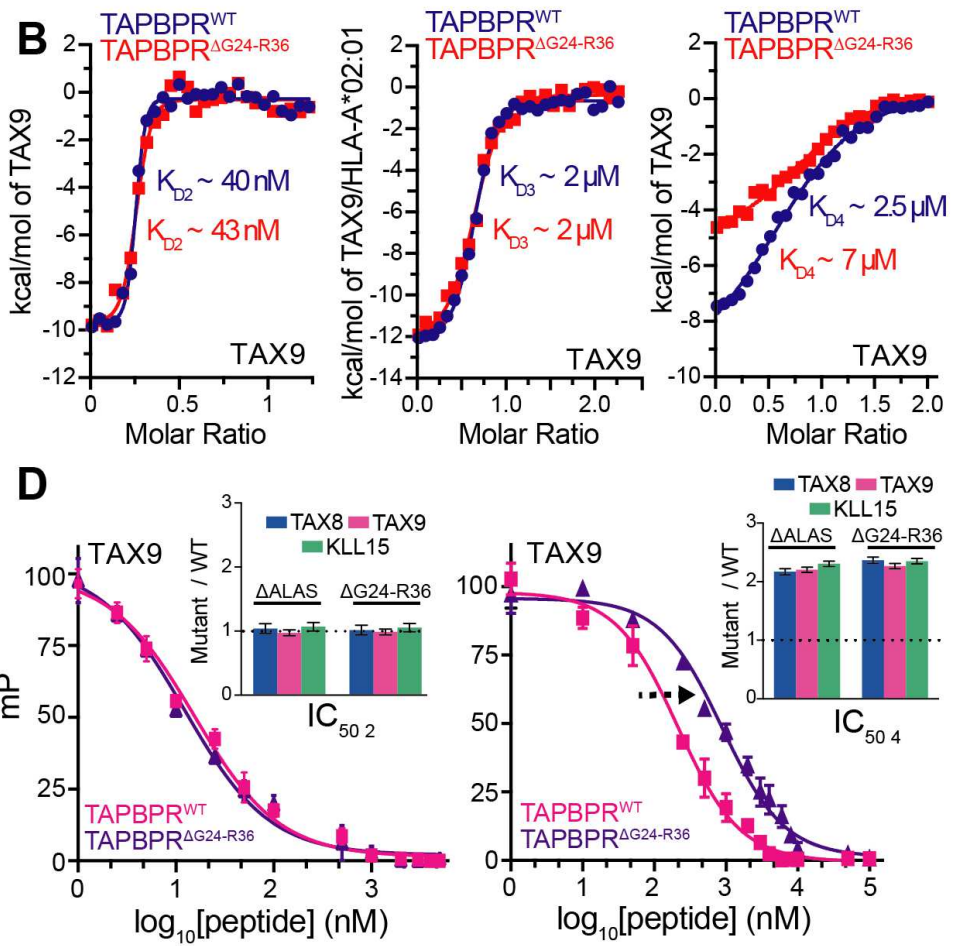

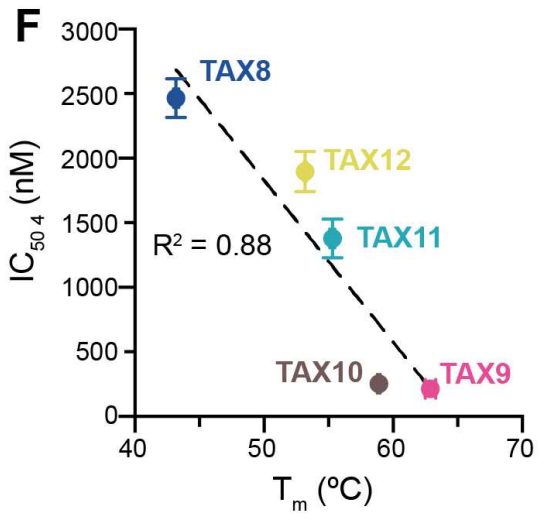

1138

1139

1140

1141

1142

1143

1144

1145

1146

1147

1148

1149

1150

1151

1152

1153

Figure 5. The TAPBPR G24-R36 loop promotes peptide binding on empty MHC-I.

(A) Schematic of the TAPBPR-mediated MHC-I peptide exchange cycle. The dissociation constant $\left(\mathrm{K}_{\mathrm{D}}\right)$ of each step is noted. (B) ITC performed at different stages of the peptide exchange cycle $\left(\mathrm{K}_{\mathrm{D} 2}, \mathrm{~K}_{\mathrm{D} 3}, \mathrm{~K}_{\mathrm{D} 4}\right)$ for TAX9/HLA-A $* 2: 01 / \mathrm{h} \beta_{2} \mathrm{~m}$ with TAPBPR ${ }^{\mathrm{WT}}$ or TAPBPR ${ }^{\Delta \mathrm{G} 24-\mathrm{R} 36}$ (Materials and Methods). $\mathrm{K}_{\mathrm{D} 1}$ was not measured directly, but inferred from thermodynamic balance along the cycle shown in (A). (C) Apparent $\mathrm{K}_{\mathrm{D}}$ ratios determined by ITC for TAPBPR ${ }^{\triangle \mathrm{G} 24-}$ R36 / TAPBPR ${ }^{\mathrm{WT}}$ for TAX8, TAX9 and KLL15 peptides. The dotted line represents no effect. (D) FP performed under substoichiometric (left) and stoichiometric (right) conditions. Millipolarization $(\mathrm{mP})$ values are plotted as a function of the $\log _{10}$ peptide concentration for TAX8, TAX9 and KLL15 competitor peptides. Error bars were obtained from three technical replicates. The insets show a comparison of the ratio of FP determined $\mathrm{IC}_{50}$ values for TAPBPR ${ }^{\Delta \mathrm{G} 24-\mathrm{R} 36}$ or $T_{\text {TAPBPR }} \triangle \mathrm{ALAS}$ versus TAPBPR ${ }^{\mathrm{WT}}$. The dotted line represents no effect. (E) X-ray structures (TAX8, TAX9) and RosettaCM models (TAX10, TAX11, TAX12) show peptide bulging within the HLA-A*02:01 groove. The open and closed conformation of the TAPBPR G24-R36 loop from MD simulations are shown in gray and black, respectively. (F) Comparison of FP determined $\mathrm{IC}_{50}$ 
1154 values under stoichiometric conditions for TAX length variants versus pMHC-I thermal stability. 1155 The $\mathrm{R}^{2}$ value of the linear regression fit (black line) is shown. (G) Comparison of FP determined $1156 \mathrm{IC}_{50}$ values under stoichiometric conditions for TAX length variants for TAPBPR ${ }^{\mathrm{WT}}$ versus $1157 \mathrm{TAPBPR}^{\triangle \mathrm{ALAS}}$ or TAPBPR $^{\triangle \mathrm{G} 24-\mathrm{R} 36}$. The dotted red line represents a conceptual 1:1 correlation (no 1158 effect).

1159 

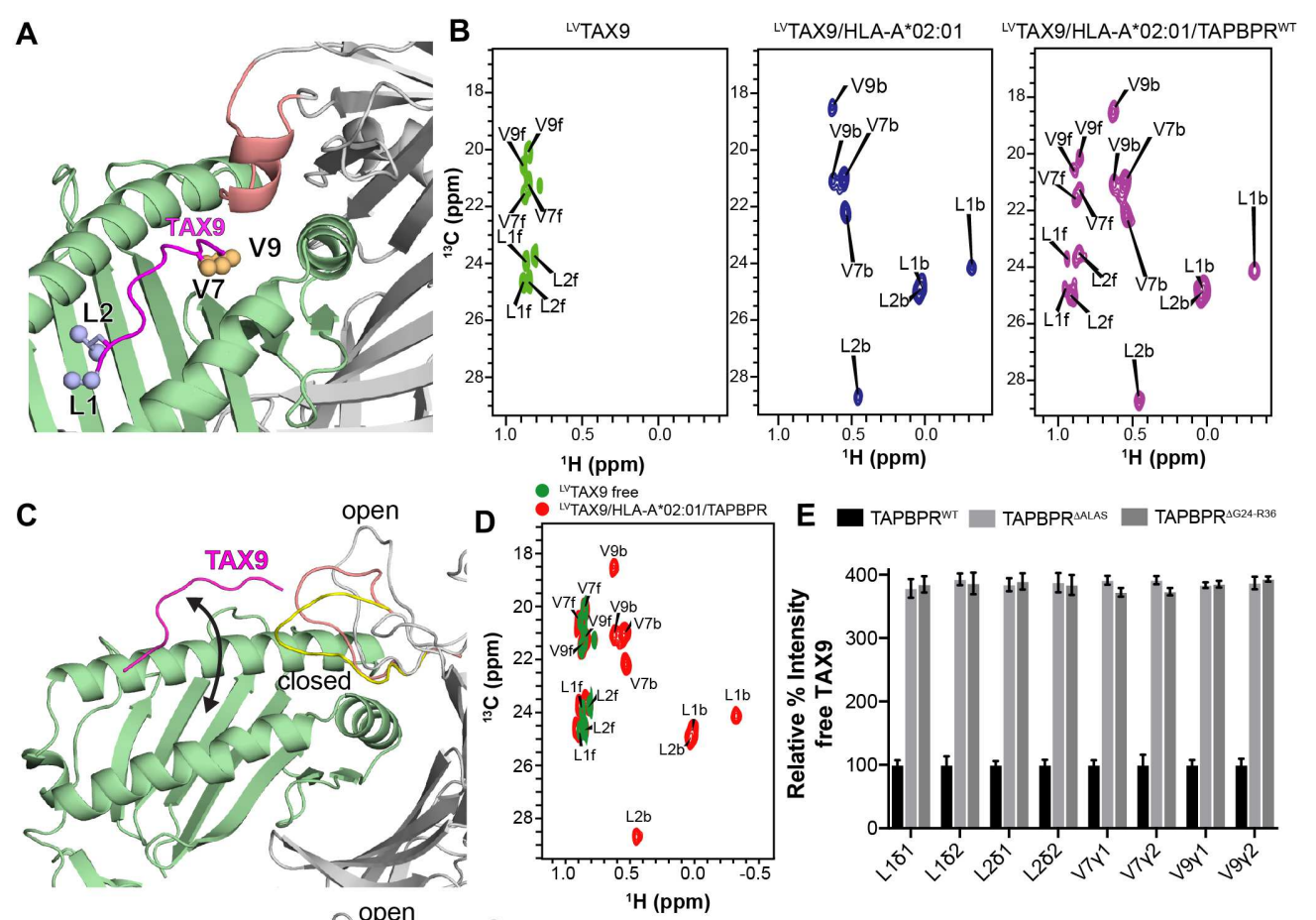

E $\square$ TAPBPR $^{W T} \square$ TAPBPR $^{\triangle A L A S} \square$ TAPBPR $^{\triangle{ }^{A 624 R 36}}$
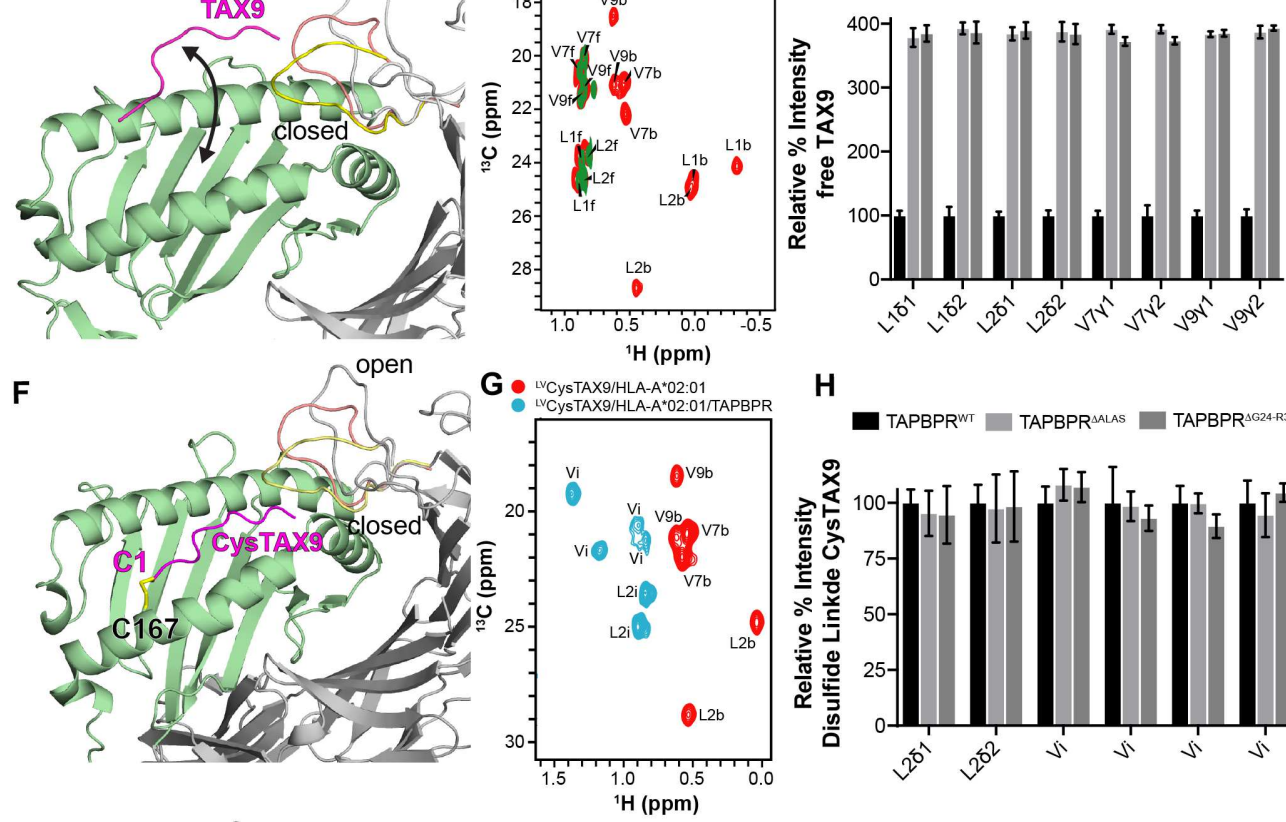

$\mathrm{H}$
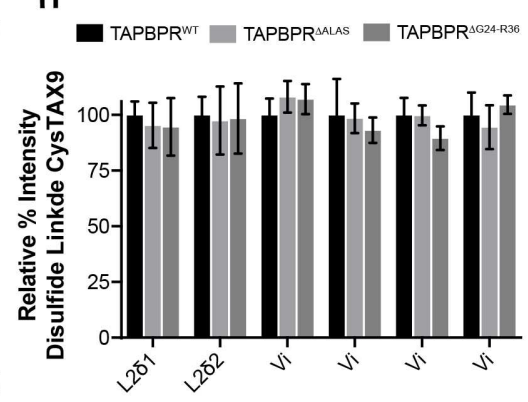

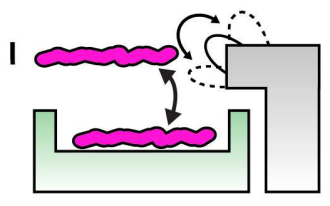

peptide binding promoted by TAPBPR G24-R36 loop

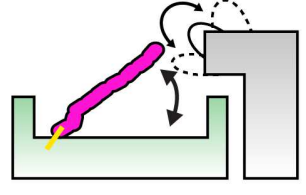

peptide binding not promoted by TAPBPR G24-R36 loop

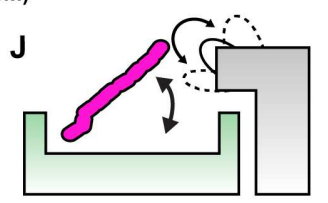

early capture of peptide binding from $\mathrm{N}$-terminus

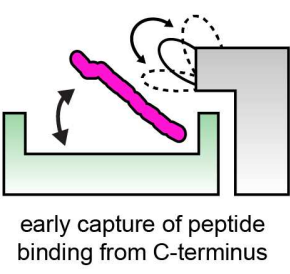

Figure 6. NMR characterization of chaperone-mediated peptide exchange on MHC-I using selective methyl ${ }^{13}$ C-labeled peptides. (A) Rosetta model of the TAX9/HLA-A*02:01/TAPBPR complex using template PDB ID 5OPI. The Leu/Val methyl groups of TAX9 are shown as spheres. HLA-A*02:01 is green, TAX9 is magenta, TAPBPR is grey, and the TAPBPR "scoop loop" is colored salmon. (B) $2 \mathrm{D}{ }^{1} \mathrm{H}^{13} \mathrm{C}$ methyl HMQC spectra of $100 \mu \mathrm{M}{ }^{15} \mathrm{~N} /{ }^{13} \mathrm{C}$ LV labeled TAX9 peptide in the free state (left, green), in complex with HLA-A*02:01/h $\beta_{2} \mathrm{~m}$ (middle, blue), and in complex with HLA-A*02:01/h $\beta_{2} \mathrm{~m}$ in the presence of saturating concentration (8-fold molar excess) TAPBPR (right, purple). All spectra were recorded at $25^{\circ} \mathrm{C}$ at a ${ }^{1} \mathrm{H}$ field of $800 \mathrm{MHz}$. Assignments of methyl resonances corresponding to the free and MHC-bound peptide states are denoted with 'f' and ' $b$ ', respectively (C) Rosetta model of the TAX9/HLA-A*02:01/TAPBPR complex using template PDB ID 5WER is shown highlighting that TAPBPR promotes release of TAX9 peptide. The open, intermediate and closed conformations of the TAPBPR G24-R36 loop 
1173 obtained from MD simulations are shown in grey, salmon and yellow. (D) Overlay of $2 \mathrm{D}^{1} \mathrm{H}^{-13} \mathrm{C}$ 1174 methyl HMQC spectra from 'A' of: ${ }^{13} \mathrm{C}-\mathrm{LV}$ labeled TAX9 in the free state (green), and in complex with HLA-A*02:01/h $\mathrm{h} \beta_{2} \mathrm{~m}$ in the presence of saturating concentration of TAPBPR (red). (E) Comparison of NMR signal intensity for each methyl resonance of TAX9 when released from the MHC-I/TAPBPR complex formed with and without the TAPBPR G24-R36 loop. (F) Rosetta model of disulfide-linked CysTAX9/HLA-A*02:01 in complex with TAPBPR designed using Disulfide by Design v2. The disulfide is formed between C1 of CysTAX9 (CLFGYPVYV) and W167C of HLA-A*02:01. The open and closed conformations of the TAPBPR G24-R36 loop obtained from MD simulations are shown in grey, salmon and yellow. (G) $2 \mathrm{D}{ }^{1} \mathrm{H}-{ }^{13} \mathrm{C}$ methyl HMQC spectra of ${ }^{13} \mathrm{C}-\mathrm{LV}$ labeled CysTAX9 in complex with HLA-A*02:01/h $\beta 2 \mathrm{~m}$ (red) and HLA-A*02:01/ $\mathrm{h} \beta 2 \mathrm{~m}$ in the presence of 8-fold molar excess TAPBPR (blue) recorded at $25^{\circ} \mathrm{C}$ at $\mathrm{a}^{1} \mathrm{H}$ field of $600 \mathrm{MHz}$. Methyl resonances of the pMHC-I bound state are denoted "b" for bound. Methyl resonances of the pMHC-I/TAPBPR state are denoted " $\mathrm{i}$ " for intermediate, corresponding to a free peptide conformation that is still tethered to the MHC groove. (H) Comparison of NMR signal intensities for each methyl resonance of CysTAX9 in the pMHC-I/TAPBPR intermediate state, formed with and without the TAPBPR G24-R36 loop. The intermediate states for the Valines were not assigned. (I) NMR-based model of how the TAPBPR G24-R36 loop influences peptide loading on pMHC-I. (J) Two putative mechanisms for how the TAPBPR G24-R36 loop promotes the early capture of peptide within the MHC-I groove with an intermediate annealing from the $\mathrm{N}$ terminus (left) or C-terminus (right). 
A

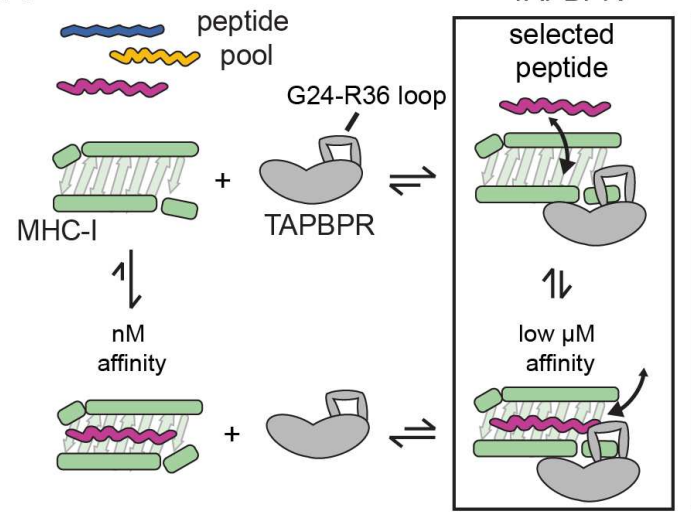

C Peptide Concentration

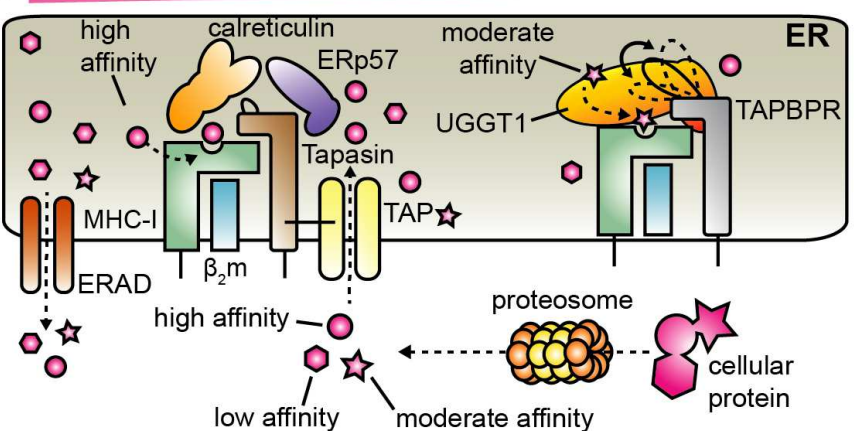

B
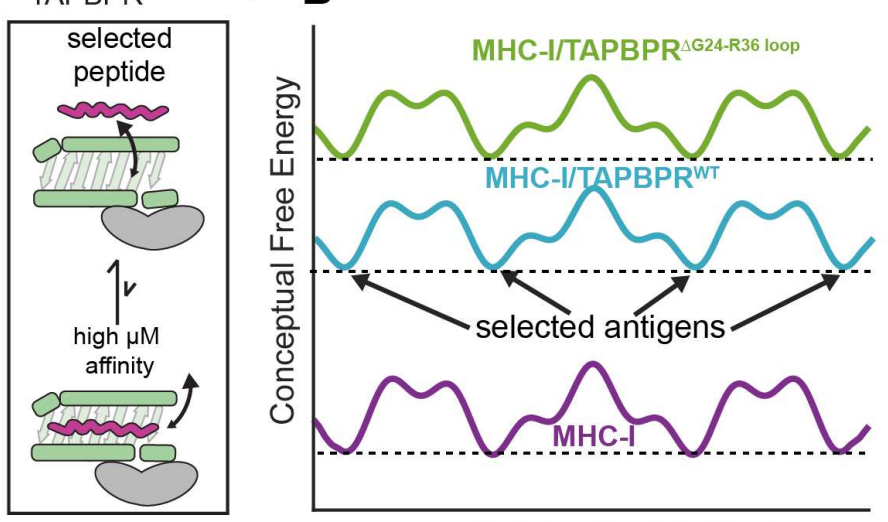

Cellular Peptide Pool

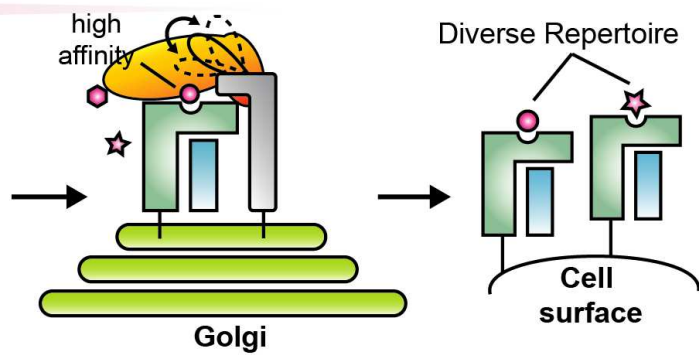

Figure 7. Proposed model of auxiliary peptide editing functions of TAPBPR. (A) Schematic of how the TAPBPR G24-R36 loop influences the peptide exchange cycle. The G24-R36 loop serves as a trap, promoting peptide binding on the MHC-I/TAPBPR complex with low $\mu \mathrm{M}$ affinity. When TAPBPR is mutated to have a shorter loop, the affinity of peptides is reduced to high $\mu \mathrm{M}$ range. (B) Conceptual example of the free energy landscape across the cellular peptide pool. The TAPBPR G24-R36 loop shapes the selected peptide repertoire by stabilizing peptide binding across the cellular pool, functioning as an auxiliary loading chaperone for peptides of low and moderate affinity. (C) In the ER, peptide selection is governed both by the effective concentration of peptides and the absence (in tapasin) or the presence of the kinetic trap (in TAPBPR). Tapasin is tethered to the TAP transporter and because it is restricted to an environment of high peptide concentration and has a shorter loop, it primarily loads high affinity peptides. In contrast, TAPBPR is not tethered to TAP and because it functions in environments of lower peptide concentration, it employs a trap to load both high and moderate affinity peptides and/or to minimize dissociation of peptides during transient TAPBPR/pMHC-I interactions. This process results in a diverse peptide repertoire being displayed by MHC-I molecules on the cell surface. 
1212 Table 1. ITC derived apparent dissociation constants for each step of the TAPBPR-mediated 1213 peptide exchange cycle

\begin{tabular}{|c|c|c|}
\hline & TAPBPR $^{\mathrm{WT}}$ & TAPBPR $^{\triangle \mathrm{G} 24-\mathrm{R} 36}$ \\
\hline \multicolumn{3}{|c|}{ Thermodynamic Balance: $K_{D 1} K_{D 4}=K_{D 2} K_{D 3}$} \\
\hline \multicolumn{3}{|c|}{$\mathbf{K}_{\mathbf{D 1}}$} \\
\hline TAX8 K ${ }_{D 1}$ & $37.4 \mathrm{nM}$ & $13.9 \mathrm{nM}$ \\
\hline TAX9 K $\mathrm{D} 1_{1}$ & $30.6 \mathrm{nM}$ & $11.1 \mathrm{nM}$ \\
\hline KLL15 K & $38.8 \mathrm{nM}$ & $14.2 \mathrm{nM}$ \\
\hline \multicolumn{3}{|l|}{$\mathrm{K}_{\mathbf{D} 2}$} \\
\hline TAX8 KD2 & $325.7 \pm 14.2 \mathrm{nM}$ & $315.5 \pm 19.2 \mathrm{nM}$ \\
\hline TAX9 KD2 & $40.2 \pm 6.5 \mathrm{nM}$ & $42.6 \pm 8.3 \mathrm{nM}$ \\
\hline KLL15 KD2 & $383.1 \pm 21.8 \mathrm{nM}$ & $334.4 \pm 19.6 \mathrm{nM}$ \\
\hline \multicolumn{3}{|l|}{$\mathbf{K}_{\mathbf{D} 3}$} \\
\hline TAX8 K $\mathrm{D}_{3}$ & $2.6 \pm 0.5 \mu \mathrm{M}$ & $2.4 \pm 0.6 \mu \mathrm{M}$ \\
\hline TAX9 K & $1.9 \pm 0.7 \mu \mathrm{M}$ & $1.8 \pm 0.3 \mu \mathrm{M}$ \\
\hline KLL15 K $\mathrm{D}_{3}$ & $2.2 \pm 0.5 \mu \mathrm{M}$ & $2.1 \pm 0.3 \mu \mathrm{M}$ \\
\hline \multicolumn{3}{|l|}{ KD4 } \\
\hline TAX8 KD4 & $22.7 \pm 8.2 \mu \mathrm{M}$ & $54.4 \pm 9.4 \mu \mathrm{M}$ \\
\hline TAX9 KD4 & $2.5 \pm 0.8 \mu \mathrm{M}$ & $7.3 \pm 0.7 \mu \mathrm{M}$ \\
\hline KLL15 KD4 & $21.6 \pm 7.0 \mu \mathrm{M}$ & $49.5 \pm 8.6 \mu \mathrm{M}$ \\
\hline
\end{tabular}




\section{Figures}

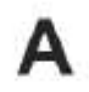

HsTAPBPR MmTAPBPR RNTAPBPR HsTapasin MmTapasin RnTapasin

C

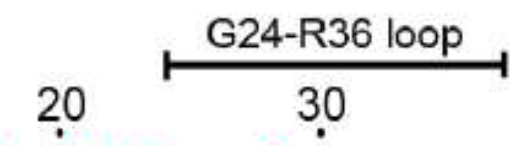

VDVVLDCFLVKDGAHRGALASSEDRARASLVLKOVP TDIILDCFLVTEDRHRGAFASSGDRERALLVLKOVP VDIVLDCFLVTEDKHRGAFGSSEDREKALLVLKQVP GPAVIECWFVEDASGKGLA-----KRPGALLLRQGP GPEAIECWFVEDAGGGGLS-----KKPATLLLRHGP GPQTIECWFVEDAGGGGLS-----KKPATLLLRHGP 10

MHC-I / Tapasin PDB: $6 E N Y$
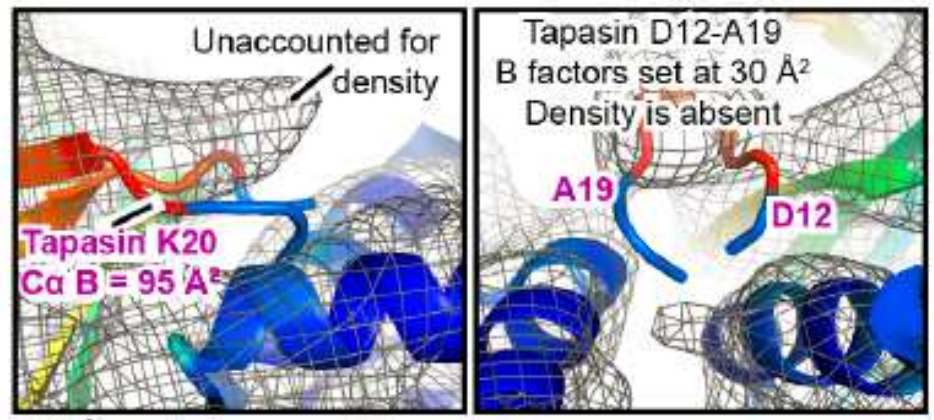

$5.8 \AA$ A resolution, cryo-EM $\longrightarrow$

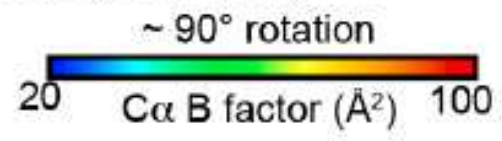

20

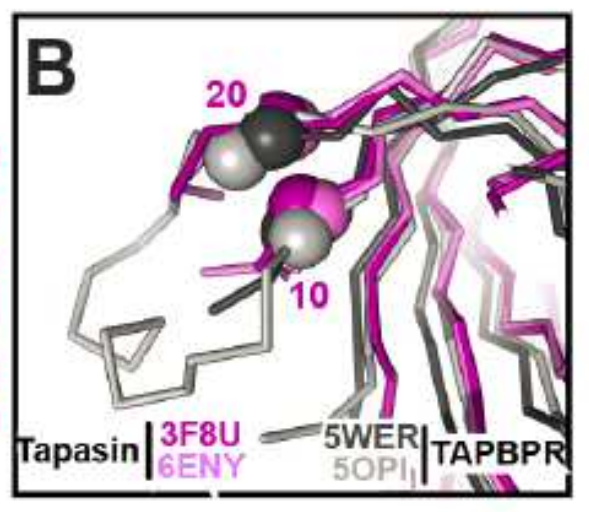

MHC-I / TAPBPR

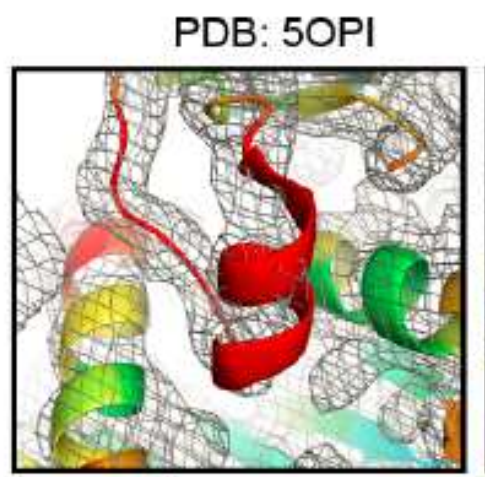

$3.3 \AA$ resolution, $\mathrm{X}$-ray

Average $\mathrm{B}$ factor $=153 \mathrm{~A}^{2}$

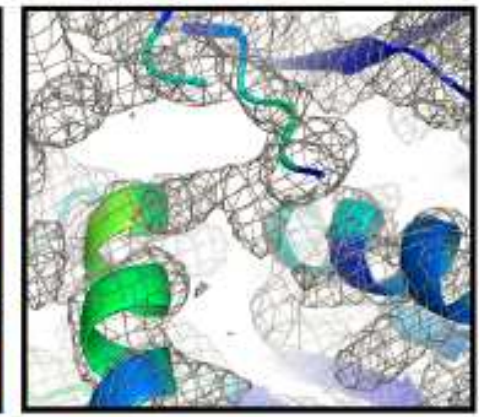

3.4 A resolution, $\mathrm{X}$-ray Average $B$ factor $=76 \AA^{2}$
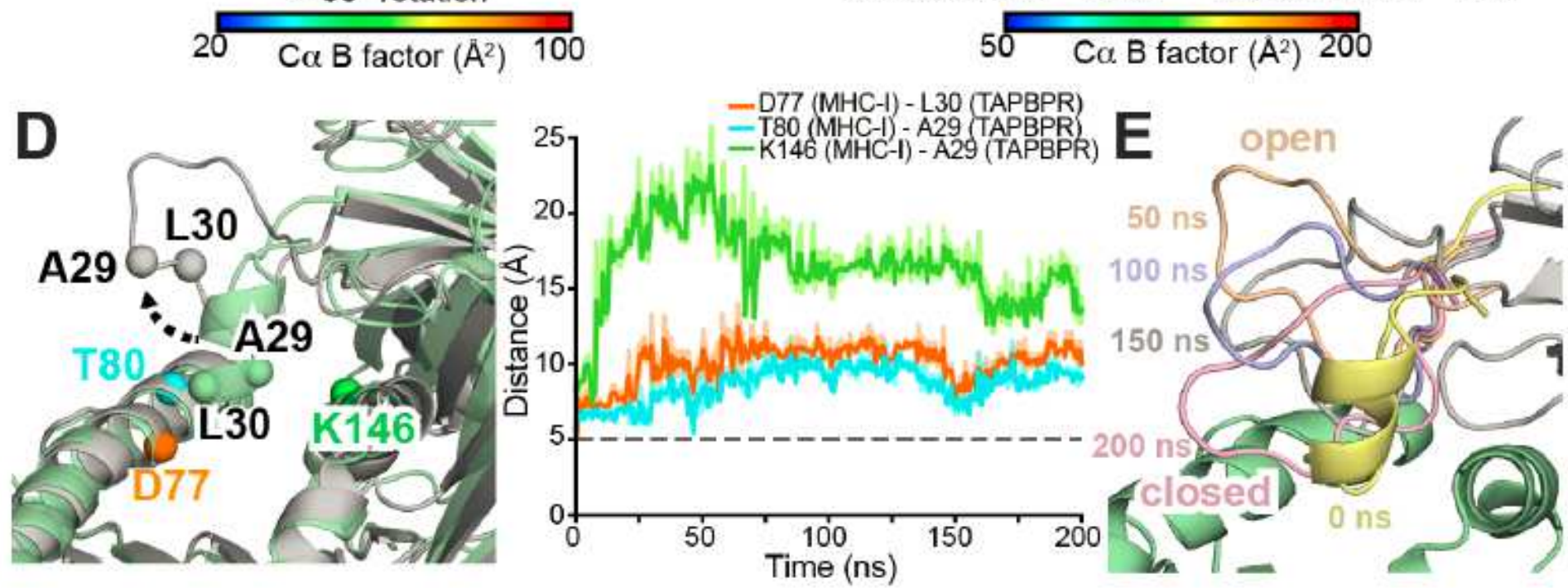

Figure 1

Conformational plasticity of the TAPBPR G24-R36 loop. (A) Sequence alignment between TAPBPR and tapasin from Homo sapiens (Hs, human), Mus musculus (Mm, mouse) and Rattus norvegicus (Rn, rat) highlighting differences in the TAPBPR G24-R36 loop region. Black and purple numbering reference TAPBPR and tapasin, respectively. Red residues are conserved. (B) Overlay of X-ray structures of tapasin (PDB IDs 3F8U and 6ENY) and TAPBPR (PDB IDs 5WER and 50PI). (C) (Left) Cryo-EM density map (gray 
mesh, $5.0 \mathrm{~s}$ ) plotted on the cartoon of MHC-I in complex with tapasin (PDB ID 6ENY). (Right) 2Fo-Fc electron density maps (gray mesh, $1.0 \mathrm{~s}$ ) plotted on the cartoon of MHC-I in complex with TAPBPR (PDB ID 5OPI and 5WER). The cartoons are colored by Ca B factors. (D) (Left) Before (green) and during (gray) snapshots of peptide-deficient HLA-A*02:01/h $\beta 2 \mathrm{~m} /$ TAPBPR complex from all-atom MD simulations. The $\mathrm{Ca}$ atoms used for distance measurements are shown as spheres. (Right) Intermolecular Ca-Ca distances measured between HLA-A*02:01 groove (D77, T80, K146) and TAPBPR G24-R36 loop (A29, L30) residues over the course of the simulation. The dotted line represents $\mathrm{Ca}-\mathrm{Ca}$ distances at the start of the simulation. (E) The range of conformations of the TAPBPR G24-R36 loop captured at different times during the MD simulation. The open (wheat, $50 \mathrm{~ns}$ ) and closed (pink, $200 \mathrm{~ns}$ ) states of the TAPBPR G24R36 loop are oriented away from and covering the HLA-A*02:01 groove, respectively. The MHC-I groove (green) and TAPBPR $\mathrm{N}$ domain (gray) are shown as a static snapshot from the $0 \mathrm{~ns}$ MD time point for clarity. 
A

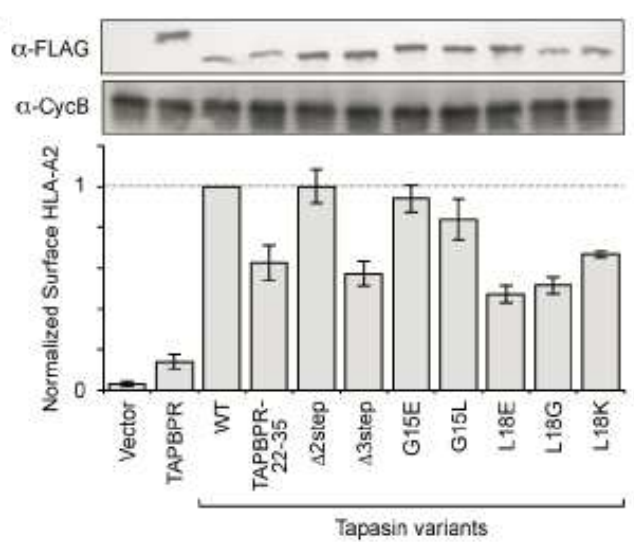

C
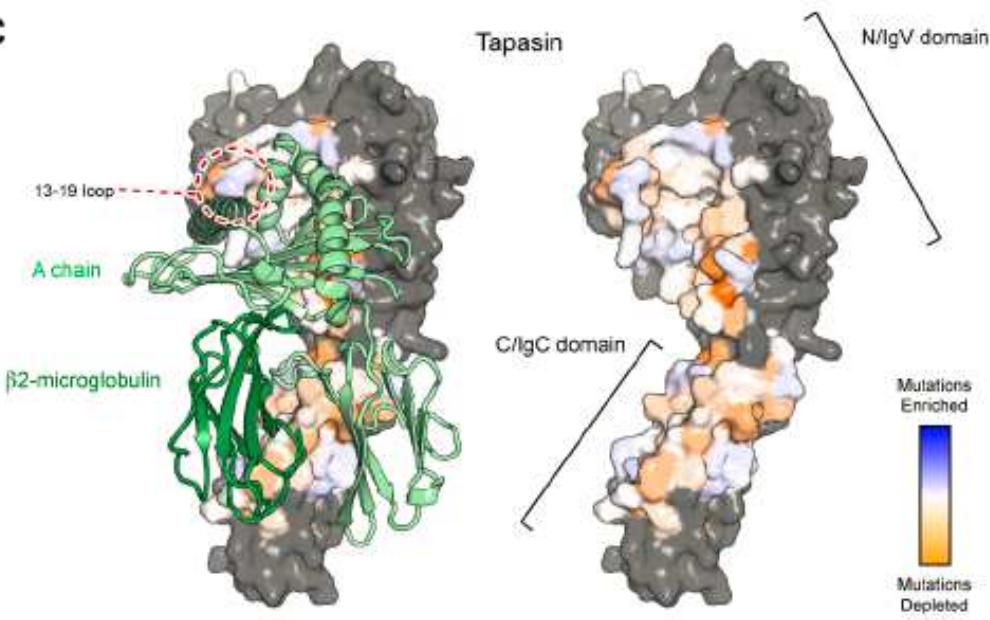

D

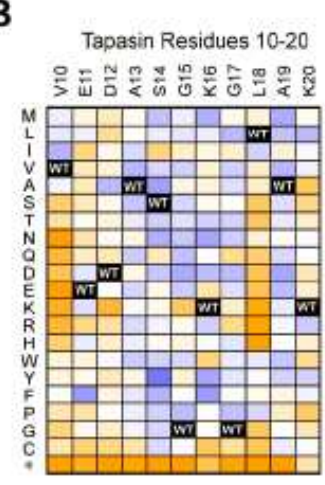

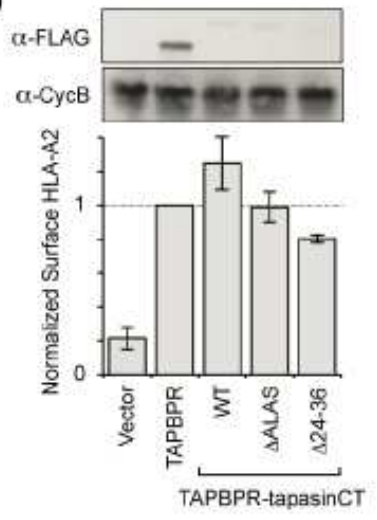

E

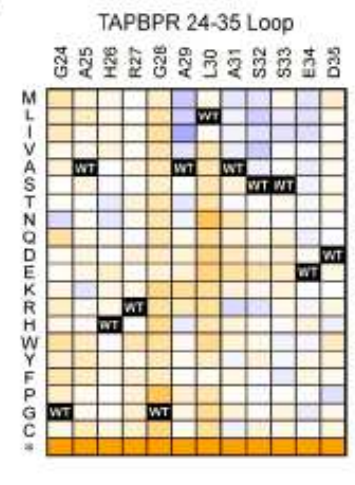

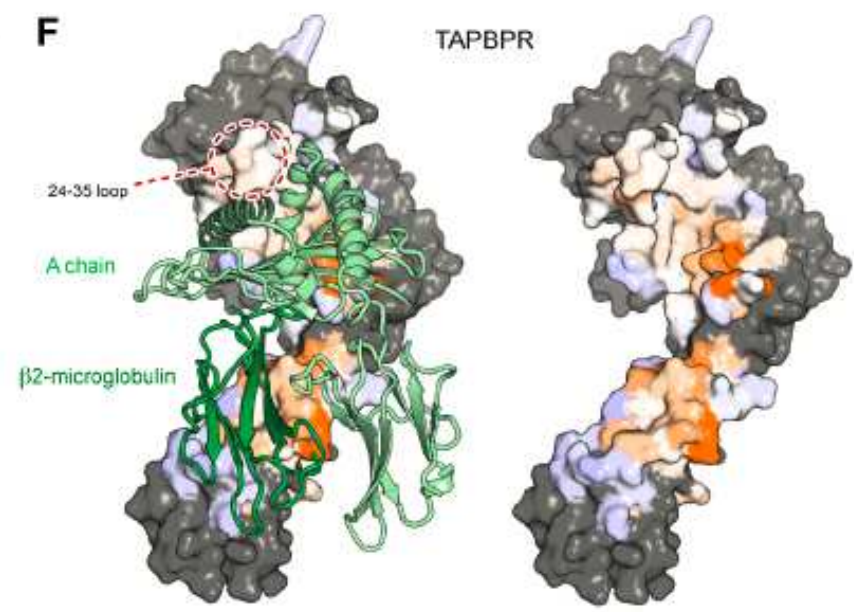

G

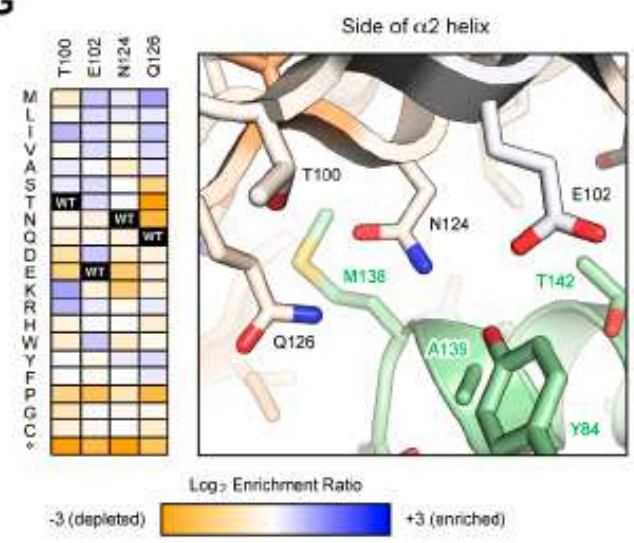

H

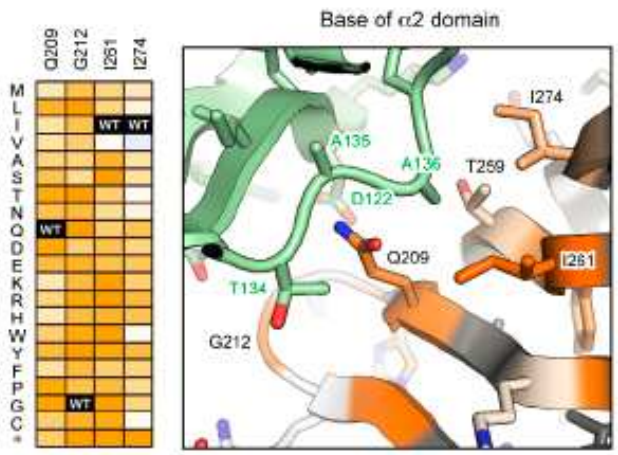

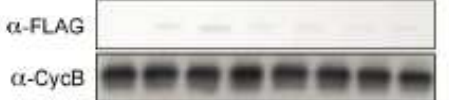

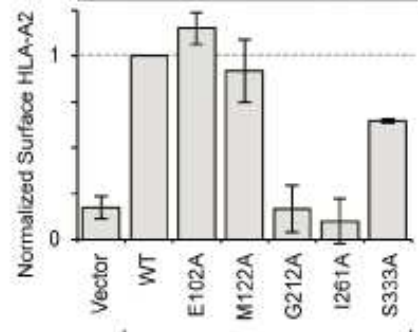
TAPBPR-tapasinCT

\section{Figure 2}

Important chaperone features for functional replacement of tapasin localize to scaffolding sites for MHCI. (A) TAPBPR and variants of tapasin were transfected in tapasin- KO Expi293F cells, and relative surface $H L A-A * 02: 01$ expression as measured by flow cytometry is plotted. Data are mean $\pm S D, n=4$. Proteins were FLAG-tagged at their luminal N-termini and immunoblots of whole lysate are shown, with cyclophilin $\mathrm{B}(\mathrm{CycB})$ used as a loading control. (B) Tapasin was deep mutationally scanned based on selection of tapasin-KO cells with rescued surface HLA-A*02:01. Log2 enrichment ratios for mutations across residues 10-20 are plotted from $\leq-3$ (depleted/deleterious, orange) to $\geq+3$ (enriched, dark blue). Residue 
position is on the horizontal axis, and amino acid substitutions are on the vertical axis ( ${ }^{*}$, stop codon). (C) Conservation scores from the entire deep mutational scan of the tapasin/MHC-I interface are mapped to a homology model of HLA-A*02:01-bound tapasin. Highly conserved residues for mediating the folding and surface trafficking of HLA-A*02:01 are colored orange, while neutral regions are pale white/blue. Residues excluded from the library and analysis are grey. MHC-I $\mathrm{H}$ chain and $\mathrm{hb} 2 \mathrm{~m}$ are pale and dark green ribbons, respectively. (D) A chimera of the TAPBPR luminal domain with the tapasin TM and cytosolic domains, called TAPBPR-CT, has increased activity for chaperoning endogenous HLA-A*02:01, despite reduced protein expression by immunoblot (upper inset). Variants of TAPBPR were tested for rescue of surface HLA-A*02:01 in the TAPBPR-CT background. Data are mean $\pm S D, n=4$. (E) As in $B$, now plotting log2 enrichment ratios for mutations in TAPBPR residues 24-35 from a deep mutational scan for rescue of surface HLA-A*02:01 in TAPBPR library-transfected tapasin-KO cells. (F) As in C, now showing sequence conservation from a deep mutational scan of TAPBPR mapped to a model of TAPBPR/HLA-A*02:01. (G) Close up views of two structural regions, colored as in F. Accompanying heatmaps plot log2 enrichment ratios for each mutation from depleted/deleterious (orange) to neutral (white and pale colors) to enriched (dark blue). (H) Individual mutations of TAPBPR-CT were validated by targeted mutagenesis in the tapasin surrogate assay. Data are mean $\pm S D, n=4$.
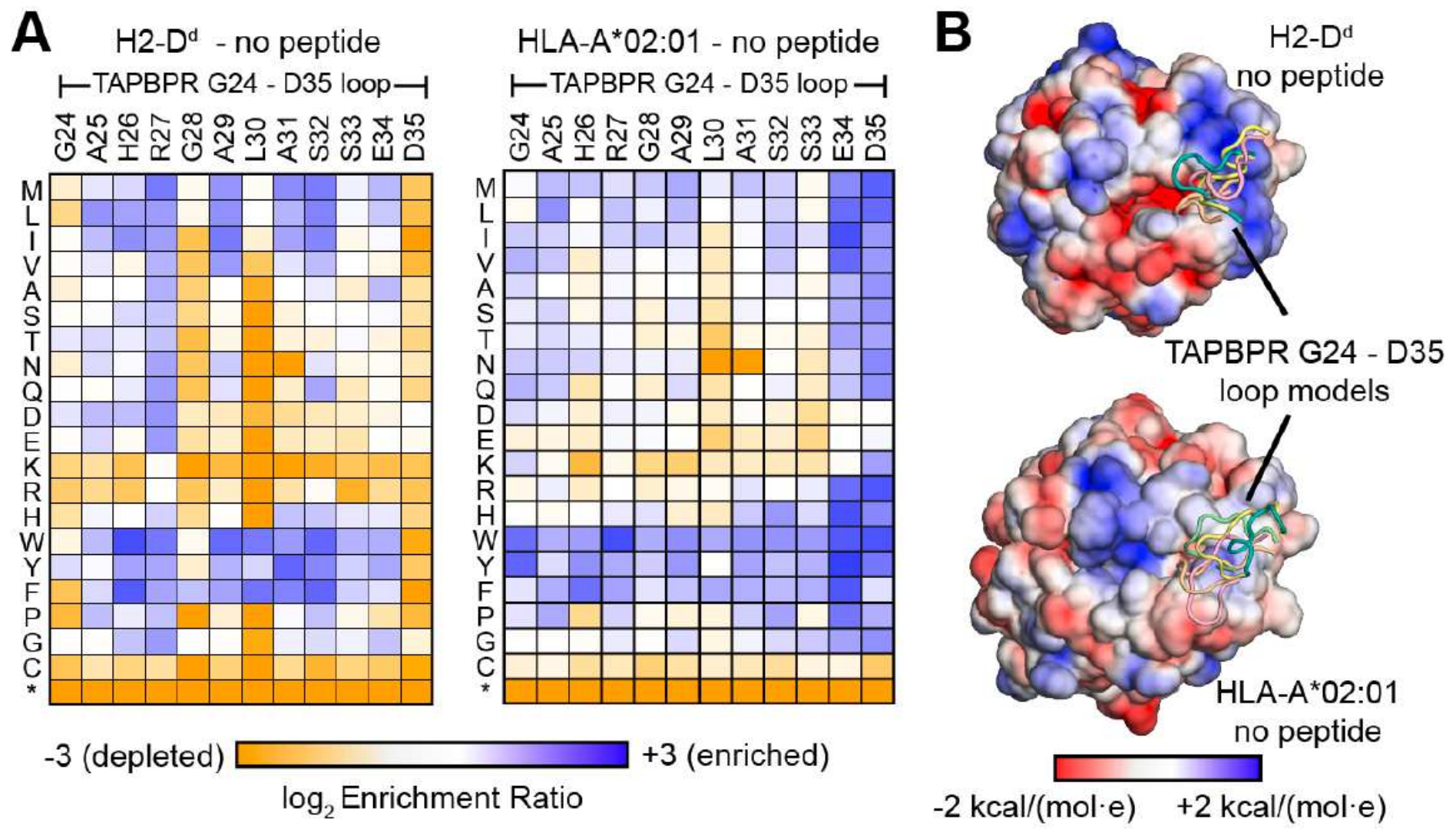

\section{Figure 3}

TAPBPR 24-35 loop sequence interaction landscape is pMHC-I allele-dependent. (A) A TAPBPR library of substitution mutants in the 24-35 loop was displayed on the yeast surface and sorted for high binding signal to fluorescent PMHC-I tetramers made using refolded P18- I10/H2-Dd and TAX9/HLA-A*02:01. In 
these experiments there was no excess of competing peptide; see Figure S3 for data from equivalent selections with competing free peptide. In the mutational landscapes, log2 enrichment ratios for each mutation are plotted from $\leq-3$ (depleted/deleterious, orange) to $\geq+3$ (enriched, dark blue). TAPBPR 24-35 loop residue position is on the horizontal axis, and amino acid substitutions are on the vertical axis $(*$, stop codon). (B) Solvent-accessible surfaces of MHC-I molecules colored by electrostatic potential (negative in red, to positive in blue) as calculated in CHARMM-GUI PBEQ-Solver for H2-Dd (PDB 3ECB) and HLA-A*02:01 (PDB 1DUZ). The five lowest energy RosettaCM models of the TAPBPR 24- 35 loop are shown as references.

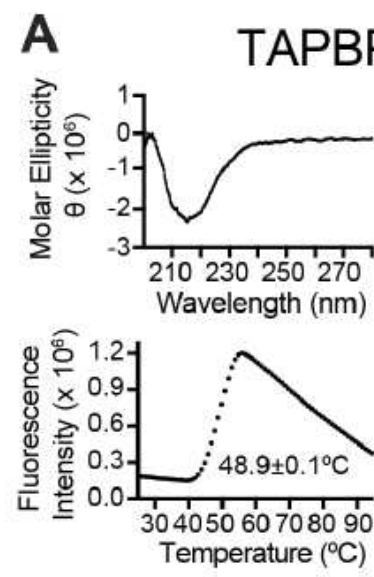

B

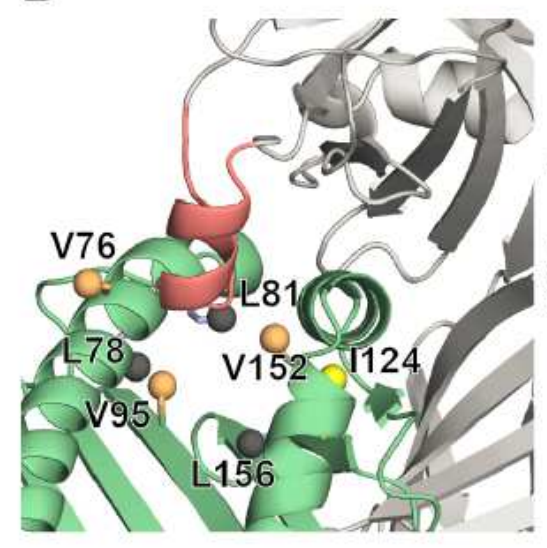

TAPBPR ${ }^{\triangle A L A S}$
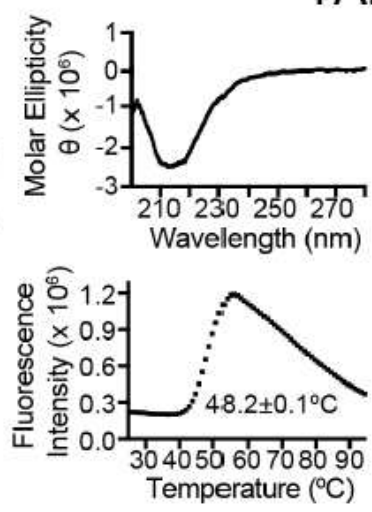

TAPBPR $^{\mathrm{AG} 24-\mathrm{R} 36}$
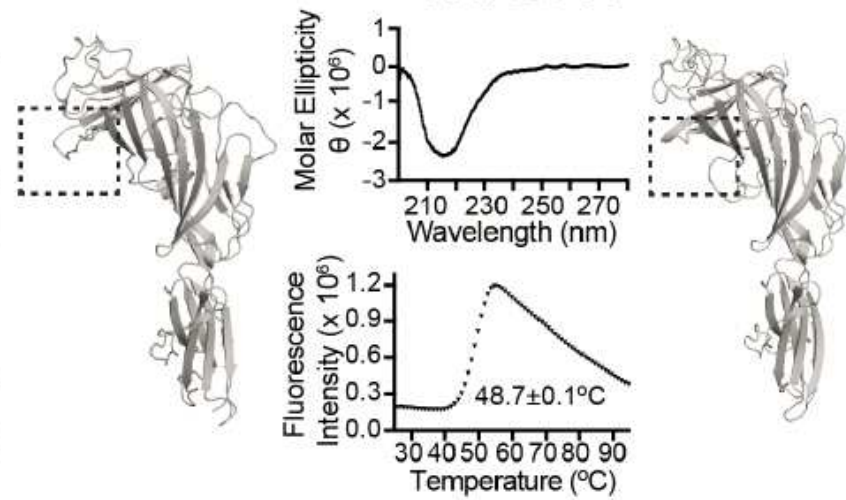

empty HLA-A*02:01/TAPBPR
(ILVpros labeled HLA-A*02:01)
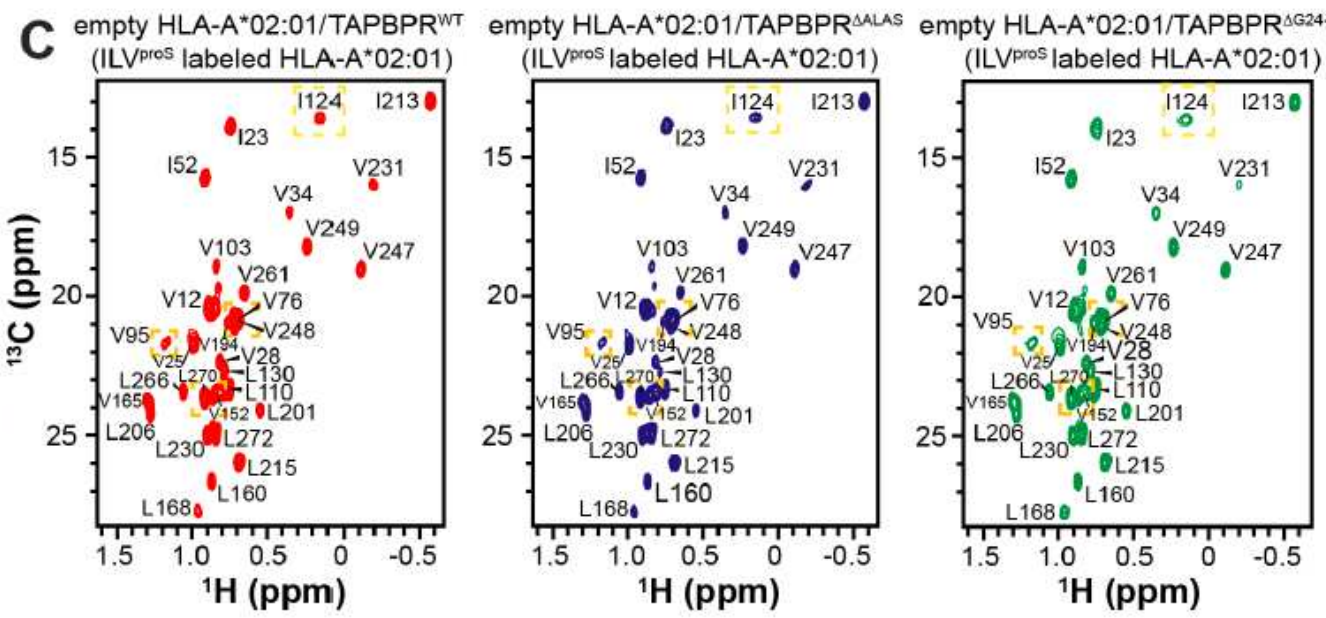

Figure 4

The TAPBPR G24-R36 loop does not enter the HLA-A*02:01 groove. (A) Comparison between wild-type (WT) and mutant TAPBPR constructs used in this study. $\triangle$ ALAS = deletion of residues A29-S32 and $\triangle$ G24-R36 = deletion of residues G24-R36. (Top) Far-UV CD and (Bottom) DSF spectra of each TAPBPR construct. The average from three technical replicates is shown. An inset in the DSF spectra notes measured thermal melt (Tm) values. The corresponding RosettaCM model of each TAPBPR construct is shown. The dotted box highlights differences in the G24-R36 loop region. (B) View of the peptide-deficient HLA A*02:01/TAPBPR model (template PDB ID 5OPI) showing ILVproS methyl probes on HLA A*02:01 (as spheres) within $10 \AA$ of the TAPBPR G24-R36 loop (salmon). Methyl resonances of residues L78, L81 and L156 (shown in black) are missing in 2D 1H-13C methyl HMQC spectra of peptide-deficient HLA- 
$A^{*} 02: 01 / T A P B P R$ complex due to conformational exchange induced line broadening. (C) $2 \mathrm{D} 1 \mathrm{H}-13 \mathrm{C}$ methyl HMQC spectra of $80 \mu \mathrm{M}$ peptide-deficient HLA-A*02:01 (ILVproS labeled) $/ \mathrm{h} \beta 2 \mathrm{~m}$ in complex with TAPBPRWT (red), TAPBPR ALAS (blue) or TAPBPR $\triangle$ G24- R36 (green) recorded at $25^{\circ} \mathrm{C}$ at a $1 \mathrm{H}$ field of $800 \mathrm{MHz}$. Dotted boxes highlight methyl probes (shown in panel $\mathrm{B}$ ) that are modeled to be near the TAPBPR G24-R36 loop.

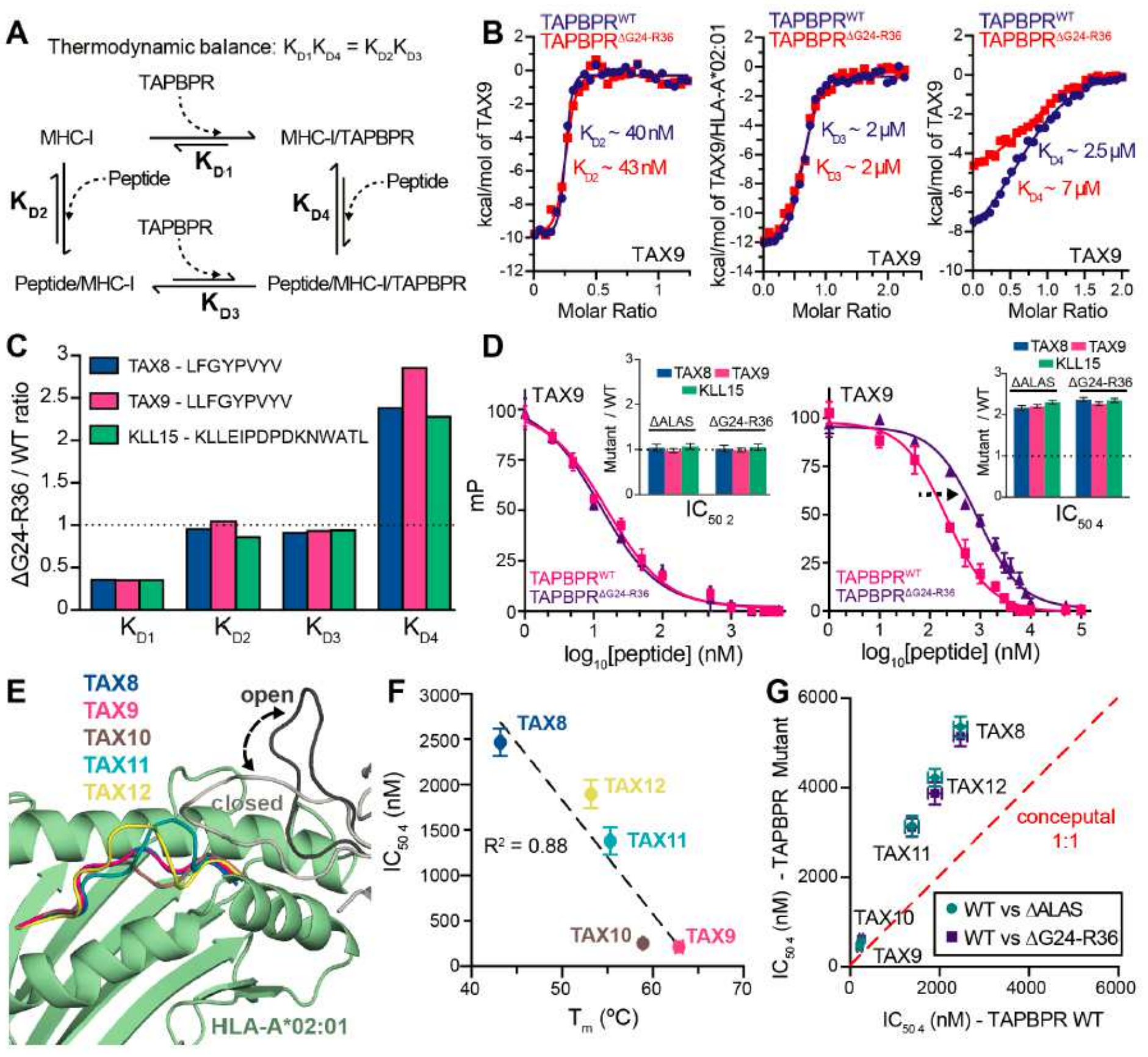

Figure 5

The TAPBPR G24-R36 loop promotes peptide binding on empty MHC-I. (A) Schematic of the TAPBPRmediated MHC-I peptide exchange cycle. The dissociation constant (KD) of each step is noted. (B) ITC performed at different stages of the peptide exchange cycle (KD2 ,KD3, KD4) for TAX9/HLA$A^{\star 02: 01 / h \beta 2 m}$ with TAPBPRWT or TAPBPR $\triangle$ G24-R36 (Materials and Methods). KD1 was not measured 
directly, but inferred from thermodynamic balance along the cycle shown in (A). (C) Apparent KD ratios determined by ITC for TAPBPR G 24- R36 / TAPBPRWT for TAX8, TAX9 and KLL15 peptides. The dotted line represents no effect. (D) FP performed under substoichiometric (left) and stoichiometric (right) conditions. Millipolarization (mP) values are plotted as a function of the log10 peptide concentration for TAX8, TAX9 and KLL15 competitor peptides. Error bars were obtained from three technical replicates. The insets show a comparison of the ratio of FP determined IC50 values for TAPBPR $\triangle$ G24-R36 or TAPBPR $\triangle$ ALAS versus TAPBPRWT. The dotted line represents no effect. (E) X-ray structures (TAX8, TAX9) and RosettaCM models (TAX10, TAX11, TAX12) show peptide bulging within the HLA-A*02:01 groove. The open and closed conformation of the TAPBPR G24-R36 loop from MD simulations are shown in gray and black, respectively. (F) Comparison of FP determined IC50 values under stoichiometric conditions for TAX length variants versus PMHC-1154 I thermal stability. The R2 value of the linear regression fit (black line) is shown. (G) Comparison of FP determined IC50 values under stoichiometric conditions for TAX length variants for TAPBPRWT versus TAPBPR $\triangle A L A S$ or TAPBPR $\triangle$ G24-R36. The dotted red line represents a conceptual 1:1 correlation (no effect). 

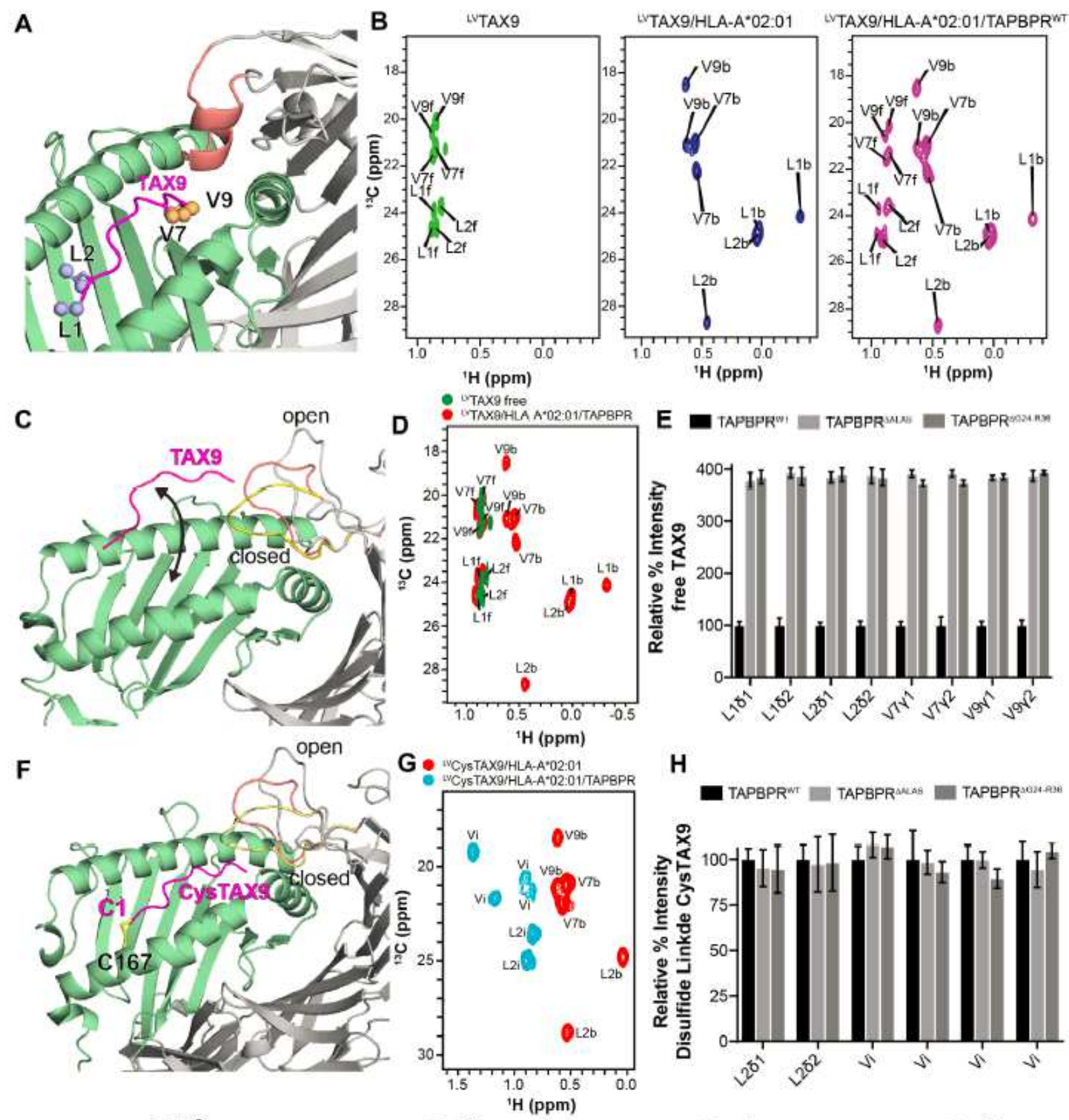

E TAPBPR"1 TAPBPR

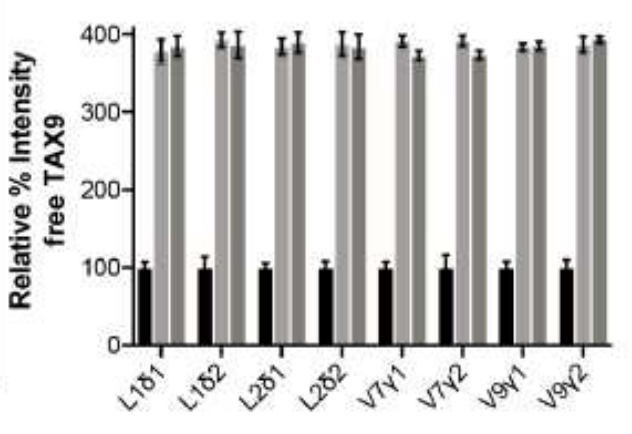

H

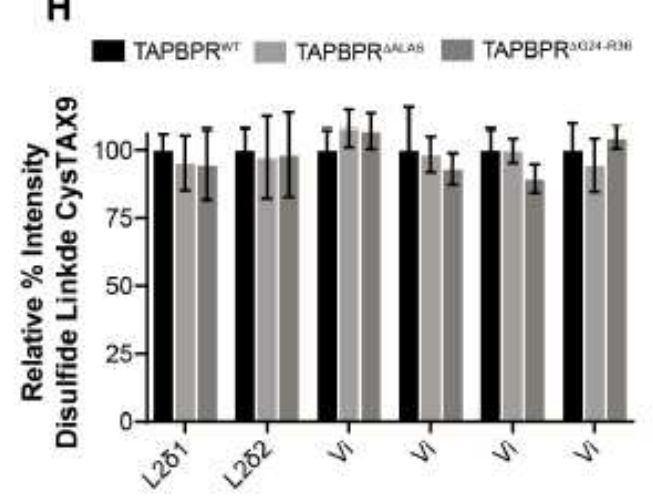

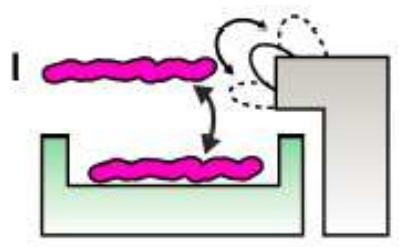

peptide binding promoted by TAPBPR G24-R36 loop

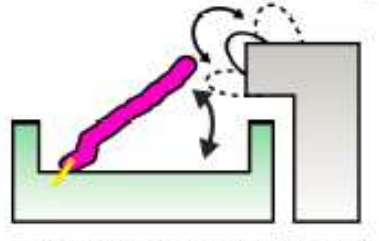

peptide binding not promoted by TAPBPR G24-R36 loop

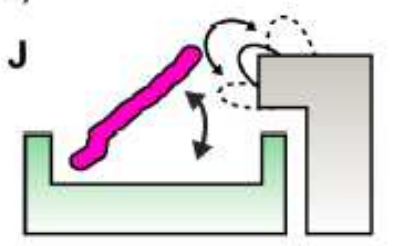

early capture of peptide binding from $\mathrm{N}$-terminus

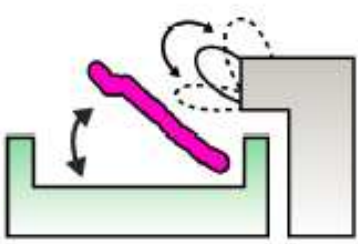

early capture of peptide binding from $\mathrm{C}$-terminus

\section{Figure 6}

NMR characterization of chaperone-mediated peptide exchange on MHC-I using selective methyl 13Clabeled peptides. (A) Rosetta model of the TAX9/HLA-A*02:01/TAPBPR complex using template PDB ID $50 P I$. The Leu/Val methyl groups of TAX9 are shown as spheres. HLA-A*02:01 is green, TAX9 is magenta, TAPBPR is grey, and the TAPBPR "scoop loop" is colored salmon. (B) 2D 1H-13C methyl HMQC spectra of $100 \mu \mathrm{M} 15 \mathrm{~N} / 13 \mathrm{C}$ LV labeled TAX9 peptide in the free state (left, green), in complex with HLA- 
$A^{*} 02: 01 / \mathrm{h} \beta 2 \mathrm{~m}$ (middle, blue), and in complex with HLA-A*02:01/h $\beta 2 \mathrm{~m}$ in the presence of saturating concentration (8-fold molar excess) TAPBPR (right, purple). All spectra were recorded at $25^{\circ} \mathrm{C}$ at a $1 \mathrm{H}$ field of $800 \mathrm{MHz}$. Assignments of methyl resonances corresponding to the free and $\mathrm{MHC}$-bound peptide states are denoted with ' $f$ ' and ' $b$ ', respectively (C) Rosetta model of the TAX9/HLA-A*02:01/TAPBPR complex using template PDB ID 5WER is shown highlighting that TAPBPR promotes release of TAX9 peptide. The open, intermediate and closed conformations of the TAPBPR G24-R36 loop obtained from MD simulations are shown in grey, salmon and yellow. (D) Overlay of 2D $1 \mathrm{H}-13 \mathrm{C}$ methyl HMQC spectra from ' $A$ ' of: 13C-LV labeled TAX9 in the free state (green), and in complex with HLA-A*02:01/hß2m in the presence of saturating concentration of TAPBPR (red). (E) Comparison of NMR signal intensity for each methyl resonance of TAX9 when released from the MHC-I/TAPBPR complex formed with and without the TAPBPR G24-R36 loop. (F) Rosetta model of disulfide-linked CysTAX9/HLA-A*02:01 in complex with TAPBPR designed using Disulfide by Design v2. The disulfide is formed between C1 of CysTAX9 (CLFGYPVYV) and W167C of HLA-A*02:01. The open and closed conformations of the TAPBPR G24-R36 loop obtained from MD simulations are shown in grey, salmon and yellow. (G) 2D 1H-13C methyl HMQC spectra of 13C-LV labeled CysTAX9 in complex with HLA-A*02:01/h $\beta 2 \mathrm{~m}$ (red) and HLA-A*02:01/ h $\beta 2 \mathrm{~m}$ in the presence of 8-fold molar excess TAPBPR (blue) recorded at $25^{\circ} \mathrm{C}$ at a $1 \mathrm{H}$ field of $600 \mathrm{MHz}$. Methyl resonances of the PMHC-I bound state are denoted " $b$ " for bound. Methyl resonances of the pMHCI/TAPBPR state are denoted " $i$ " for intermediate, corresponding to a free peptide conformation that is still tethered to the MHC groove. $(\mathrm{H})$ Comparison of NMR signal intensities for each methyl resonance of CysTAX9 in the pMHC-I/TAPBPR intermediate state, formed with and without the TAPBPR G24-R36 loop. The intermediate states for the Valines were not assigned. (I) NMR-based model of how the TAPBPR G24R36 loop influences peptide loading on pMHC-I. (J) Two putative mechanisms for how the TAPBPR G24R36 loop promotes the early capture of peptide within the MHC-I groove with an intermediate annealing from the $\mathrm{N}$ terminus (left) or C-terminus (right). 
A

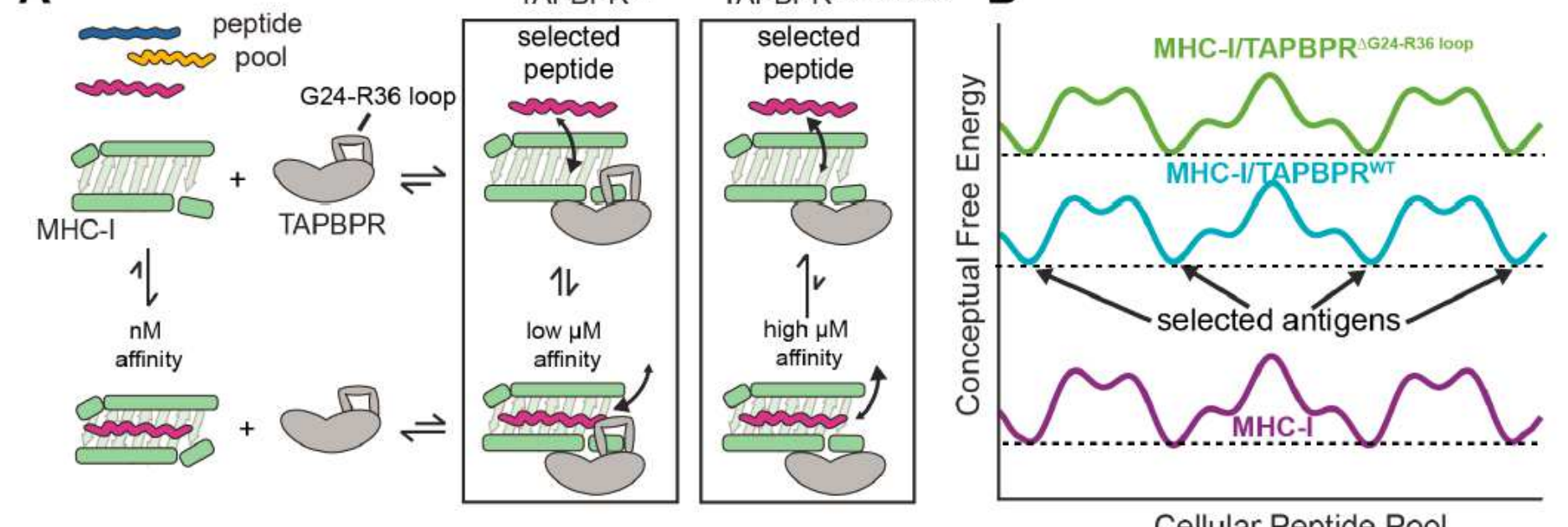

B

Cellular Peptide Pool

\section{Peptide Concentration}

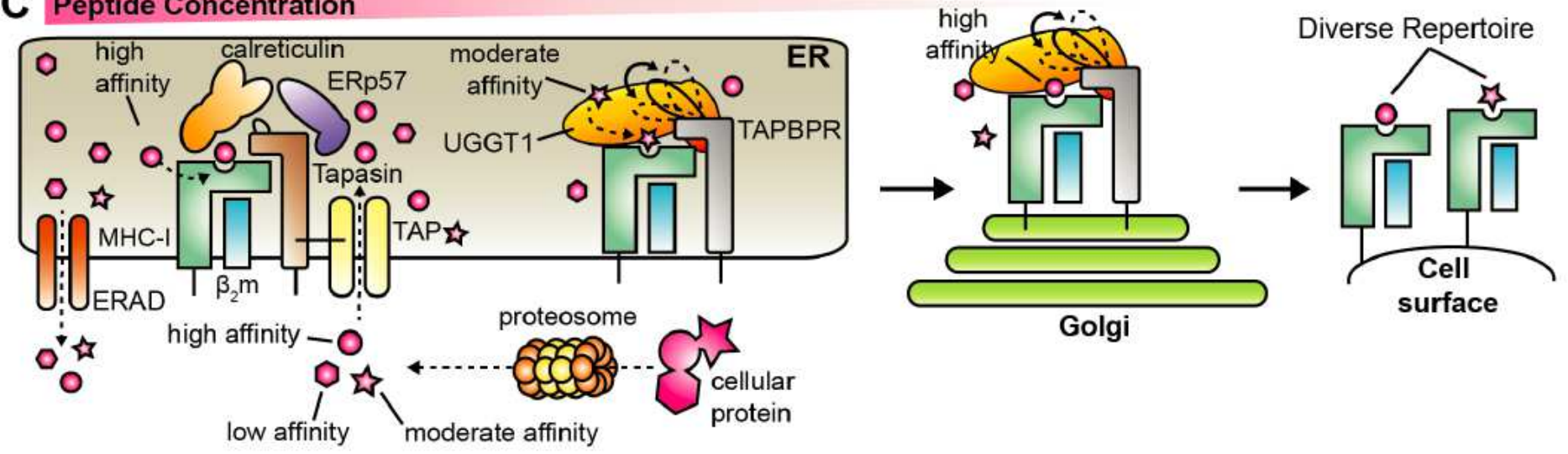

Figure 7

Proposed model of auxiliary peptide editing functions of TAPBPR. (A) Schematic of how the TAPBPR G24-R36 loop influences the peptide exchange cycle. The G24-R36 loop serves as a trap, promoting peptide binding on the MHC-I/TAPBPR complex with low $\mu \mathrm{M}$ affinity. When TAPBPR is mutated to have a shorter loop, the affinity of peptides is reduced to high $\mu \mathrm{M}$ range. (B) Conceptual example of the free energy landscape across the cellular peptide pool. The TAPBPR G24-R36 loop shapes the selected peptide repertoire by stabilizing peptide binding across the cellular pool, functioning as an auxiliary loading chaperone for peptides of low and moderate affinity. (C) In the ER, peptide selection is governed both by the effective concentration of peptides and the absence (in tapasin) or the presence of the kinetic trap (in TAPBPR). Tapasin is tethered to the TAP transporter and because it is restricted to an environment of high peptide concentration and has a shorter loop, it primarily loads high affinity peptides. In contrast, TAPBPR is not tethered to TAP and because it functions in environments of lower peptide concentration, it employs a trap to load both high and moderate affinity peptides and/or to minimize dissociation of peptides during transient TAPBPR/pMHC-I interactions. This process results in a diverse peptide repertoire being displayed by $\mathrm{MHC}-\mathrm{I}$ molecules on the cell surface.

\section{Supplementary Files}


This is a list of supplementary files associated with this preprint. Click to download.

- SIMHCTAPBPRtrapNature.pdf 